\title{
THE PRESENCE OF HONEY TRIGGERS INHIBITION OF PSEUDOMONAS AERUGINOSA VIRULENCE AND METABOLISM
}

\author{
BY \\ Maryam Goudarzi \\ Bachelor of Science Biology, Ryerson University, 2011 \\ A thesis \\ Presented to Ryerson University \\ in partial fulfillment of the \\ requirements for the degree of \\ Master of Science \\ in the Program of \\ Molecular Science
}

Toronto, Ontario, Canada, 2014

(C) Maryam Goudarzi, 2014 


\section{AUTHOR'S DECLARATION}

I hereby declare that I am the sole author of this thesis.

I authorize Ryerson University to lend this thesis to other institution or individuals for the purpose of scholarly research

I further authorize Ryerson University to reproduce this thesis by photocopying or by other means, in total or in part, at the request of other institution or individuals for the purpose of scholarly research. 


\title{
THE PRESENCE OF HONEY TRIGGERS INHIBITION OF PSEUDOMONAS AERUGINOSA VIRULENCE AND METABOLISM
}

\section{Maryam Goudarzi}

\author{
Master of Science, Molecular Science, Ryerson University, 2014
}

\begin{abstract}
Honey is an ancient remedy with a high potency against drug-resistant bacteria, which has gained renewed interest in naturopathic medicine for its beneficial effect in treatment and prevention of wound infections. The exact antibacterial property and mode of action of honey is still unknown, however in recent years, there has been various studies focusing on the effect of honey on bacterial gene regulation. With the focus of current literature being at the molecular level, the first aim of this study was to examine the effect of honey at the cell level and its influence on the metabolism of $P$. aeruginosa biofilm. The second objective of this study was to test the influence of the combination of the iron chelating agent (EDTA) and honey on biofilm metabolism. P. aeruginosa metabolism in this study was analyzed through (i) siderophore excretion and (ii) monitoring of the biofilm $\mathrm{CO}_{2}$ respiration rate with a Carbon dioxide Evolution Measurement System (CEMS). The results obtained indicate that honey reduces biofilm metabolism and inhibits siderophore production, while the combination of honey and EDTA has a greater impact on biofilm metabolism, which influences $P$. aeruginosa iron homeostasis, inhibits siderophore production, and increases bacterial recovery time after exposure. However, when provided at concentrations lower than its inhibitory concentration, honey is used as a nutrient source for biofilm development. The results obtained illustrated the importance of the environmental conditions on biofilm metabolism, as the biofilm response varied with minor changes in the composition of their media. In summary, this study showed that biofilm cells shut down their metabolism in the presence of honey, which also inhibits bacterial siderophore production and can play an importance role on the virulence of $P$. aeruginosa.
\end{abstract}




\section{ACKNOWLEDGMENTS}

I would like to start with this quote that I always admired and remembered since childhood:

"Ali Ibn Abi-Taleb stated to Komail:

O komail! Knowledge is better than wealth, since knowledge, is your protector, but you should protect your wealth. If you give from your wealth, it would reduce, but if you give from your knowledge, you would gain more. The position you obtain with wealth might be lost one day. O komail!, Learning knowledge gives you rewards, and with knowledge human beings (male and female) will know god better, which will help them praise him better. After death you will be remembered (for the knowledge that will be pass on to the next generations). Knowledge is sovereign, and wealth is obedient. (Nahj Al-balagheh, Wisdom 147:2)."

I would like to thank god for giving me the opportunity to pursue my graduate studies and work with fabulous professors Dr. Gideon Wolfaardt, Dr. Otini Kroukamp and great lab members during my graduate studies. I consider myself to be very fortune of having such a great supervisors that guided me throughout my studies and helped me to learn, observe and tackle problems and gaps in scientific research. They have not only thought me scientific principles but also great life lessons that I will carry on through the years.

Similarly, I would like to thank my committee member Dr. Martina Hausner for her guidance through my undergraduate and graduate studies. In addition, I would like to thank Romeo Dumetrache for being patience in answering my endless questions. I am very grateful to be working with the Wolfaardt lab members, Lindsay Jackson, Wendy Stone, Alex Dumtrache, Evan Ronan, Gabriel Wolfaardt, Roshanak Pashang and all those who created a fun and friendly environment to work with. Moreover, I would like to also thank Elanna Bester for her patience and support in the Wolfaardt group.

Lastly, I would like to thank my family, if it wasn't the results of my parent's patience and sacrificing to immigrate to Canada, I would not stand at the place where I am today. It was their effort and guidance that helped thought out the hard times. No matter how many times I thank them, it will not be equivalent for the effort and amount of time they had put for me. I feel wealthy for having my family's support and companion. 


\section{Table of Contents}

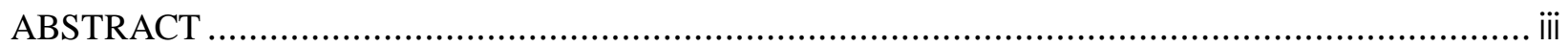

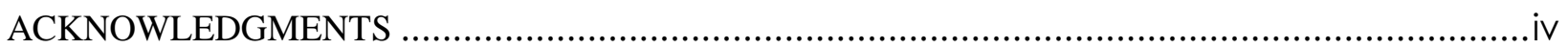

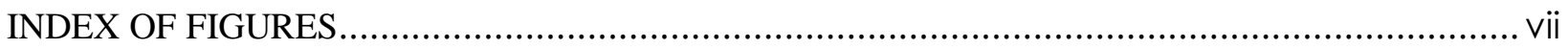

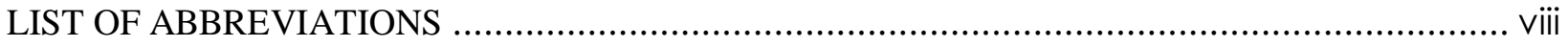

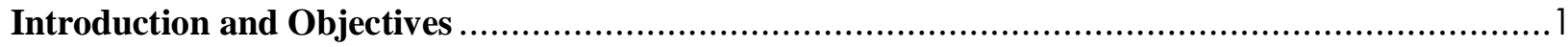

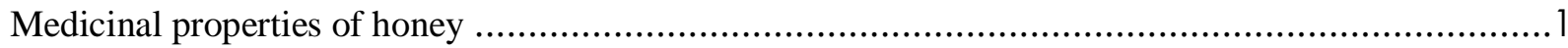

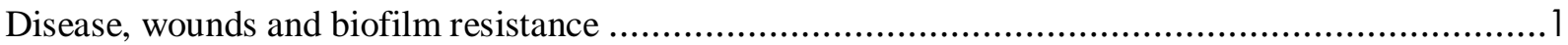

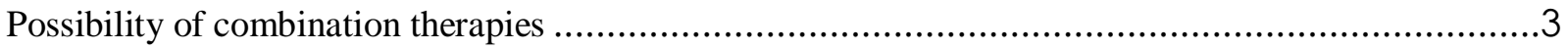

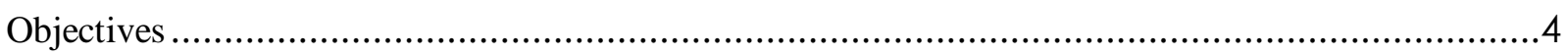

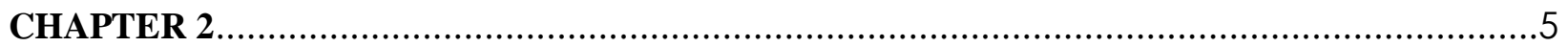

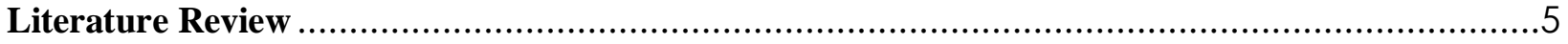

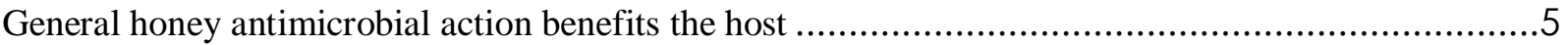

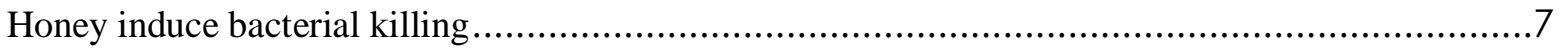

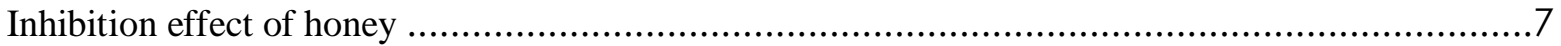

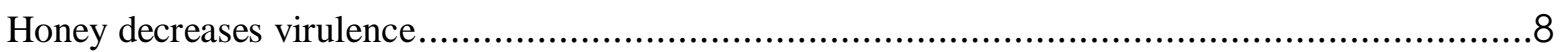

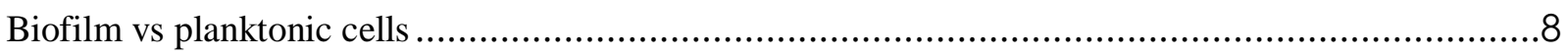

Bacterial differences between Gram-positive and Gram-negative bacteria ............................ 10

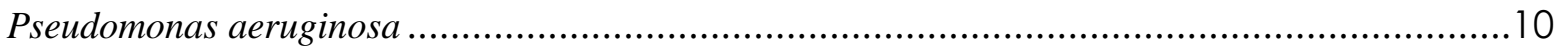

Virulence factors in gram negative bacteria ............................................................ 11

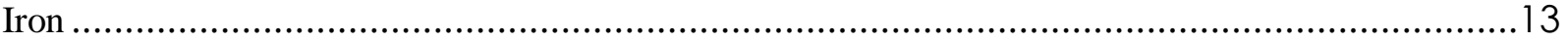

Iron Uptake System in $P$. aeruginosa .................................................................... 13

The P. aeruginosa Siderophore mediated $\mathrm{Fe}^{3+}$ uptake system......................................... 14

P. aeuginosa Siderophore-Pyochelin ............................................................. 17

P. aeruginosa Siderophore-Pyoverdine ...................................................................... 18

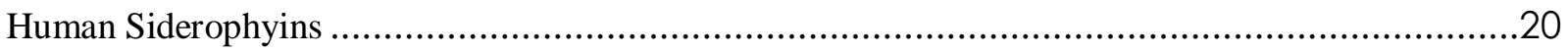

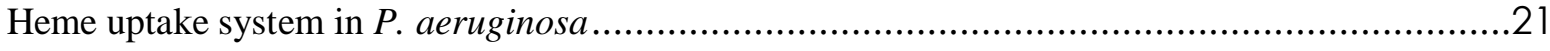

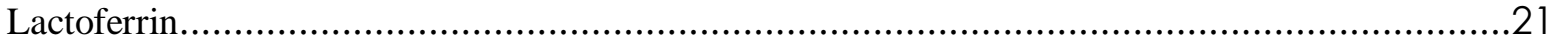

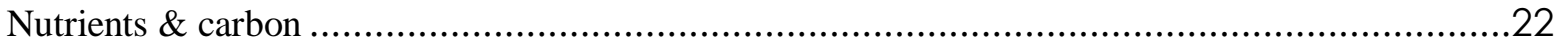

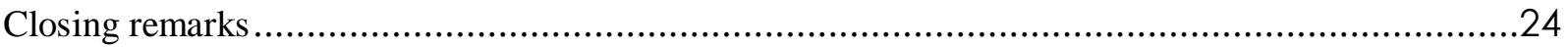

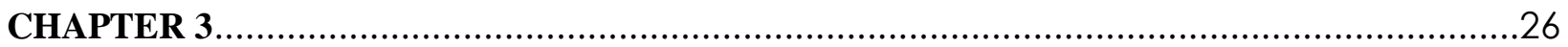

The effect of honey on bacterial metabolism as measured by $\mathrm{CO}_{2}$ production and siderophore secretion in a real time system. 


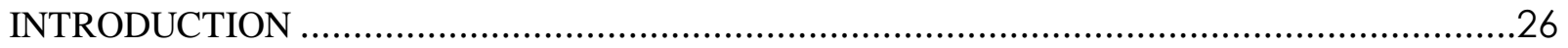

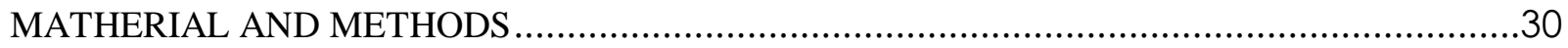

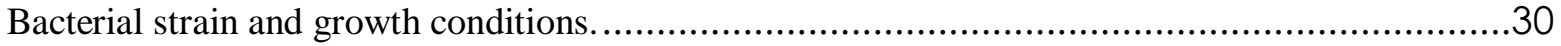

Honey

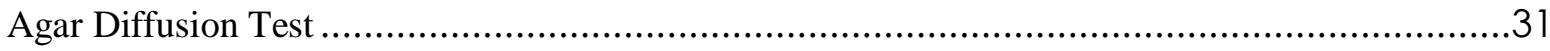

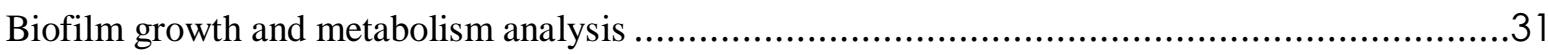

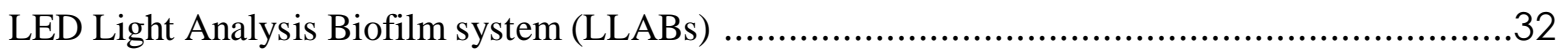

Siderophore- pyoverdine (PVD) spectrum measurement …….................................................32

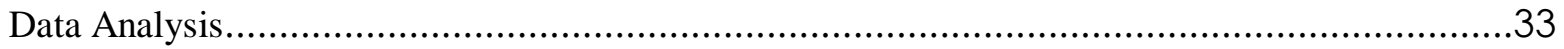

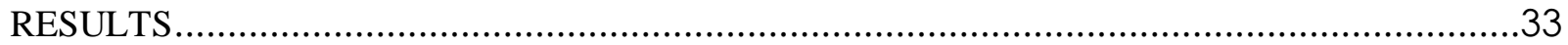

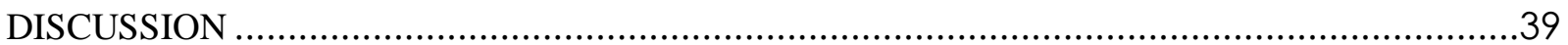

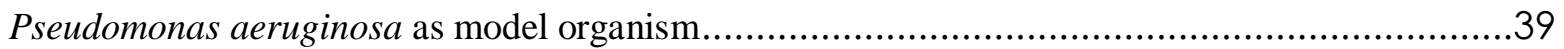

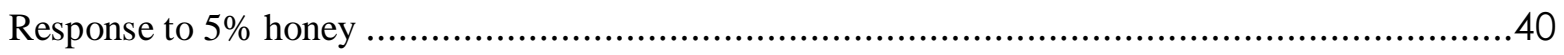

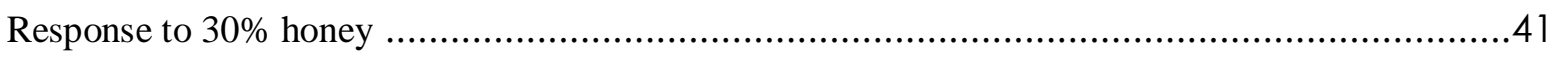

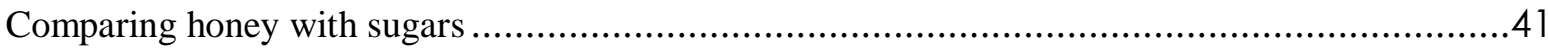

Biofilm response to $30 \%$ honey was mimicked under starvation conditions ................................42

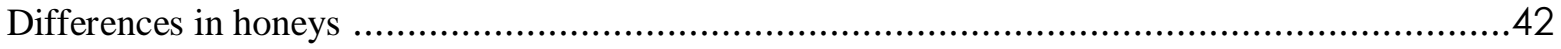

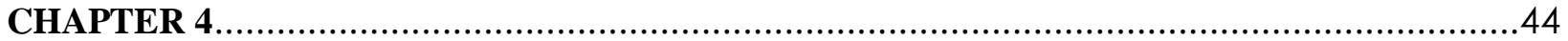

The combined effect of honey and ethylenediamine tetraacetic acid disodium (EDTA) on biofilm

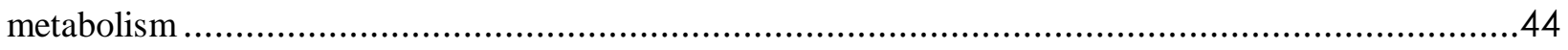

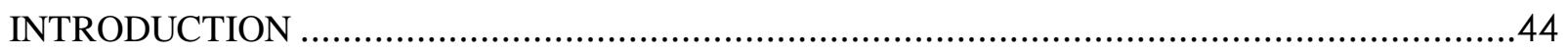

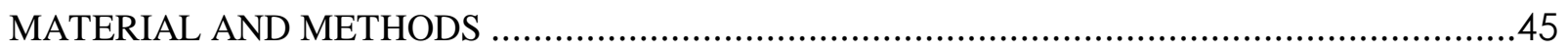

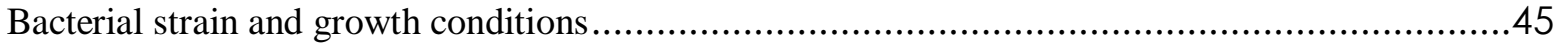

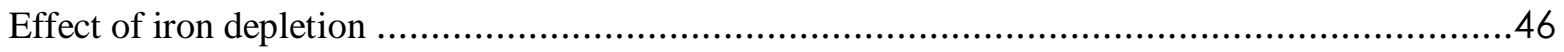

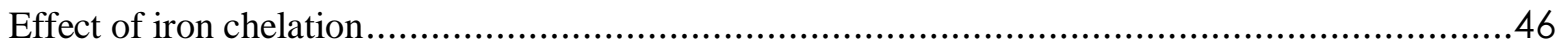

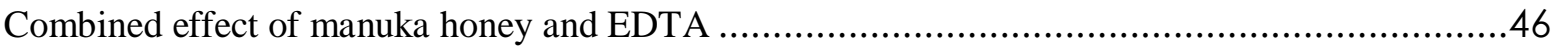

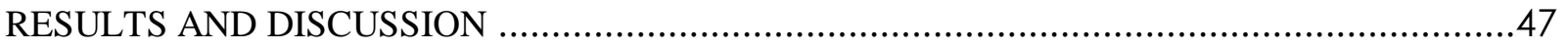

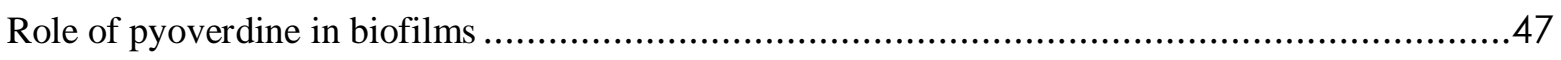

Combination effect of honey and an iron chelator in rich growth medium ...................................48

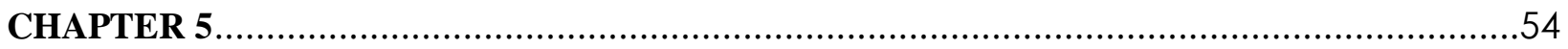

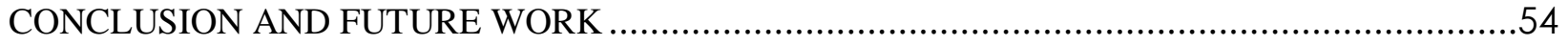

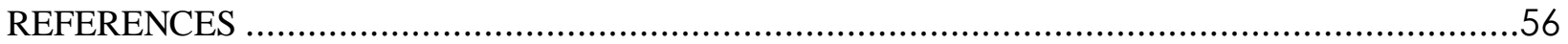




\section{INDEX OF FIGURES}

Figure 2. 1 Iron transport system in gram negative bacterium. .14

Figure 2. 2 Iron uptake system in P. aeruginosa bacterium via siderophore or heme. .......................15

Figure 2. 3 Siderophore transport system across gram negative membranes .................................... 16

Figure 2. 4 Pyoverdine biosynthesis in P. aeruginosa ...................................................... 19

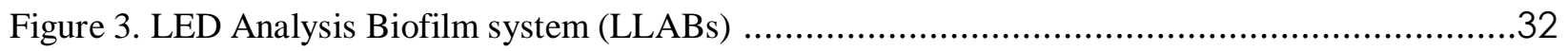

Figure 3. 1. Real time analysis of pyoverdine secretion in $P$. aeruginosa biofilm...........................34

Figure 3. 2. Real time analysis of pyoverdine secretion of $P$. aeruginosa biofilm in CEMS.................35

Figure 3. 3. Effect of $5 \%(\mathrm{w} / \mathrm{w})$ honey on $P$. aeruginosa siderophore production and biofilm metabolism.

Figure 3. 4. Effect of 24 hour exposure of $30 \%(\mathrm{w} / \mathrm{w})$ honey on P. aeruginosa siderophore production and biofilm metabolism.

Figure 3. 5. Effect of 2.5 hour exposure of $30 \%(\mathrm{w} / \mathrm{w})$ honey on P. aeruginosa siderophore production and biofilm metabolism 38

Figure 4. 1. Effect of EDTA on P. aeruginosa $\mathrm{CO}_{2}$ production and siderophore secretion..................49

Figure 4. 2. Effect of iron depleted environment on $P$. aeruginosa metabolism..................................50

Figure 4. 3. Effect of honey on P. aeruginosa biofilm under iron depleted conditions. .......................51

Figure 4. 4. The combined effect of $30 \%$ honey and EDTA on $P$. aeruginosa in a defined growth medium.

Figure 4. 5. The combined effect of honey and EDTA on $P$. aeruginosa in rich growth medium. 


\section{LIST OF ABBREVIATIONS}

\begin{tabular}{|c|c|}
\hline $\mathrm{AH}$ & Artificial honey \\
\hline AHL & Acylhomoserine lactone \\
\hline$A_{w}$ & Activity of water \\
\hline CEMS & Carbon dioxide evolution measurement system \\
\hline $\mathrm{CF}$ & Cystic fibrosis \\
\hline $\mathrm{CH}$ & Clover honey \\
\hline CRBI & Catheter-related blood stream infections \\
\hline CRI & Catheter related infections \\
\hline CSE1034 & Ceftriaxone and sulbactam \\
\hline DI & Distilled water \\
\hline $\mathrm{DFO}$ & Deferoxamine \\
\hline DSX & Defrasirox \\
\hline EDTA & Ethylenediamine tetraacetic acid disodium \\
\hline HAIs & Healthcare-associated Infections \\
\hline $\mathrm{Hb}$ & Hemoglobin \\
\hline Lf & Lactoferrin \\
\hline LPS & Lipopolysaccharide \\
\hline MDR & Multidrug resistance \\
\hline $\mathrm{MH}$ & Manuka honey \\
\hline MRSA & Methicillin-resistance Staphylococcus aureus \\
\hline MSSA & Methicillin-sensitive Staphylococcus aureus \\
\hline NRPS & Non-ribosomal peptide synthetases \\
\hline QS & Quorum sensing \\
\hline PVD & Pyoverdine \\
\hline PA & Pseudomonas aeruginosa \\
\hline Pch & Pyochelin \\
\hline
\end{tabular}


Transferrin

TSA Tryptic Soy Broth Agar

TSB Tryptic Soy Broth

UTIs Urinary tract infections 


\section{CHAPTER 1}

\section{Introduction and Objectives}

\section{Medicinal properties of honey}

Honey is an ancient remedy used for treatment of infected wounds, which was reintroduced into modern medicine during the 21st century (Al-Waili et al., 2005; Al-Waili et al., 201; Israili, 2013). The beneficial use and consumption of honey date back to $5500 \mathrm{BC}$, and the nutritional and medicinal quality of this compound has been documented in Hindu, Greek, Roman, Jewish, Christian, Islamic and other faiths (Israili, 2013). Health benefits of honey have been reported in a variety of conditions including treatment of skin (Fidaleo et al., 2010; Israili, 2013), eye disease, respiratory diseases (Sio et al., 2006), urinary diseases (Al-Wali, 2005), gastrointestinal diseases, skin ulcers, psoriasis, and eczema (Daglia et al., 2013; Al-Wali et al., 2003; Allen et al., 1991). Honey is known to inhibit reactive oxygen species (Mesaik et al., 2008; Erejuwa, 2012), and inhibit quorum sensing (QS) molecules in a biofilm (Lee et al., 2011; Truchado et al., 2009- A; Truchado et al., 2009- B). Studies have also shown that honey exhibits a broad spectrum of antibacterial activities that can inhibit growth of more than 80 species of pathogenic bacteria including methicillin-resistant S. aureus (Jervis-Bardy, 2011; Maddock et al., 2012; Stover et al., 2000; Truchado et al., 2009), methicillin-resistant Staphylococcus epidermis (Truchado et al., 2009), Pseudomonas aeruginosa (Singh et al., 2000; Schalk and Guillon, 2012) and Escherichia coli to mention a few.

\section{Disease, wounds and biofilm resistance}

Bacterial cells in the form of biofilms which is defined as establishment of microorganisms as communities (Abdallah, 2011), can be up to a thousand times more resistant to antibiotics and disinfectants when compared to planktonic cells (Mah et al., 2003). The formation of $P$. aeruginosa biofilm is the main cause of the intrinsic resistance of this bacterium to several antibiotics. The main reasons for an increase in antibiotic resistance in biofilms are low antibiotic 
penetration in the EPS, expression of various efflux pumps and expression of various antibiotic inactivating enzymes (Storz and Hengee-Aronis, 2000), all of which can result in increased resistance of the bacterium to antibiotics.

For more than half of a century antibiotics have been credited as the foundation of many infectious disease therapies (Sekhri, 2013). The commercial use and availability of manufactured antibiotics date back to the 1950's when scientists and medical practitioners started to realize the beneficial use of antibiotics for treatment of infection, and its power of reducing the rate of human mortality. However, only two decades after the start of antibiotic production, scientists realized that bacterial species are capable of forming resistance to most available antibiotics and overcoming the innovation of modern medicine (Gould and Van-Der-Meer, 2007; Gregoire et al., 2010). The term "antimicrobial resistance" of microorganisms was then defined as the ability of microorganisms to resist the growth inhibitory or killing activity of any anti-microbial beyond the normal susceptibility (Verrases et al., 2013; McDonnell and Russell, 1999).

As stated above, microorganisms use one or a variety of mechanisms to overcome the presence of antibiotics, for example, enzymatic degradation or modification of antibiotics (Verrases et al., 2013). Enzymatic modification of antibiotics is one of the main concerns in treatment of Gram-negative bacteria and is commonly seen in the presence of aminoglycosides or $\beta$-lactam antibiotics (Verrases et al., 2013). Gram-negative bacteria are capable of producing $\beta$ lactamase enzymes that hydrolyze the $\beta$-lactam ring (Levin et al., 1984) or acetyltransferases, nucleotidyltransfrases and phosphotransferases that are known to degrade aminoglycosides (Zichichi et al., 2000).

However, studies have shown that the nature of biofilm structure attribute to inherited resistance to antimicrobial agents, whether these are antibiotics, disinfectants or germicides (Donlan and Costerton, 2002). This indicates that exposure of biofilms to high doses or new antibiotics will not necessarily solve the problem of antibiotic resistance.

Due to an increase of antimicrobial resistance to the present synthetic antibiotics, the need for novel therapies has generated renewed interest in natural products exhibiting antibacterial properties, especially when studies have also shown that antibiotic consumption is not without risk to humans (Alandejani et al., 2009). 
This has led many researchers to study the effect of medicinal plants for treatment of infection. Although this route has not solved the current problem of antibiotic resistance it has shown some promising results compared to synthetic antibiotics. Many of these traditional medicines have shown to have anti-QS activity. QS is a molecular crosstalk that bacteria use for cell-to-cell communication. Inhibition of this molecule results in loss of the signal and can interfere with biofilm formation and development (Brackman et al., 2009). For example a study by Adonizo et al., has shown that Conocarpus erectus, Chamaesyce hypericifolia, Callistemon viminalis, Bucida buceras, Tetrazygia bicolor, and Quercus virginiana extracts have anti-QS properties and can be used to treat $P$. aeruginosa infection (Adonizo et al., 2008). Traditionally these plants were used to treat respiratory and skin infections.

The underlying reasons attributed to the antimicrobial action of honey were related to high osmolality, acidity, sugar content, viscosity and presence of enzymes. However, the antimicrobial mechanisms of honey have shown to vary among different floral source, which depends on factors such as environmental condition, climate and pollen source of the plant (Azeredo et al., 2003; Maddocks and Jenkins, 2013). Studies have shown that hydrogen peroxide present in almost all types of honey, with the exception of manuka honey, is capable of inhibiting microbial growth and stimulates production of new capillaries in wound tissue (Tur et al., 1995; Bang et al., 2003). In the host system, honey has been shown to stimulate inflammatory cytokines from monocytic cells, and act as an antioxidant at the site of infection. In addition to this, other cationic antimicrobial peptides, such as bee defesion-1, which has been identified in honey are known to have a broad acting contribution to the antimicrobial properties of honey (Maddocks and Jenkins, 2013). In other honeys, such as manuka, bee defesin-1 is modified and changed to phytochemical methylglyxoal (MGO), which is the main active ingredient contributing to the antimicrobial activity of manuka honey (Maddocks and Jenkins, 2013).

\section{Possibility of combination therapies}

With an increase in antibiotic resistance to the current available antibiotics, research has shifted to look at a variety of alternative routes to treat infections. One of the recent routes that received interested is combination therapy of honey with antibiotics (Muller et al., 2013). This route of treatment with honey was first tested in 1998, between Indian honey and multidrug resistance 
(MDR) bacterial isolates (Karavil et al., 1998). Since then many studies have considered the combination effect of honey and different classes of antibiotics such as gentamicin, amikacin, oxacillin, tetracycline, rifampicin, imipenen and mupirocin (Jenkins and Cooper, 2012; Muller et al., 2013; Karavil et al., 1998). One of the advantages of using this route of therapy is the improved effectiveness of this treatment in the killing of antibiotic resistant bacteria. To date, no bacterial resistance to combination therapy has been reported.

\section{Objectives}

The central objective of this research was to test the effect of honey in inhibiting bacterial metabolism. This research is novel with respect to testing the effect of honey on bacterial metabolism through a real-time analysis. Therefore, the goal was to investigate the metabolic response of $P$. aeruginosa biofilms to different concentrations of honey. The research presented in this thesis is divided into two parts, each detailing the research conducted to address a specific objective. Chapters three and four address the two objectives of this study, which are as follows: Objective 1. To determine the influence of honey on bacterial metabolism through two indirect methods: $\mathrm{CO}_{2}$ production and siderophore secretion in a real time system.

Objective 2. To test the combined effect of honey and ethylenediamine tetraacetic acid disoidum (EDTA) on biofilm metabolism (through $\mathrm{CO}_{2}$ and pyoverdine secretion). 


\section{CHAPTER 2}

\section{Literature Review}

Honey has been used as a food source as well as for medicinal purposes since ancient times. Recent publications on the beneficial uses of honey for medicinal purposes have rekindled interest in the use of honey as a naturopathic source for treatment of infections such as burns and wounds (Cooper et al., 2010). Especially when in vivo studies have confirmed that 'no bacterial resistance' is formed through the use of this remedy for treatment of infections (Cooper et al., 2010; Lerrer et al., 2007). Numerous studies have confirmed that honey contains both antibacterial and antifungal properties, and is capable of reducing inflammation, stimulating epithelialization and tissue growth, proliferating of phagocytes, B and T lymphocytes (Fidaleo et al., 2010; Israili, 2013; Daglia et al., 2013; Al-Wali et al., 2003; Sio et al., 2006; Jervis-Bardy, 2011; Maddocks et al., 2012; Allen et al., 1991). It is known that honey from varying botanical sources have different levels of antibacterial activity (Israili, 2013).

Honey on its own is not an antibiotic, but its complex mixture of sugars, enzymes and other substances afford these unique biocidal characteristics to honey (Merckoll et al., 2009).

\section{General honey antimicrobial action benefits the host}

Studies have evaluated the activity of different types of honey against planktonic and biofilm cultures, concluding that the addition of $5 \%-11 \%$ honey to media inhibits growth of planktonic cells, and 60-90\% honey can inhibit growth of biofilms (Merckoll et al., 2009; Schalk and Guillon, 2012; Singh et al., 2000; Truchado et al., 2009; Van der Strate et al., 2001). No studies have identified the exact antimicrobial mechanism of honey, although various reported factors that contribute to the antimicrobial properties of honey include: the presence of a high sugar content ( 80\%), minerals and vitamins (Vasil et al., 1991; Singh et al., 2000); its acidity (pH $3.2-6$ ); production of hydrogen peroxide due to glucose oxidase (Ahmas et al., 2008; White et al., 1963); osmotic effects, antioxidant contents and stimulation of immunity neutrophils (Ahmed et al., 2011).

A study performed by Truchado et al. (2009) illustrated that chestnut honey could inhibit the production of N-Acyl-L-homoserine lactone (AHL) in a biofilm (Verrases et al., 2013). Also, 
in their previous studies, different unifloral honey could inhibit the QS of Chromobacterium violaceum (Wahjudi et al., 2013). In addition, through genetic screening of E. coli, Lee et al. 2011 have shown that low concentrations of honey in growth media significantly repress genes responsible for motility, QS signals and virulence factors (Adonizio et al., 2008; Wiehlmann et al., 2007). Moreover, other studies have also confirmed that the presence of honey in growth media affects dextran (polysaccharides of glucose) production of $S$. mutans, which in turn affects formation of biofilm and adherence to hard surfaces such as glass and teeth (Fjallman, 2000; Badet and Quero, 2011). Additionally, the vast amount of research performed on different aspects of honey has shown the benefits of using this substance for the treatment of wounds and burns (Blair et al., 2009; Carnwath et al., 2014).

Out of the vast range of available honey, the honey that is mainly used for medicinal purposes and available in various commercial wound dressing is Manuka honey that originates from the manuka tree (Leptospermum scoparium), which is mainly found in New Zealand (Israili, 2013). One of the known advantages of manuka honey, is the fact that no bacterial resistance was observed after exposure of the sub-inhibitory concentration of honey to E. coli, multidrug-resistant Staphylococcus aureus (MRSA), P. aeruginosa and S. epidermidis (Lusby et al., 2005; Cooper et al., 2010; Müller et al., 2013). In vitro studies have indicated that the antibacterial activity of manuka honey is associated with a high concentration of methylglyoxal (MGO), which is normally derived from the conversion of dihydroxyacetone (Wright and Romano, 2006; Mavric et al., 2008). MGO is a $\alpha$-dicarbonyl compound and has been widely used in many food products and beverages (Yanaihara et al., 2000; Da Silva Ferreira et al., 2007). A number of investigators suggested that MGO is the main compound that increases the antibacterial properties of honey (Yeterian et al., 2010), whereas other studies reject this phenomenon. Most manuka honey marketed for medicinal purposes has a potency rating based on "Unique Manuka Factor" (UMF) which ranges between 10 - 20 UMF (equivalent to $10-20 \%$ of phenol activity against bacteria). UMF activity is unrelated to the content of hydrogen peroxide in manuka, as studies have shown that manuka and clover honey have non-peroxide activity (Allen et al., 1991; Carnwath et al., 2013; Majtan et al., 2013), and UMF is primarily based on the S. aureus inhibition test (Yeterian et al., 2010). 


\section{Honey induce bacterial killing}

Although the exact antimicrobial killing effect of honey is still not known, studies at the gene level have attributed this effect to down regulation of important genes, which can mainly be influenced by the actual composition of honey with regards to high acidity, osmolality, and other components (Al-Waili and Saloom, 1999; Al-Waili and Noori, 2004; Alvarez-Suarez et al., 2010). The killing effect of honey has been reported at different concentrations between $25 \%$ - 100\% (AlWaili et al., 2013; Israili, 2013), which vary among different bacterial species. Studies on honey have tested the effect of this compound on Gram-positive bacteria such as MRSA, moreover genetic analysis of honey on gram positive and Gram-negative bacteria has shown that treatment of honey on Gram-negative bacteria was as successful as Gram-positive bacteria (Al-Waili and Saloom, 1999; Cooper et al., 2002). A large amount of studies have focused on the effect of honey on S. aureus and antibiotic-resistant strains. S. aureus isolates have been shown to have a high sensitivity to the presence of honey. In addition, no microbial resistance to honey has been reported to date (Lusby et al., 2005; Cooper et al., 2010; Müller et al., 2013), which could be due to multiple properties of honey presenting too many different pressures for resistance to occur (Maddocks and Jenkins, 2013).

\section{Inhibition effect of honey}

Numerous studies have determined the minimum inhibitory concentration (MIC) of honey against different bacterial isolates. MIC studies are mainly used for identifying the minimum concentration that inhibits bacterial growth. In the case of honey, MIC values change among different types and strains of bacterium. The lowest MIC value recorded for manuka honey was at a concentration between $2 \%$ to $4 \%(\mathrm{w} / \mathrm{v})$ honey that inhibited a total of 58 isolates of $S$. aureus (Cooper et al., 1999). Although sensitivity amongst bacterial species was different, the sensitivity amongst stains of the same species are consistent (Maddocks and Jenkins, 2013). In addition, the inhibitory action of honey varies among species and between planktonic cells and biofilms. Earlier studies have shown that honey not only is capable of inhibiting growth of individual cells, but can initiate reduction of biomass in E. coli biofilm (Lee et al., 2013).

Honey is known to target different parts of the cell. For example, proteomic studies on MRSA have shown that manuka honey is capable of inhibiting production of universal stress 
protein (UspA) up to 16- fold (Jenkins and Cooper, 2011), where this effect causes the bacterium to lose its ability of surviving in the presence of cellular and metabolic stress. A similar response was observed in the case of E. coli, where a total of $2 \%$ of its genome was up-regulated and $1 \%$ was down regulated. Moreover, transcriptome analyses have indicated that down regulated genes in $E$. coli were all associated with stress response and protein synthesis (Blair et al., 2009). Honey has not only been shown to inhibit gene regulation, but also influences bacterial surface adhesion in Streptococcus mutans (Nassar et al., 2012) and S. pyrogenes (Maddocks et al., 2012), and can prevent biofilm formation by P. aeruginosa, S. aureus and E. coli .

\section{Honey decreases virulence}

The use of honey as an anti-virulent remedy for treatment of infection has also gained interest, and a few recent studies have indicated the inhibitory role of honey on bacterial virulence. The effect of honey on bacterial virulence was tested when researchers confirmed the inhibitory action of honey on the expression of quorum sensing molecules, as these molecules are known to regulate the production of virulence factors. Studies have shown that the concentration of honey that inhibits bacterial quorum sensing and virulence is normally below their MIC, indicating the sensitivity of bacterial virulence to their environment (Wang et al., 2012; Maddocks and Jenkins, 2013; Lee et al., 2011). Microarray and qRT-PCR analysis, have shown that honey mediates inhibition of curli genes, AI-2 genes in quorum sensing, and virulence genes of E. coli O157:H7 (Lee et al., 2011). Similarly, other studies have shown that honey is capable of impairing las and $r h l$ genes and transcriptional regulator MvfR in $P$. aeruginosa which are all associated with quorum sensing and regulatory networks that control virulence of this organism (Wang et al., 2012; Maddocks and Jenkins, 2013).

\section{Biofilm vs planktonic cells}

Biofilm formation is a developmental progression that is regulated through various processes, and relies on the controlled expression of a collection of biofilm-specific genes (Bjarnsholt et al., 2010). Previous studies have shown that production of the extracellular polymeric matrix (EPS) by bacteria is one of the defining features of biofilm formation (Parsek and Tolker-Nielsen, 2008). These matrices, which are composed of mainly exopolysacchrides, proteins, lipids, surfactants, DNA and ions, shield the outer layer of a biofilm and act as a 
protective barrier against toxic substances (O'Toole and Ghannoum, 2004; Karatan and Watnick, 2009; Francis, 2008). The extracellular matrices of bacterial biofilms contain an interwoven structure of negatively charged and neutral polysaccharides that may prevent penetration of antimicrobial agents through ionic or electrostatic interactions (Ingle et al., 2008).

The presence of these matrices plays an important role in the structural scaffold of the biofilm, which also facilitates cell to cell communication (Parsek and Tolker-Nielsen, 2008; O'Toole and Ghannoum, 2004; Francis, 2008). Therefore, the formation of P. aeruginosa biofilm is the main cause of the intrinsic resistance of this bacteria to several antibiotics. Notable potential reasons for an increase in antibiotic resistance in biofilms is due to low antibiotic penetration in the EPS, expression of various efflux pumps and expression of various antibiotic inactivating enzymes (Storz and Hengee-Aronis, 2000).

Bacterial defense mechanisms are known to be major contributors to prolonged or acute infections. Recent studied have shown that these defense mechanisms arise due to the formation of biofilms. Biofilm formation by bacteria was noticed back in the early 1970's when J.W. Costerton and K.J. Cheng were studying bacterial cultures with transmission electron microscopy and noted the difference in bacterial morphology of an old culture versus fresh (planktonic) cultures (Abdallah, 2011). This led to the birth of the term 'biofilm' in microbiology.

Biofilm formation is a multistage process that starts with an initial reversible attachment of free floating microbial cells to a surface followed by a maturation stage which include cell replication, proliferation and production of an outer shell made of exopolysaccharide around the community (Coenye and Nelis, 2010). The establishment of bacteria in the context of biofilm is known to increase the defense mechanisms of bacteria in harsh and unfavorable environments, which is one of the underlying reasons for the increased resistance to toxic substances such as biocides or antibiotics (Harrison et al., 2007; Perez et al., 2010). Biofilm formation does not only increase the defense mechanisms of bacteria in the presence of antibiotics; it also helps microorganisms to establish and maintain a long-term relationship with each other, through physical and chemical interaction of cells (O'Toole and Ghannoum, 2004). Moreover, research has confirmed that bacterial resistance is higher in a biofilm, compared to planktonic (individual) cells (Barrett and Stanberry, 2009; Harrison et al., 2007). The formation of biofilm provides an advantage for the bacterial cells by reducing the penetration of antibiotic within the community, 
decreasing space for bacterial communication through quorum sensing and increasing the chance of gene transfer; all of which contribute to the increasing of bacterial resistance to antibiotics. Although this form of mechanism is advantageous to microorganisms, studies have shown that biofilm formation is a serious threat to the public health systems; almost $60 \%$ of microbial infections are as a result of this strategy (Barrett and Stanberry, 2009; Harrison et al., 2007; Spoering and Lewis, 2001).

\section{Bacterial differences between Gram-positive and Gram-negative bacteria}

Bacterial species are characterized into two broad groups that are mainly differentiated based on their structure and composition of their cell wall, which plays an important role in growth and survival of the organism in all non-isotonic environments. All bacterial species contain peptidoglycan, a substance composed of polysaccharide chains interlinked with short peptides, which contributes as a part of the bacterial cell wall (Al-Waili and Saloom, 1999). The amount of peptidoglycan in the bacteria separates the organisms into two distinct groups, Gram-positive and Gram-negative bacteria. Peptidoglycan in Gram-positive bacteria is thicker than Gram-negative species, which benefits the bacteria by reducing the passage of some groups of antimicrobial agents into the cell (Roberts et al., 2012). However, Gram-negative bacteria have a different shield that gives them an extra protection compared to Gram-positive and that is the presence of outer and inner cell membrane separated by periplasmic space (Mercholl et al., 2009).

A large portion of research on the effect of honey was performed mainly on Gram-positive bacteria. Therefore the need for research on understanding the effect of honey and the microbial mode of action on Gram-negative species needs further investigation.

\section{Pseudomonas aeruginosa}

$P$. aeruginosa has been recently categorized as one the most dangerous multidrug-resistant (MDR) bacteria, responsible for causing healthcare-associated infections (HAIs) (Hirdon et al., 2008; Rice, 2008; Macor, 2011). In the US alone, the annual cost for treatment of infection as a result of MDR species ranged between USD \$15 million to \$30 billion a year (2008 dollars), whereby according to the U.S department of Healthcare and Human Services about $13 \%$ of severe HAIs are as a result of $P$. aeruginosa infection (Frieden, 2013; Richand et al., 2001; Niederkom 
and Kaplan, 2007). Treatment of this species has become very difficult due to the adaptation and increase of antibiotic resistance to the available antibiotics.

P. aeruginosa is a Gram-negative rod shaped bacterium commonly found in the soil, fresh water environments, around the sinks, showers and hospital environments (Levin et al., 1984; Zichichi et al., 2000). This bacterium was first isolated by Carle Gessard in 1882 from wound infections of soldiers (Gessard, 1925). Later in 1894, Walter Migula was the first to propose the genus of Pseudomonas as a Gram-negative rod shape bacterium (Pexi et al., 2009). P. aeruginosa is a ubiquitous bacteria and is known to cause various types of infections in humans, animals and plants (Wiehlmann et al., 2007; Rahme et al., 2000; Elrod and Braun, 1942).

P. aeruginosa is responsible for causing up to $4 \%$ of Catheter Related Infections (CRI), $19 \%$ of respiratory infections and $17 \%$ of urinary tract infection but also causes a variety of chronic and acute infections such as, pneumonia, surgical wound infections, blood stream infections, infections of neutropenic patients, burn wound infections, chronic infections of respiratory pathways (including panbronchiolitis, bronchiectasis), and cystic fibrosis (Wisplinghoff et al., 2004; Wright et al., 2006; Koch and Hoiby, 1993; Bjarnsholt and Givskov, 2007). In the United States, approximately 80,000 Catheter-Related Blood Stream Infections (CRBI) occur annually at a substantial cost, both in terms of morbidity and financial resources expended for treatment of CRI (Grady et al., 2011). The annual treatment of CRI can cost up to $\$ 2.3$ billion dollars (Sadfar, 2011), out of which $\$ 50$ to $\$ 350$ million dollars is spent on the treatment of Urinary tract infections (UTI) (Barrett and Stanberry, 2009).

One of the most classical examples of biofilm formation which has threatened and caused an increase of chronic infections in cystic fibrosis (CF) patients is the colonization and biofilm formation of $P$. aeruginosa in lungs, which causes a decline in pulmonary function by influencing oxygen availability in lungs (Evans et al., 1996; Kerem et al., 1990).

\section{Virulence factors in gram negative bacteria}

$P$. aeruginosa is known to produce a wide range of virulence factors such as exoprotease elastase (Bjarnsholt, and Givskov, 2007; Woods et al., 1982), ADP ribosylating enzymes (Vasil et al., 1989; Bjarnsholt, and Givskov, 2007); lipopolysaccharides (Tang et al., 1996; Bjarnsholt, and Givskov, 2007); hemolytic phosphatase (Vasil et al., 1991); lipases; phospholipases; exotoxin A; 
pyocyanin and siderophores (iron-chelating compounds) such as pyochelin and pyoverdine (Cox, 1982; Cornelis, 2010). The presence of these virulence factors is known to cause extensive tissue damage. Studies have shown that the production of many virulence factors are controlled by expression of small molecular weight molecules known as quorum sensing molecules (Cornelis and Dingemans, 2013). In P. aeruginosa, virulence factors are expressed differently depending on the environmental signals and metabolic factors (Bjarnsholt et al., 2010). It is known that $P$. aeruginosa uses an estimated 468 transcriptional regulators to control expression of different virulence factors (Bjarnsholt et al., 2010; Stover et al., 2000).

In addition, one of the most unique characteristics of $P$. aeruginosa is the production of pyocyanin, a green water-soluble pigment, which is an indication of $P$. aeruginosa colonization of the host or the environment (Stephen and Hawkey, 2006). The study by Stephen and Hawkey has indicated that pyocyanin has antibiotic activity against other bacteria and fungi, which provides an advantage over competing bacteria occupying the same niche (Stephen and Hawkey, 2006).

Communication is the degree of agreement between the message sent and the meaning understood by the receiver. In the microbial world, bacterial communication or quorum sensing (QS) involves synthesis, excretion, and detection of low molecular weight molecules called autoinducers (AI), which are known to have a significant advantage for the microorganism. In $P$. aeruginosa species, QS involves production of $\mathrm{N}$-acyl-homoserine lactones (AHL) molecules which are mediated by the expression of las and $r h l$ genes (Annapoorani et al., 2012; Davies et al., 1998; Jung, 2011). Previous studies have confirmed the role of AHL molecules in controlling the expression of various sets of genes that are responsible for biofilm formation (Shrout et al., 2006), conjugation (McLean et al., 1997), pigment production (Pessi et al., 2001), swarming motility (Shrout et al., 2006), and expression of many virulence factors such as exoproteases, hemolysins, exotoxin A, exoenzymes, pyoverdine and pyocyanin (Pearson et al., 2000; Hentzer et al., 2003). It is known that AHL molecules are regulated with an increase in cell population which then results in activation of regulator proteins LasR and RhlR, responsible for the regulation of virulence genes (Clutterbuck et al., 2007). A study by Clutterbuck et al., has shown that irreversible attachment of cells activated the rhlR-rhlI gene, which activates C4-HSL and plays a role in biofilm development (Clutterbuck et al., 2007). 
Iron is the most abundant element on earth and comprises 5\% of the earth's crust (Heli et al., 2011). It is an essential nutrient and is crucial for the biochemical function of all living species (Weinberg, 2009). Iron can exist in two oxidation states, $\mathrm{Fe}^{2+}$ and $\mathrm{Fe}^{3+}$. It is known that $\mathrm{Fe}^{3+}$ (ferric iron) has a low solubility and dominates in oxygenated environments (Andrews et al., 2003). At physiological $\mathrm{pH} 7$, the concentration of bioavailable $\mathrm{Fe}^{3+}$ in the environment is about $10^{-9} \mathrm{M}$. However this concentration decreases inside the host to $10^{-18} \mathrm{M}$ (Brandel et al., 2012). Therefore soluble iron cannot get into the cell via diffusion as the concentration of iron in the cytoplasm of bacteria is $10^{-6} \mathrm{M}$ (Braun et al., 2013). Conversely, the soluble $\mathrm{Fe}^{2+}$ is mainly found in anaerobic environments or in environments with low $\mathrm{pH}$ (Andrews et al., 2003). The solubility of ferric iron can be calculated by the product constant $\mathrm{K}_{\mathrm{sol}}=\left[\mathrm{Fe}^{3+}\right][\mathrm{OH}-]^{3} ;\left[\mathrm{Fe}^{3+}\right]=\left(10^{-38}\right) /\left[\mathrm{OH}^{-}\right]^{3}$, which indicates that at $\mathrm{pH} \mathrm{3,5}$, and 7, the concentration of ferric ion is approximately $10^{-5}, 10^{-11}$, and $10^{-}$ ${ }^{7}$ M (Yoder and Kisaalita, 2011; Neilands et al., 1987).

A normal human body contains $40-50 \mathrm{mg} / \mathrm{kg}$ of iron. It is known that iron plays an important role in mammalian metabolism such as oxygen transport (Heli et al., 2011), the electron transport chain (cytochrome C) (de Ungria et al., 2000; Heli et al., 2011), oxidation-reduction (alcohol dehydrogenases, dihydroorotate dehydrogenase, cytochrome oxidase) (Heli et al., 2011), glycolysis (Oxele et al., 1999; Racker and Krimsky, 1947), pentose shunt (Dhur et al., 1989; Heli et al., 2011), proteolysis (Rana and Meares, 1991), production of new erythroid cells (Heli et al., 2011) and many more.

\section{Iron Uptake System in $P$. aeruginosa}

Bacterial pathogens are challenged with the problem of acquiring iron in the host since iron is sequestered by circulating proteins such as transferrin and lactoferrin, or is bound to heme molecules (Finkelstein et al., 1983; Cornelis and Dingemans, 2013). The uptake of iron by microorganisms varies, depending on the type of bacterium and the environment (Donlan and Costerton, 2002). P. aeruginosa uses four different strategies to acquire iron from the environment such as inside a host (Donlan and Costerton, 2002; Ratledge and Dover, 2000; Cornelis, 2010; Jakubovics and Jenkinson, 2001; Poole and McKay, 2003; Drake and Gulick, 2011). 
These strategies include (Figure 2.1.):

(i) Production of high-affinity iron uptake molecules called siderophores that chelate extracellular $\mathrm{Fe}^{3+}$

(ii) Direct contact of the bacterium with the source of iron containing proteins such as transferrin, lactoferrin or heme proteins

(iii) Uptake of xenosiderophores that are not produced by the bacterium itself

(iv) and use of Feo transport system.

Overall, depending upon the type of infection, $P$. aeruginosa adapts itself to the environment to fulfill the need for iron from the host (Cornelis and Dingemans, 2013).

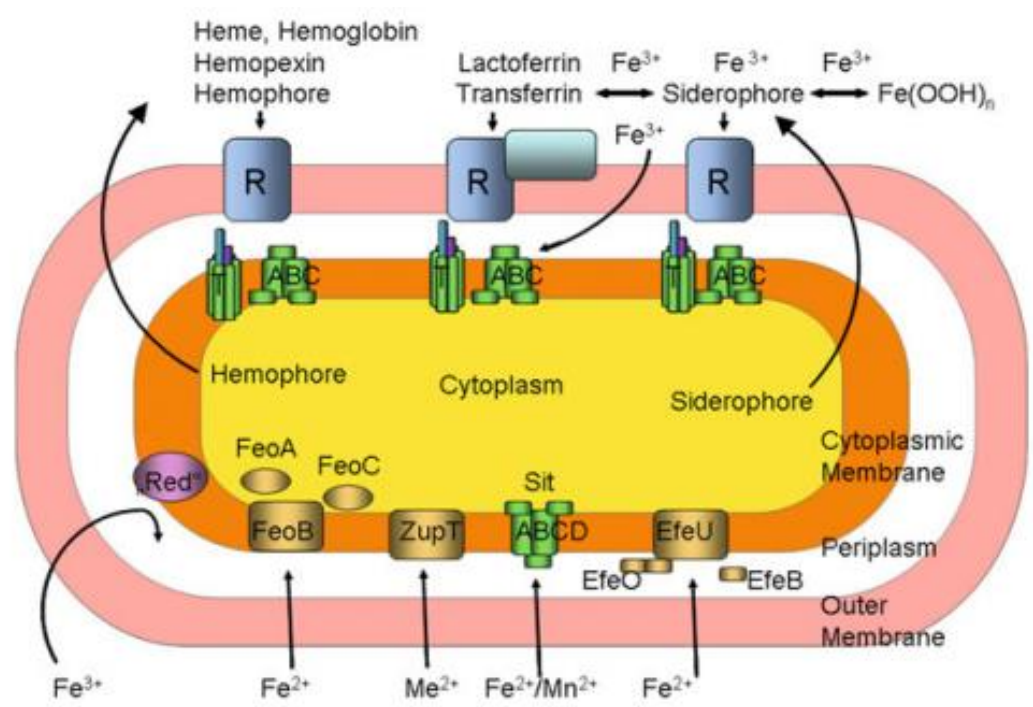

FIGURE 2. 1 IRON TRANSPORT SYSTEM IN GRAM NEGATIVE BACTERIUM

Transport of ferric iron complex across the outer membrane to the periplasm occurs through binding of the ferric complex to the membrane receptors (denoted as $\mathrm{R}$ ). The ferric iron complex is transported from the periplasm to the cytoplasm through ATP-binding cassette transporter (denoted as ABC) (Figure modified from Braun et al., 2013).

\section{The $P$. aeruginosa Siderophore mediated $\mathrm{Fe}^{3+}$ uptake system}

Siderophores are low molecular weight molecules produced and excreted from the bacterium to chelate iron from the environment. Siderophore production is known to play an important role in the virulence of pathogenic Pseudomonas. Consistent with being a virulence factor, siderophores are mainly important for acquisition of iron within the host. It is known that 
siderophores have specific affinity for $\mathrm{Fe}^{3+}$ iron. All Gram-negative bacteria such as fluorescent pseudomonads transport iron across the outer membrane to the cytoplasmic membrane in an independent manner (Braun et al., 2013). The outer membrane of pseudomonads contains a TonBdependent receptor complex, which is a large porin with $\alpha$-barrel shaped membrane protein that gates the entry of compounds inside the cell and is responsible for recognition of iron-load complexes (Cornelis, 2010). Regardless of whether iron is bound to siderophore or heme protein, the iron ligand binds tightly to the transporter and a change in conformation of the binding site causes the bound iron to enter the periplasm. This occurs thought the N-terminal end of the TonBreceptor located in the outer membrane (Figure 2.2).

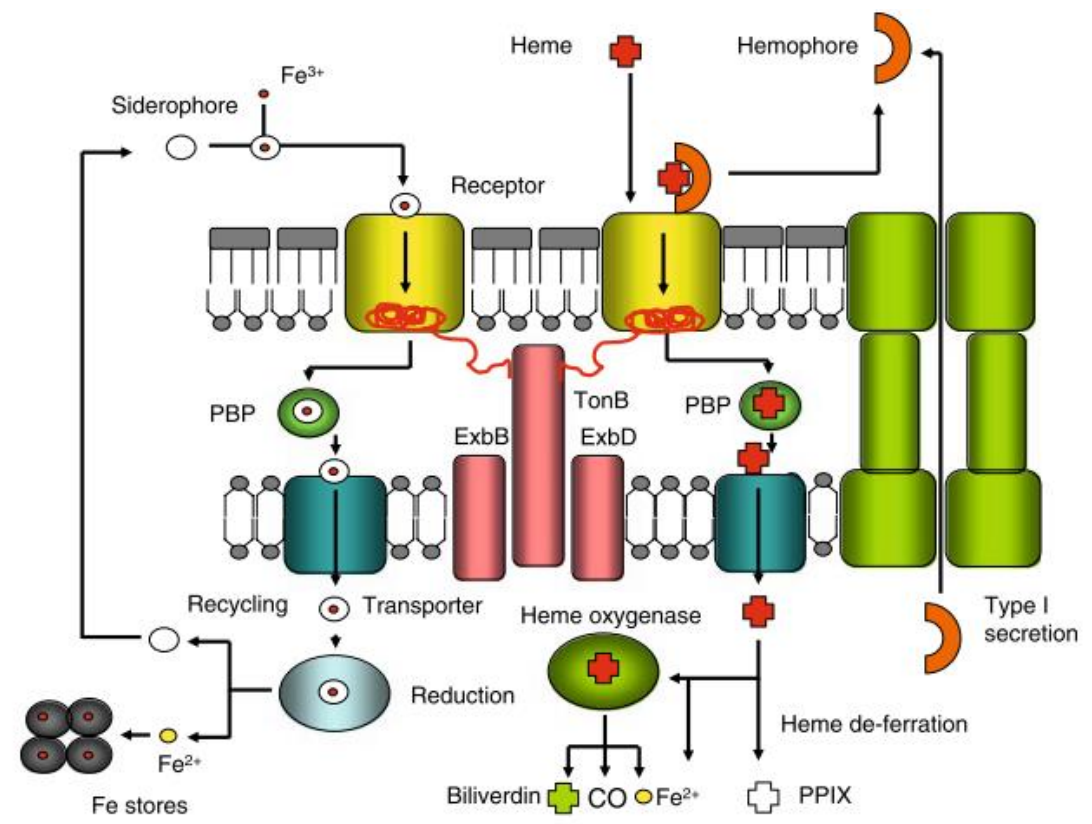

FIGURE 2. 2 IRON UPTAKE SYSTEM IN P. AERUGINOSA BACTERIUM VIA SIDEROPHORE OR HEME.

Iron-Siderophore complex is recognized by the outer membrane TonB-dependent receptor, which is a gated porin and is in contact with TonB. TonB complex contains ExbB and ExbD, which transmit the energy from the proton-motive-force to open the gate where ironsiderophore complex can be transported to the periplasm. (Figure adopted from Cornelis, 2010).

The TonB receptor is a part of the TonB complex that is located inside the periplasmic space and bacterial cytoplasmic membrane of the cell. TonB is also connected to ExbB and ExbD proteins, which are responsible to transmit energy of the protein motive force and allows the opening, closing, and transport of ferric complex into the periplasm (Cornelis, 2010; Postle and Larsen, 2007). Once the iron is transported inside the periplasm of the cell, the complex will be 
transported into the cytoplasm through ATP-binding cassette transporter $(\mathrm{ABC})$ receptors located on the cytoplasmic membrane (Figure 2.3). The ABC transporter consists of the transmembrane permease which separates the siderophore and iron complex and reduces $\mathrm{Fe}^{3+}$ to $\mathrm{Fe}^{2+}$ (Heli et al., 2011). This occurs through the redox system and the proposed reaction can be summarized as follows:

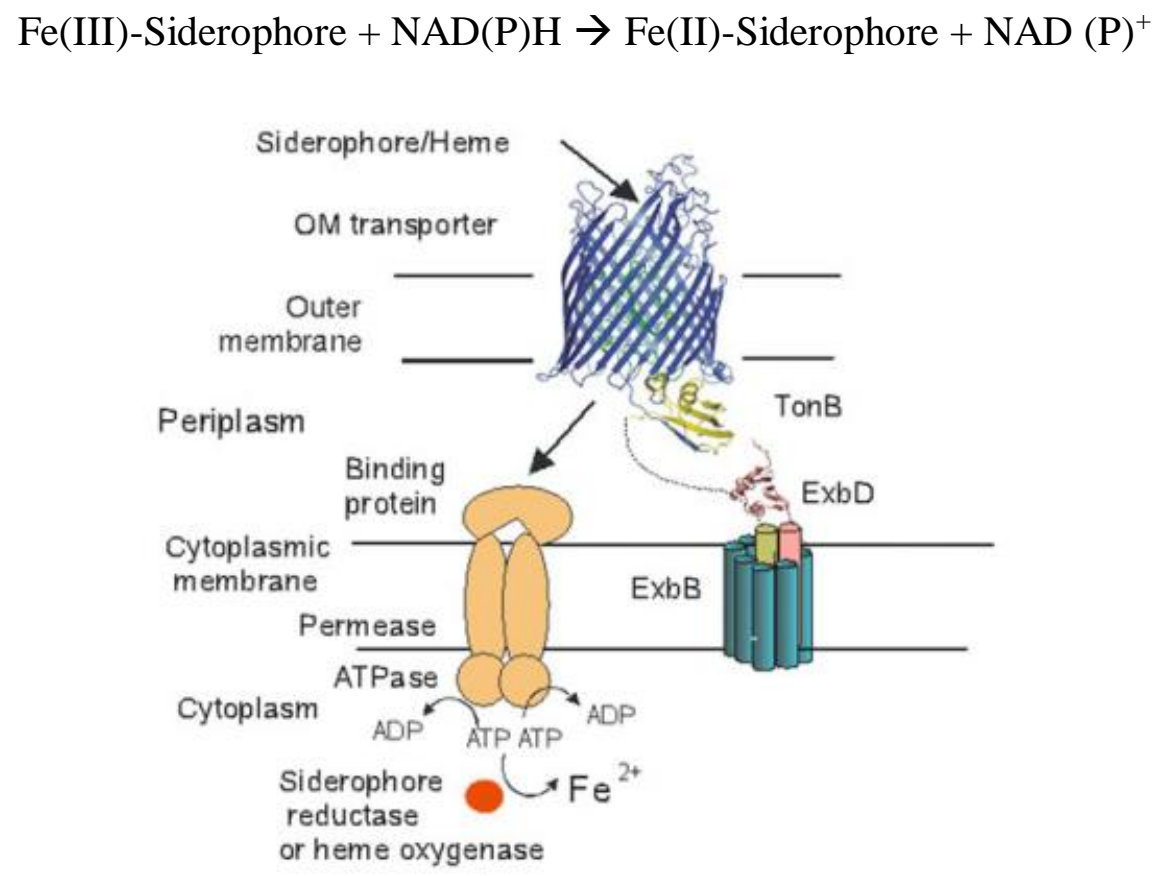

FIGURE 2. 3 SIDEROPHORE TRANSPORT SYSTEM ACROSS GRAM NEGATIVE MEMBRANES

In Gram-negative bacteria, siderophore complex is transported into the cell through the TonB complex, located in the periplasm of the cell. One end of the TonB complex is attached to the outer membrane transport receptor and the other end is connected to the cytoplasmic receptor of the cell. TonB complex located on the cytoplasmic membrane controls the uptake of iron-siderophore complex, through providing the energy required for opening of the outer membrane complex. Once the iron-siderophore complex is transported into the periplasm it is then transported to the cytoplasm through $\mathrm{ABC}$ transporter. The $\mathrm{ABC}$ transporter consist of the transmembrane permease to which to which an ATPase is attached in the cytoplasm. Separation of siderophore and iron complex occurs via the permease which reduces $\mathrm{Fe}^{3+}$ to $\mathrm{Fe}^{2+}$. (Adopted from Braun et al., 2013).

Research on siderophore-mediated iron acquisition systems of Pseudomonas has mainly focused on fluorescent pseudomonads, however other studies have shown that non-fluorescent strains such as Burkholderia are capable of producing siderophores (Poole and McKay, 2003). One of the striking characteristics of Pseudomonas is its ability to acquire iron through other bacterial siderophores (for example aerobactin, enterobactin cepabactin) (Poole and McKay, 2003; 
Schalk and Guillon, 2012; Liu and Shokrani, 1978), fungal siderophores (Poole and McKay, 2003; Poole et al., 1990), synthetic chelators (Poole and McKay, 2003; Hohnadel and Meyer, 1988) and natural occurring chelators (Poole and McKay, 2003; Meyer and Hohnadel, 1992; Harding and Royt, 1990). P. aeruginosa is capable of synthesizing two well-studied siderophores, pyoverdine (also referred to as PVD) and pyochelin (also referred to as Pch). Both of these iron mediated siderophores have an outer membrane transporter protein with a high affinity for ferric iron in the range of nanomolar concentrations (Cox, 1980; Brandel et al., 2012). It is important to note that siderophores are different from one another, and this difference arises based on the way that the iron is complexed. Based on these differences, siderophores are categorized as phenolate-, catecholate-, hydroxamate-, carboxylate-, or mixed type of siderophores (Cornelis and Dingemans, 2013).

\section{P. aeuginosa Siderophore-Pyochelin}

Pyochelin is a hydroxyphenyl-thiazolinyl-thiazolidin molecule and is known to be a member of hydrophobic siderophores (Brandel et al., 2012; Ankenbauer et al., 1985). Due to its hydrophobicity, this molecule is known to be poorly soluble in aqueous media (Brandel et al., 2012). Pyochelin is known to have a very low affinity for $\mathrm{Fe}^{3+}$, however it is capable of releasing iron from transferrin under acidic conditions. Previous studies have shown that the pyochelin molecule is capable of chelating other metallic ions, such as $\mathrm{Zn}$ (II), $\mathrm{Cu}$ (II), $\mathrm{Co}$ (II), $\mathrm{Mo}$ (VI) and Ni (II) (Brandel et al., 2012; Cox et al., 1981; Visca et al., 1992), as well as non-biologically relevant cations (Brandel et al., 2012; Hayen and Volmer, 2006). Pyochelin biosynthesis involves a different cascade of production than pyoverdine. Recent studies have shown that $P$. aeruginosa first produces pyochelin and switches to pyoverdine production when the iron concentration is extremely low in the environment (Dumas et al., 2013; Cornelis and Dingemans, 2013). Studies have shown that in chronic infections, such as lungs of CF patients, pyochelin production can play a significant role in causing tissue damage (Cornelis and Dingemans, 2013). This effect is mainly due to the redox cycle that pyochelin-iron complexes possess in the presence of pyocyanin, another extracellular compound produced by $P$. aeruginosa (Cornelis and Dingemans, 2013; Coffman et al., 1990; Britigan et al., 1992; Britigan et al., 1997). 


\section{P. aeruginosa Siderophore-Pyoverdine}

Pyoverdine, also known as pseudobactin, is a mixed siderophore that contains a conserved chromophore and a peptide chain (Cornelis and Dingemans, 2013; Meyer, 2000). These siderophores are mainly secreted from $P$. putida, $P$. syringae, $P$. aeruginosa and $P$. fluorescence species in low iron environments (Cornelis and Dingemans, 2013; Meyer, 2000; Gross and Loper, 2009; Hannauer et al., 2012). Pyoverdine is a fluorescent, water-soluble molecule (Musthafa et al., 2010) that binds strongly to $\mathrm{Fe}^{3+}$, and this results in fluorescent quenching of this molecule (Yoder and Kisaalita, 2008, 2011; Ongela et al., 2002). The length of peptide chains in pyoverdine can vary among different bacteria, however studies have shown that the chromophore region is conserved among species (Escaich, 2010). The chromophore region of pyoverdine contains a dihydroxyquinoline (fluorescent) chromophore linked to a small dicarboxylic acid and is unique in producing a green-yellow fluorescent emission upon exposure to UV light (Drake and Gulick, 2011).

The process of pyoverdine biosynthesis begins in the cytoplasm and ends in the periplasm of the cell, where it is then secreted to the outside of the cell (Hoegy et al., 2005; Schalk and Guillon, 2012). The biosynthesis of pyoverdine involves the expression of a variety of enzymes specifically non-ribosomal peptide synthetases (NRPSs), which are responsible for the synthesis of both the chromophore backbone and peptide moiety of pyoverdine (Schalk and Guillon, 2012). Briskot et al., (1989) suggested that assembly of the PVD backbone in PA01 strain starts in the cytoplasm through the PvdL, which is the only common PVD-synthesis NRPS (Briskot et al., 1989; Mossialos et al., 2002; Gross and Loper, 2009). PvdL enzyme is responsible for many things such as forming the structure of cytoplasmic PVD precursor (Briskot et al., 1989; Hannauer et al., 2012), coupling coenzymes A and fatty acids (Drake and Gulick, 2011), building pyoverdine backbone, followed by formation of a tetrahydropyrimidin ring (precursor of the dihydroxyquinolne chromophore) (Briskot et al., 1989; Mossialos et al., 2002), and catalyses in the attachment of the first amino acid of the peptide moiety of PVDI (Briskot et al., 1989). PVD synthesis is then followed by the progression of cytoplasmic enzymes PvdI, PvdJ, and PvdD. The cytoplasmic PVDI precursor has an unformed chromophore, and a myristoleic chain that is bound to the peptide backbone (Glu), which is responsible for attaching the cytoplasmic PVDI precursor bound to the inner membrane (Briskot et al., 1989; Hannauer et al., 2012). As shown in Figure 
2.4., the non-fluorescent PVDI precursor is transported across the inner membrane into the periplasm by the export ABC transporter pump, PvdE (Briskot et al., 1989; Yeterian et al., 2010). In the periplasm, the PVD precursor (also known as ferribactin) goes through a maturation process of PVDI chromophore that happens by condensation of Try and Dab by periplasmic acylase PvdQ (Yeterian et al., 2010). This enzyme was first recognized as a periplasmic quorum quenching enzyme that was responsible for cleaving of acyl homoserine lactone of AHL molecule (Briskot et al., 1989; Sio et al., 2006). This role was also confirmed in an in vitro study with Caenorhabditis elegans where addition of PvdQ quenched the signaling molecule or quorum sensing molecule (Papaioannou et al., 2009). In another study Wahjudi et al. (2013) showed the beneficial effect of combining PvdQ enzyme and antibiotic as an inhaler for treatment of $P$. aeruginosa infection of lungs (Wahjudi et al., 2013).

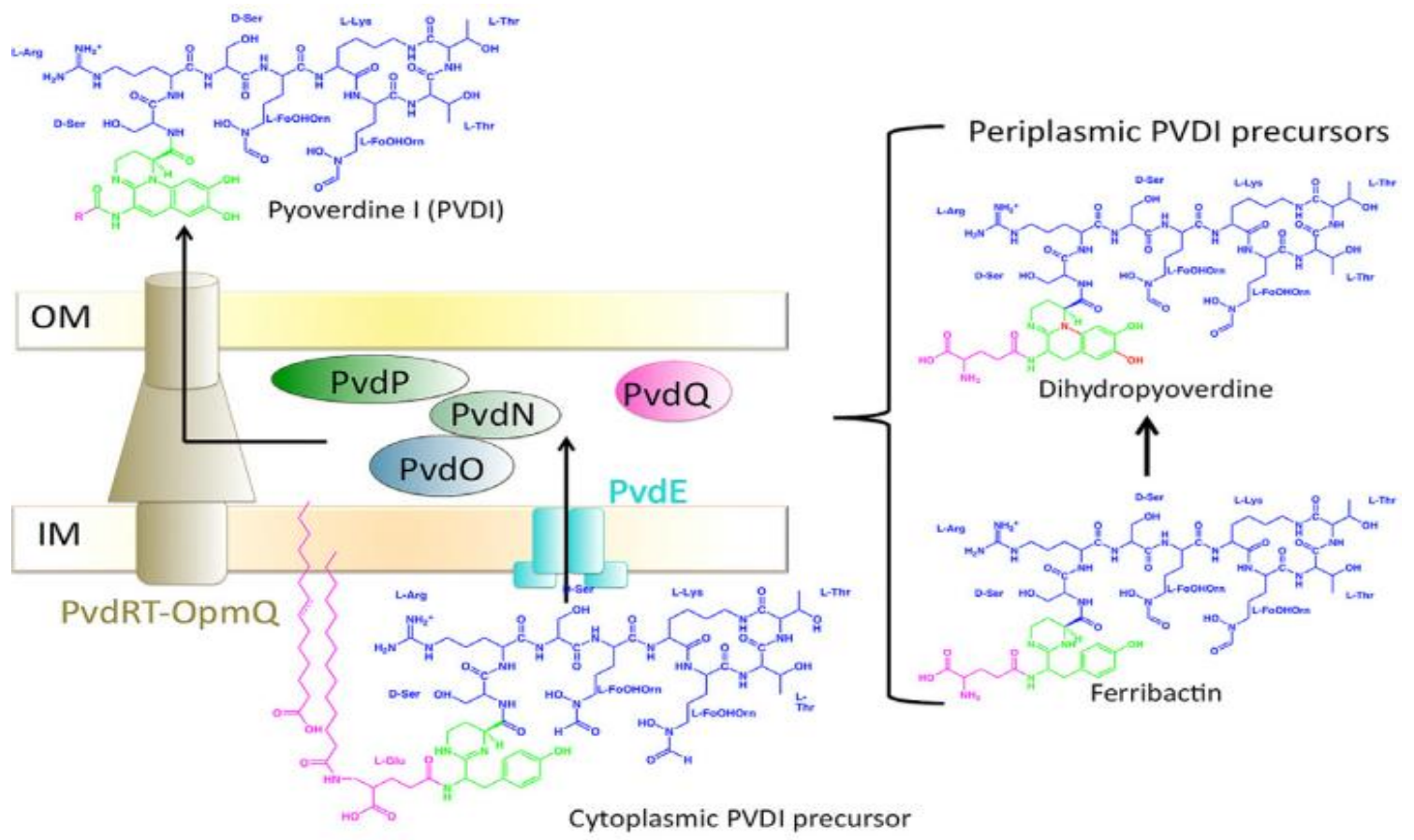

FIGURE 2. 4 PYOVERDINE BIOSYNTHESIS IN P. AERUGINOSA.

PVD precursor backbone is assembled in the cytoplasm by four enzymes (PvdL, PvdI, PvdJ and PvdD), which is then transferred to the periplasm. The cytoplasmic PVD precursor has unformed chromophore and a myristic acid chain that keeps the cytoplasmic PVD precursor bound to the inner membrane. Once the PVD precursor is transported across the inner membrane through the $\mathrm{ABC}$ transporter, periplasmic acylase PvdQ changes, the fatty acid of PVD. With the help of PvdN, PvdQ, and PvdP, the chromophore of PVD is formed though condensation of tyr and Dab. (Refer to text for more details) (Adopted from Isabelle and Guillon, 2012). 
Recent studies by Yeterian et al. suggested that newly synthesized siderophores with a formed chromophore are stored in the periplasm (Briskot et al., 1989; Yeterian et al., 2010). It is known that these newly synthesized PVDI are secreted to the extracellular environment through PvdRT-OpmQ efflux system (Yeterian et al., 2010). In P. aeruginosa the extracellular PVDI-Fe complex crosses the outer membrane through two specific membrane transporters FpvA (Briskot et al., 1989) and FpvB (Briskot et al., 1989; Ghysels et al., 2004) that are activated through TonB machinery (Briskot et al., 1989, Postle and Larsen, 2007). The release of iron from PVDI occurs through a reduction mechanism that involves no chemical modification of the siderophore. In addition to chelating iron, pyoverdine is known to be responsible for chelating a variety of metals such as $\mathrm{Al}^{3+}, \mathrm{Cd}^{2+}, \mathrm{Co}^{2+}, \mathrm{Cu}^{2+}, \mathrm{Ga}^{3+}, \mathrm{Mn}^{2+}, \mathrm{Ni}^{2+}$ and $\mathrm{Zn}^{2+}$ (Briskot et al., 1989; Braud et al., 2009).

As stated earlier, pyoverdine binds iron with a high affinity. In addition to its role as a siderophore, it can also act as a signaling molecule that triggers the production of other extracellular virulence factors, such as exotoxin A and protease PrpL (Cornelis and Dingemans, 2013; Lamont et al., 2002; Cornelis, 2010). In addition this siderophore has shown to be involved in the establishment of biofilms (Cornelis and Dingemans, 2013; Banin et al., 2005; Patriquin et al., 2008; Heli et al., 2011; Martin et al., 2011).

\section{Human Siderophyins}

The second common method that bacterial species use to acquire iron within the host is through protein receptors that bind to lactoferrin (Lf), transferrin (Tf), or hemoglobin (Hb). Transferrin and lactoferrin proteins are common constituents of plasma or mucosal secretions and contribute to host defense mechanisms by acting as an iron storage and reducing the availability of iron during an infection (Britigan et al., 1993). Studies have shown that some bacterial species are able to overcome the presence of these proteins through production of specific enzymes. For example the production of elastase enzyme by Pseudomonas species has been shown to cleave iron bound to transferrin protein and enable PVD siderophore to chelate the iron (Ankenbauer et al., 1985; Britigan et al., 1993). 


\section{Heme uptake system in $P$. aeruginosa}

Many Gram-negative bacteria including Pseudomonas have the ability to uptake iron from the environment though their Heme uptake system, which is a process that involves regulation and synthesis of proteins though Has and Phu systems (Cornelis and Dingemans, 2013; Ponka, 1997). Heme is always extracted from hemoproteins such as hemoglobin or hemopexin that contain bound iron (Cornelis and Dingemans, 2013). The Has system is known to regulate production of hemophore (shown in Figure 2.2.), which involves binding and transferring of a heme molecule to the cytoplasm of bacterium. Once the heme-hemophore complex is transferred to the periplasm, it is then bound to a protein that transports the complex across the $\mathrm{ABC}$ transporter. In the cytoplasm, a heme complex is degraded to form biliverdin, $\mathrm{CO}$ and $\mathrm{Fe}^{2+}$ (Cornelis and Dingemans, 2013; Bhakta and Wilks, 2006; Barker et al., 2012; O'Neill et al., 2012).

\section{Lactoferrin}

Lactoferrin is an $80 \mathrm{kD}$ iron-binding glycoprotein, produced by mucosal epithelial cells in various mammalian species and is known to be responsible for transport of iron in blood serum, which also plays an important role in the defense mechanism of the body (Yeterian et al., 2010; Adlerova et al., 2008). Lactoferrin is mainly found in sites of infection and inflammation, especially in mucosal secretions such as tears (González-Chávez et al., 2009), saliva, semen (Jensen et al., 1986), vaginal fluids (Buckett et al., 1997), nasal and bronchial secretion (Pillay et al., 2001), bile, gastrointestinal fluids and urine (Harada et al., 1999). This glycoprotein is also known to regulate the concentration of unbound iron, prevent the formation of hydroxyl radicals (rf), and retain metal over a wide $\mathrm{pH}$ range (Abergel et al., 2006). Lactoferrin is the second most abundant protein found in milk (Abergel et al., 2006; Pan et al., 2010; Murata et al., 2013).

Lactoferrin is a well-known protein responsible for sequestering iron from the site of infection, and is also able to cause cell lysis during bacterial, viral, or fungal infection by interacting with anionic molecules on the surface of cells (Abergel et al., 2006). This protein has an $\alpha$ - helix and $\beta$ - pleated sheet on each of its lobes that can bind two metal ions such as $\mathrm{Fe}^{3+}, \mathrm{Fe}^{2+}$, $\mathrm{Cu}^{2+}, \mathrm{Zn}^{2+}$, and $\mathrm{Mn}^{2+}$ (Abergel et al., 2006; Croguennec et al., 2012). Studies by Ellison et al., have shown that siderophyins, specifically lactoferrin damage the external membrane of Gram-negative bacteria by binding to lipopolysaccharide (LPS) of the bacterial cell wall and causing LPS to 
release from the cell wall thereby increasing the membrane's permeability and damaging the bacterial membrane (Ellison et al., 1988; Abergel et al., 2006; Van der Strate et al., 2001).

During a microbial infection inside the host, iron levels within the host can be depressed due to the presence of defense proteins. This happens due to the proteins secreted mainly in mucosal glands such as lipocalins that are responsible for taking away the catechol siderophores that are produced by pathogenic bacteria (Yeterian, et al., 2010). However, this is not true for all siderophores, as some siderophores such as pyoverdine (Weinberg, 2009) and petrobactin synthesized by Bacillus anthracis (Fluckinger et al., 2004) resist capture of lipocalins and can promote bacterial growth. Studies performed by Xiao and Kisaalita., have shown that lactoferrin has a high affinity for iron similar to transferrin, however, this affinity increases in low $\mathrm{pH}$ environments, and unlike transferrin, lactoferrin does not release the bound iron at low $\mathrm{pH}$ (Xiao and Kisaalita, 1997).

External administration of lactoferrin is known to be effective in reducing kidney infections (Xiao and Kisaalita, 1997; Yanaihara et al., 2000), can stimulate the proliferation of endometrium stroma cells (Yanaihara et al., 2000; Cornish et al., 2004), stimulate osteoblast proliferation, reduce apoptosis of osteoblasts (Yanaihara et al., 2000; Damiens et al., 1999), and halt the growth of human mammary gland carcinoma (Yanaihara et al., 2000; Bhimani et al., 1999). In other studies lactoferrin has shown to prevent biofilm formation and stimulate twitching motility by binding to LPS and disrupting bacterial membrane (Singh et al., 2002).

\section{Nutrients \& carbon}

Biofilm formation is not specific to bacterial species but is also seen in fungi, algae and other microorganisms (Miller et al., 2013). As mentioned earlier biofilm formation occurs through a complex interplay between different factors such as cell migration and proliferation, molecular signals, and more importantly, nutrient availability (Parsek and Tolker-Nielsen, 2008). Several studies have shown the importance of nutrient sources on initiating biofilm formation and biofilm structure (Parsek and Tolker-Nielsen, 2008). For example, depending upon the carbon source, $P$. aeurginosa biofilms have been shown to have a different structural scaffold.

Klausen et al., have shown that $P$. aeruginosa biofilm forms flat shaped biofilms when citrate was used as the carbon source (Klausen et al., 2003). In their study, time lapse microscopy 
indicated that $P$. aeruginosa pilA mutant (strain that was deficient in biogenesis of type IV pili) was unable to migrate as efficiently in citrate medium as opposed to glucose medium (Parsek and Tolker-Nielsen, 2008; Klausen et al., 2003) showing the influence of carbon source on surface migration of the bacteria or type IV pili activation (Parsek and Tolker-Nielsen, 2008). In addition, the study showed that carbon source influenced microcolony formation and biofilm development. Biofilms grown in the presence of glucose seem to form a mushroom-shaped structure whereas bacteria form a flat-shaped structure when citrate is present in their medium (Parsek and TolkerNielsen, 2008; Klausen et al., 2003). In another study Ponraj et al. demonstrated the influence of carbon source such as glucose on regulation and synthesis of bacterial siderophores (pyoverdine) (Ponraj et al., 2013) which will be discussed in the later chapters.

Nutrient source is not only important for biofilm development but can have a dual function within the biofilm itself. For example, it is noted that carbon sources such as citrate have a dual function and can be used in the TCA cycle or act as an iron chelator and mediate iron uptake in Pseudomonas strains (Marshall et al., 2009; Hohnadel and Meyer, 1988). In addition to carbon source, micronutrients such as phosphorus, nitrogen, and iron have been shown to have an important effect on biofilm formation and structure (Parsek and Tolker-Nielsen, 2008). In addition to the nutrient availability, optimal temperature, physiological $\mathrm{pH}$, water availability, cell migration and proliferation, and molecular signals contribute to biofilm formation (Ponraj et al., 2013).

Bacterial species all possess a versatile metabolism that allows them to use different compounds as a source of energy. Under different environmental conditions bacterial species are capable of either selecting and catabolizing carbon sources or assimilating specific compounds that afford them with the most efficient growth. The collection of regulatory processes that controls bacterial selection for specific carbon had been named as catabolite repression (CCR) or catabolite repression control (CRC), which was first studied in Escherichia coli through hierarchical assimilation of sugars (Magasanik, 1970).

CCR is known to be responsible for inhibiting expression of pathways for non-preferred compounds as well as generating important reorganization of metabolism that requires activation of several genes through a process known as Carbon Catabolite Activation (CCA). Both CCA and CCR are part of the common term of Carbon Catabolite Control (CCC). In addition, molecular 
analysis has shown that the global regulation process of CCC not only affects specific catabolic pathways, but is also responsible for impacting important aspects of cell physiology and their interaction with the environment. For example, genetic analysis of pathogenic bacteria has shown that catabolite repression is capable of controlling expression of several genes such as those responsible for bacterial virulence (Gorke and Stulke, 2008). However, the preferred carbon source in the CCC pathway of Pseudomonas is known to be different from E. coli and B. subtilis. The preferred carbon source of E. coli and B. subtilis is glucose, whereas Pseudomonas has shown to prefer some organic acids or amino acids as opposed to glucose. For example, in the presence of succinate and glucose, Pseudomonas has shown to repress expression of enzymes responsible for glucose catabolism until succinate is fully consumed (Collier et al., 1996). However it is important to note that the sequential hierarchy in Pseudomonas is still not fully understood but it is known that this species prefers some organic acids and amino acids to hydrocarbons, and glucose is lies within this hierarchy (Hester et al., 2000, Morales et al., 2004).

Environment and available nutrients are the factors that influence bacterial metabolic differences and facilitate a different life style or strategy to compete within a host. For example Pseudomonas species living in soil mainly uptake nutrients and compounds from decomposition as opposed to Pseudomonas that is associated to plant roots that can feed on organic compounds excreted by the roots.

\section{Closing remarks}

Several studies have reported the effectiveness of honey as a remedy against $P$. aeruginosa (Molan, 2006; Henriques et al., 2011). However this remedy was mainly effective in the presence of high concentrations of honey, or in combination with antibiotics. The beneficial use of ingestion of honey and milk has shown that this combination helps in enhancing the immune system of an individual. Although the exact mechanism of this combination is still unknown, it is proposed that the presence of lactoferrin (an iron chelator) in milk could promote the beneficial health effect of this combination.

Lactoferrin, a mammalian protein, is the principle component of iron-withholding defense systems in the human body. This protein has shown to have a high affinity for binding metal and is capable of retaining iron molecules at the site of infection. The advantage of lactoferrin over 
other proteins such as transferrin, is its ability to withhold the bound metal in a relatively low $\mathrm{pH}$ environment (Weinberg, 2001). Both in vivo and in vitro studies indicated the antibacterial activity of lactoferrin by producing an iron-deficient environment, which limits the bacterial growth (Ellison et al., 1988) and promotes eradication of the bacterium at the site of infection. In addition, a recent study has shown the beneficial effect of using lactoferrin/xylitol hydrogel against pathogenic P. aeruginosa (Ammons et al., 2010).

Several studies have confirmed the bactericidal nature of iron chelators or honey against many bacterial species. However, the combined effect of these two and their influence on bacterial metabolism is not known. Therefore, this study investigates the combined effect of an iron chelator and honey on a pathogenic bacterium, and evaluates the potential use of such combination as a novel therapy for treatment of infections associated with $P$. aeruginosa. 


\section{CHAPTER 3}

\section{The effect of honey on bacterial metabolism as measured by $\mathrm{CO}_{2}$ production and siderophore secretion in a real time system.}

\section{INTRODUCTION}

Honey, one of the oldest known sweeteners and health food sources, has been widely accepted throughout history for its uses as a drug and an ointment (Bogdanov et al., 2008). The consumption of honey dates back to $5500 \mathrm{BC}$, and the nutritional and medicinal quality of this compound has been documented in Hindu, Greek, Roman, Jewish, Christian, Islamic and other scripts (Israili, 2013). The medicinal use of honey waned following the discovery of penicillin and the antibiotic revolution, but this remedy has been re-introduced into modern medicine during the $21^{\text {st }}$ century (Al-Waili et al., 2005; Al-Waili et al., 2013; Israili, 2013). Honey is known to possess antimicrobial, antiviral, anti-parasitic, anti-inflammatory, antioxidant, anti-mutagenic and antitumor effects (Bogdanov et al., 2008). Health benefits of this compound have been reported in a variety of conditions including the treatment of skin diseases (Fidaleo et al., 2010; Israili, 2013), eye diseases, respiratory diseases (Sio et al., 2006), urinary diseases (Al-Wali, 2005), gastrointestinal diseases, skin ulcers, psoriasis, and eczema (Daglia et al., 2013; Al-Wali et al., 2003; Allen et al., 1991). Continued studies have shown that honey exhibits a broad spectrum of antibacterial activities and can inhibit growth of more than 80 species of pathogenic bacteria (Molan, 1992; Blair and Carter, 2005; Lu et al., 2013). Honey affords three main advantages for an infected host; killing of pathogenic bacteria, inhibition of pathogen growth and reduction of excreted virulence factors. Therefore, the first objective of this study is to investigate the influence of honey on these three areas.

In any clinical situation, successful treatment of an infection mainly refers to eradication of the pathogen from the site of infection (Harris and Misiewicz, 2002). Eradication is defined as complete removal of the pathogen. For example in the case of Helicobacter pylori infection, eradication is referred to as a negative test for the bacterium four weeks after the treatment (Harris and Misiewicz, 2002). Clinical studies have shown that due to bacterial antibiotic tolerance it is 
often difficult or impossible to eradicate bacteria with antibiotics (Costerton et al., 1999). However, clinical studies have shown that continuous treatment of infection with honey may lead to complete bacterial eradication from the site of infection (Al-Waili and Saloom, 1999; Al-Waili and Noori, 2004). In addition, no microbial resistance to honey has been reported to date (Lusby et al., 2005; Cooper et al., 2010; Müller et al., 2013), which could be due to multiple properties of honey presenting too many different pressures for resistance to develop (Maddocks and Jenkins, 2013). Honey is mainly composed of carbohydrates, proteins, enzymes, minerals, amino acids, trace elements, vitamins, aroma compounds and polyphenols (Alvarez-Suarez et al., 2010). The general mechanism of antimicrobial action of honey is attributed to various factors including its high osmolality ( $\left.\mathrm{a}_{\mathrm{w}}: 0.6\right)$, acidity ( $\mathrm{pH} 3.4-6.1$ ), production of hydrogen peroxide, and the presence of polyphenolic compounds and flavonoids (Maddocks and Jenkins, 2013). These antimicrobial mechanisms are known to vary among the botanical origin where the honey was harvested. With the exception of manuka honey, almost all honey produces different levels of hydrogen peroxide as a result of the presence of glucose oxidase in it (Bang et al., 2003). Hydrogen peroxide is an effective antimicrobial agent that is capable of inhibiting microbial growth and stimulates production of new capillaries in wound tissue (Tur et al., 1995; Bang et al., 2003). In addition to the above mechanisms, cationic antimicrobial peptides, such as bee defesin- 1 is a broad acting antimicrobial found in honey (Maddocks and Jenkins, 2013). In some honeys, especially manuka, bee defesin-1 is modified and changed to the phytochemical methylglycoxal (MGO), which is known to be the main active ingredient contributing to the antimicrobial activity of manuka honey (Maddocks and Jenkins, 2013).

Appropriate antimicrobial therapy has shown that growth inhibition of pathogenic bacteria is beneficial to the host, as it hinders bacterial duplication, giving the defense mechanism of the body an opportunity to get rid of the organism (Schaechter et al., 2007). Different types of honey possess different inhibitory concentrations. This is normally determined through bacterial minimum inhibitory concentration (MIC), which is defined as the lowest concentration of an antiseptic compound that completely inhibits multiplication (Medoff et al., 1971; Lambert and Pearson, 2000). MIC is normally measured against bacterial planktonic or free floating cells. Honey is useful against different types and strains of bacteria, but also against planktonic bacteria and biofilms (cluster of cells embedded in communities) (Mercholl et al., 2009). MIC varies among bacterial species as honey's mechanism of action against bacteria is known to vary. Honey affects 
microbial physiology and metabolism through influencing their gene regulation. For example, studies on Gram-positive bacteria such as MRSA and methicillin-sensitive S. auerus (MSSA) demonstrated that honey interrupts the cell cycle and arrests cell division (Henriques et al., 2010). In addition to this, honey is capable of influencing the universal stress proteins in MRSA (Jenkins et al., 2011) and inhibits bacterial attachment (Badet and Quero, 2011). In Gram-negative bacteria, treatment with honey resulted in different cell morphology (Henriques et al., 2011) and cell lysis (Roberts et al., 2012).

Although the majority of studies on honey have tested its effects on Gram-positive bacteria, molecular analysis on Gram-positive and Gram-negative bacteria has shown that honey is equally effective against both types of bacteria (Al-Waili and Saloom, 1999; Cooper et al., 2002). Gramnegative bacteria, such as $P$. aeruginosa possess a thinner peptidoglycan membrane enclosed in between the outer and inner membrane of the cell. The presence of inner and outer cell wall in Gram-negatives reduces the passage of antimicrobial agents to the target site within the cell. However, treatment of these bacteria with honey reduces the expression of OprF, which influences structural stability within the cell envelope of the bacteria (Roberts et al., 2012; Maddocks and Jenkins, 2013).

Genetic studies confirmed that honey inhibits genes associated with virulence factor regulation. Biofilm formation and expression of virulence factors are profound factors that initiate host colonization by pathogenic bacteria (Maddocks and Jenkins, 2013). Therefore, studies are beginning to focus on remedies that possess anti-virulent characteristics as a new paradigm for antimicrobial therapy (Cegelski et al., 2008; Clatworthy et al., 2007; Rasko and Spernadio, 2010; Escaich, 2008). Anti-virulent therapies are normally evaluated through inhibition of quorum sensing or bacterial signaling molecules which is known to be associated with adhesion to surfaces, biofilm formation and stimulation of virulence (Maddocks and Jenkins, 2013). Treatment of biofilms with honey inhibits quorum-sensing genes (Maddocks and Jenkins, 2013). In a recent study, Lee et al., demonstrated that honey represses quorum sensing genes (AI-2 importers) and virulence genes (LEE genes) in E. coli O157:H7 (Lee et al., 2011). Similarly, other studies have shown that honey is capable of impairing las and $r h l$ genes in P. aeruginosa which is associated with quorum sensing and regulatory networks that control virulence factors (Wang et al., 2012; Maddocks and Jenkins, 2013). From the many known virulence factors, siderophores such as PVD 
are regulated by quorum sensing in pathogenic bacteria (Maddocks and Jenkins, 2013). Siderophores are iron-chelating molecules that are responsible for acquisition of iron in the host environment. Pyoverdine and pyochelin are two well-studied siderophores utilized by $P$. aeruginosa and are needed for colonization and subsequent progression of infection. Pyoverdine secretion in the environment occurs through an energy dependent mechanism in the bacterium (Braun et al., 2013). Recent studies have shown that honey possesses the capability to influence bacterial siderophore production (Lee et al., 2012; Kronda et al., 2013), which indicates the applicability of honey as a novel therapy.

The proposed concept of using honey as an anti-virulent compound is still under investigation, as the beneficial use of this compound has been mainly studied at the genetic level, for example the regulation of quorum sensing genes. It is rare to identify an antimicrobial compound that possesses antimicrobial properties that target the microorganism at different levels such as extracellular, cellular and molecular. Even though the effect of honey at all these levels has been studied individually, its combined effect in a real time system has not been studied. Moreover, a large body of research on the effects of honey on pathogenic bacteria has focused on the effect of honey at the genetic level, and the MIC or minimum bactericidal concentration (MBC) of different types of honey. Although both MIC and MBC are necessary to ascertain the effects of an antimicrobial agent, they suffer from being endpoint measurements and are limited in their ability to measure the viability of a population over time (Goring and Mims, 2012). Therefore, this measured how honey influences biofilm behavior and metabolism in real-time, including the effect on biofilm killing, growth inhibition and virulence secretion. Biofilm metabolism allows one to distinguish the usual response of the bacteria to an antimicrobial compound, as it portrays microbial ability to live, function and replicate in an appropriate chemical milieu (Jurtshuk, 1996). Moreover, bacterial metabolic response to antimicrobial agents is known to be similar among most bacterial cells, regardless of species (Kluyver and Niel, 1956). This study therefore aimed to provide a deeper insight into the effect of honey on bacterial behavior and response. Pseudomonas aeruginosa biofilm response was monitored against exposure to three different types of honey (manuka, clover and artificial honey), through real time monitoring of carbon dioxide production and siderophore secretion. 


\section{MATHERIAL AND METHODS \\ Bacterial strain and growth conditions.}

Pseudomonas aeruginosa strain PAO1 $\left(\mathrm{ATCC}^{\circledR} 39324^{\mathrm{TM}}\right.$ ) was used in all experiments. Freeze cultures of this organism were made in $40 \%$ glycerol and kept at $-80^{\circ} \mathrm{C}$. The organism was cultivated at room temperature on $\mathrm{AB}$ defined medium agar plates $\left(2.20 \mathrm{mmol} / \mathrm{L} \mathrm{KH}_{2} \mathrm{HPO}_{4}, 1.51\right.$ $\mathrm{mmol} / \mathrm{L}\left(\mathrm{NH}_{4}\right)_{2} \mathrm{SO}_{4}, 3.37 \mathrm{mmol} / \mathrm{L} \mathrm{Na}_{2} \mathrm{HPO}_{4}, 179 \mathrm{mmol} / \mathrm{L} \mathrm{NaCl}, 4.2 \mathrm{mmol} / \mathrm{L} \mathrm{NaNO}, 0.01$ $\mathrm{mmol} / \mathrm{L} \quad \mathrm{MgCl}_{2} \cdot 6 \mathrm{H}_{2} \mathrm{O}, 0.01 \mathrm{mmol} / \mathrm{L} \quad \mathrm{CaCl}_{2} \cdot 2 \mathrm{H}_{2} \mathrm{O}, 0.001 \mathrm{mmol} / \mathrm{L} \quad \mathrm{FeCl}_{3}, 1 \mathrm{mmol} / \mathrm{L}$ Nacitrate $\left.2 \mathrm{H}_{2} \mathrm{O}\right)$.

Growth conditions in AB defined Medium. The overnight cultures for both static and flow systems were prepared by growing PAO1 in $10 \mathrm{ml}$ broth medium containing AB defined media with $10 \mathrm{mM}$ sodium citrate or $10 \mathrm{mM}$ glucose in a test tube which was incubated for $24 \mathrm{~h}$ at $37^{\circ} \mathrm{C}$ in a shaking incubator at $250 \mathrm{rpm}$. P. aeruginosa biofilms were grown at $25^{\circ} \mathrm{C}$ and typically reached stable growth conditions after 48 hours of incubation.

Growth conditions in Tryptic Soy Broth. The overnight cultures for both static and flow systems (see below) were prepared by growing PAO1 in 10ml tryptic soy broth (TSB) at a concentration of $3 \mathrm{~g} / \mathrm{L}$ in $20 \mathrm{ml}$ test tubes, for $24 \mathrm{~h}$ at $37^{\circ} \mathrm{C}$ and at $250 \mathrm{rpm}$. $P$. aeruginosa biofilms were grown in $0.03 \mathrm{~g} / \mathrm{L}$ TSB under continuous flow (described below). Stable growth phase of PAO1 biofilms in TSB medium was after 24 hours of incubation.

\section{Honey}

Unpasteurized commercially available Manuka honey (MH) (Loblaws TM, Canada), consisting of a blend of Australian and New Zealand honey from bees feeding on Leptospermum scoparium plants, was used and compared to clover and artificial honey.

The Canadian Clover honey 'Wild country Clover honey' ${ }^{\mathrm{TM}}$ ' (Wild Country Ltd, Canada) was chosen since a study performed by Brudzynski (2006) illustrated that this honey possesses high levels of antimicrobial action.

Artificial honey (AH) was prepared as described by Wilkinson and Cavangah (2005), in which $33.5 \%$ glucose, $40.5 \%$ fructose, $7.5 \%$ maltose, and $1.5 \%$ sucrose were added to $18 \%$ distilled water (DI), autoclaved and stored at room temperature until needed. 
In biofilm experiments, the manuka, clover and artificial honey was added to $0.03 \mathrm{~g} / \mathrm{L}$ TSB at concentrations of either $5 \%$ or $30 \%(\mathrm{w} / \mathrm{v})$, to which steady state biofilms were exposed for 2.5 hour or 24 hours at $25^{\circ} \mathrm{C}$.

To assess the number of cells detached from the biofilm prior, during and post treatment, effluent was collected at the different time intervals and the total CFU of detached cells from the biofilm were enumerated by plating on TSA agar.

\section{Agar Diffusion Test}

In order to determine if PAO1 planktonic cells grow in the presence of honey, $100 \mu \mathrm{L}$ aliquots of $10^{7} \mathrm{CFU} / \mathrm{mL}$ PAO1 overnight cultures were spread plated in triplicate onto tryptic soy agar (TSA) plates with 5\%,15\%,30\% and $50 \%$ (w/v) manuka honey, and incubated at $37^{\circ} \mathrm{C}$ for $24 \mathrm{~h}$.

\section{Biofilm growth and metabolism analysis}

Biofilms were grown on the inside of a silicone tube in a carbon dioxide evolution measurement system (CEMS) as described by Kroukamp and Wolfaardt (2009). In brief, the CEMS consists of a one meter long, sterile silicone tube with an inner diameter of $1 \mathrm{~mm}$ and encased in an outer Tygon tube, which was connected to a compressed $\mathrm{CO}_{2}$-free air supply (TOC grade, $\mathrm{CO}_{2}<0.5$ ppm, $\mathrm{CO}<0.5 \mathrm{ppm}, \mathrm{O}_{2}=20-22 \%$ and THS $<0.1 \mathrm{ppm}$, Linde, Canada). The silicone tubes were sterilized with $10 \%$ (vol/vol) bleach for two hours and rinsed with autoclaved $\mathrm{dH}_{2} \mathrm{O}$ for 24 hours. The metabolic activity in the biofilms in CEMS was measured from the diffusion of $\mathrm{CO}_{2}$ through the silicone tubing to the Tygon tube which was analyzed and recorded by the LI- $820 \mathrm{CO}_{2}$ analyzer (LI-COR Bioscience, Lincoln, N, USA). This system allowed the monitoring of metabolic activity in real-time under various environmental conditions. The silicone tubes where rinsed with sterile growth (AB defined or TSB) medium for 30 min prior to inoculation, followed by incubation at $25{ }^{\circ} \mathrm{C}$. The flow rate of the system was maintained with a Watson Marlow 205S multichannel peristaltic pump, with a rate of $14.5 \mathrm{ml} . \mathrm{h}^{-1}$, which resulted in a dilution rate of $4 \mathrm{~h}^{-1}$. For inoculation, the medium flow was halted and the silicone tubes were injected with $1 \mathrm{ml}$ of PAO1 overnight culture. The medium flow was resumed after $30 \mathrm{~min}$, to allow bacterial adherence to the silicone walls. 


\section{LED Light Analysis Biofilm system (LLABs)}

Biofilm cell density and PVD production was studied in a LED Light analysis Biofilm system (LLABs) developed in our laboratory, which uses a photo-diode light sensor that measures the amount of optical input of light that passes a medium and is received by the detector (figure M1). In this system, LLABs is placed on one region of the silicon tube and the detector measures the transfer of light from the light source that passes through the silicone tubing. The silicone tubes were rinsed with sterile growth ( $\mathrm{AB}$ defined or TSB) medium for $30 \mathrm{~min}$ prior to inoculation, followed by incubation at room temperature. The flow rate of the system was maintained with a Watson Marlow 205S multichannel peristaltic pump, with a rate of $14.5 \mathrm{ml}^{-1}$. For inoculation, the medium flow was halted and the silicone tubes were injected with $1 \mathrm{~mL}$ of PAO1 overnight culture. The medium flow was resumed after $30 \mathrm{~min}$, to allow bacterial adherence to the silicone walls.

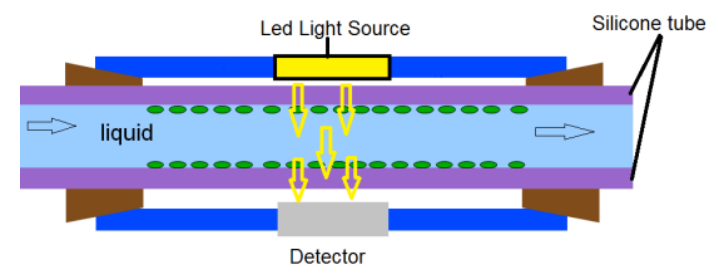

FigURE 3. LED ANALYSIS BIOFILM SYSTEM (LLABS)

\section{Siderophore- pyoverdine (PVD) spectrum measurement}

Pyoverdine was measured by collecting effluent samples in $4 \mathrm{~mL}$ cuvettes. The presence of the fluorescent chromophore group of pyoverdine produces a characteristic pattern of excitation and emission which allows the qualitative measurement of PVD by measuring fluorescence of excitation at $405 \mathrm{~nm}$ and emission at $450 \mathrm{~nm}$ (Meyer and Abdallah, 1978; Cox and Adams, 1985; Visca et al., 1992; Dao et al., 1999). In this study, a Perkin-Elmer LS-5B luminescent spectrometer (Oak Brook, Illinois) was used to measure PVD. Low $(0.01 \mu \mathrm{mol} / \mathrm{L})$ and high $(10 \mu \mathrm{mol} / \mathrm{L})$ iron was used to compare siderophore production in $P$. aeruginosa.

Growth and qualitative estimates of pyoverdine production were recorded at 20 hour intervals prior and after the exposure to the antimicrobial compound. During the antimicrobial exposure, PVD 
fluorescence was recorded at one hour intervals for the first 12 hours of exposure. Luminometer measurements were typically from a dilution of 1:100 or 1:1000 depending on the level of PVD fluorescence in the sample.

\section{Data Analysis}

Bacterial growth, biofilm formation and PVD relation to cell number were determined using oneway analysis of variance. Student's $t$ test analysis was used to assess bacterial viability at different concentrations of honey.

\section{RESULTS}

During biofilm development pyoverdine-secretion was related to cell biomass increase (figure 3.1) as determined with the light transmittance analyzer (LLABs). The $\mathrm{CO}_{2}$ measurements were used as an indication of actively respiring cells in the biofilm and similarly during biofilm development, pyoverdine secretion was related to increases in $\mathrm{CO}_{2}$ production (figure 3.2).

When biofilms were exposed to 5\% honey, biofilm cell growth increased rapidly while pyoverdine secretion levels dropped to around 19\% of pre-exposure levels (figure 3.3). Both metabolism and pyoverdine secretion returned to pre-exposure levels when the honey was removed from the system. A decrease in $\mathrm{CO}_{2}$ production can be indicative of either inhibition of metabolism or cell death. Biofilm exposure to $30 \%$ honey caused an immediate decrease in $\mathrm{CO}_{2}$ production to around 33\% of pre-exposure levels with a concomitant decrease in pyoverdine secretion (figure 3.4). The inability of $P$. aeruginosa cells to multiply while being exposed to $30 \%$ honey was confirmed when planktonically grown P. aeruginosa PAO1 was exposed to $30 \%$ (w/v) or higher concentration of honey on agar plates. Planktonically grown $P$. aeruginosa cells exposed for 24 hours to $30 \%$ and $50 \%$ honey did not grow on agar plates which provides evidence that bacterial killing occurred or severe growth inhibition that lasted longer than 24 hours after exposure.

The biofilm always recovered after 30\% honey exposure for 2.5 hours in terms of metabolism and pyoverdine secretion but exposing the biofilm for 24 hours compared to 2.5 hours resulted in longer recovery times (figure 3.4 and 3.5). 
Single sugars (data not shown), (glucose, etc) or sugar combinations, as described in the Methods section, simulating artificial honey, caused comparable responses in biofilm metabolism and pyoverdine secretion when compared to honey (figure $3.5 \mathrm{~A}$ and B). Changing the nutrient medium concentration from $0.03 \mathrm{~g} \cdot \mathrm{L}^{-1}$ to $0.003 \mathrm{~g} \cdot \mathrm{L}^{-1} \mathrm{TSB}$, resulted in biofilm behavior that mimicked exposure to $30 \%$ honey (figure $3.5 \mathrm{C}$ ).

Manuka honey at 30\% resulted in longer recovery times for recovery of biofilm metabolism and pyoverdine secretion when compared to the same concentration of clover honey. However, removal of honey from the system was followed by full biofilm recovery within 24 hours after exposure (results not shown).

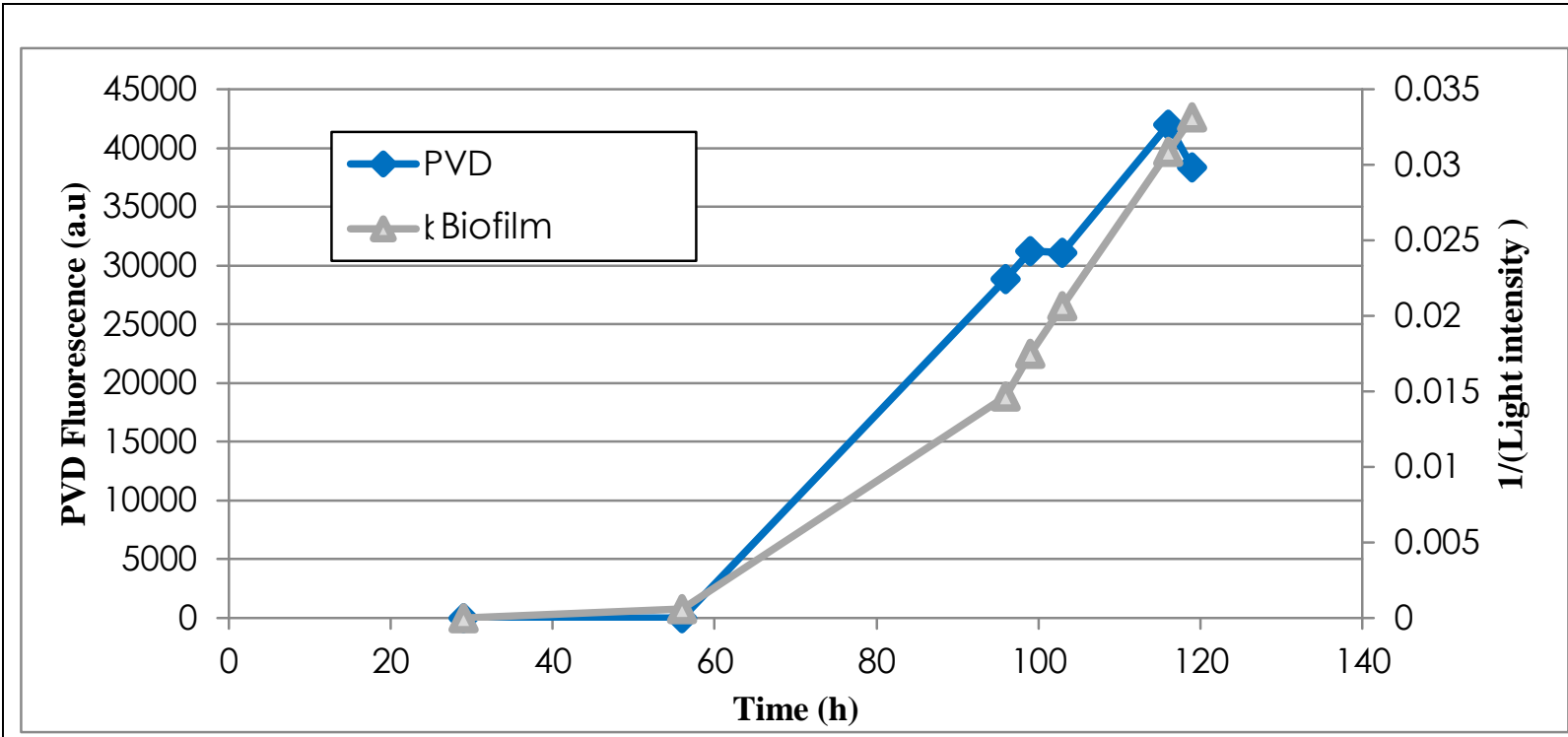

FigURE 3. 1. REAL TIME ANALYSIS OF PYOVERDINE SECRETION IN P. AERUGINOSA BIOFILM.

Pyoverdine (PVD) secretion (- blue) from $P$. aeruginosa culture on the inside of Tygon tubing was monitored during biofilm development, by the amount of light received to the LED analyzer system- LLABs system. The data shown is the inverse of the amount of light received by the analyzer (- Grey). 


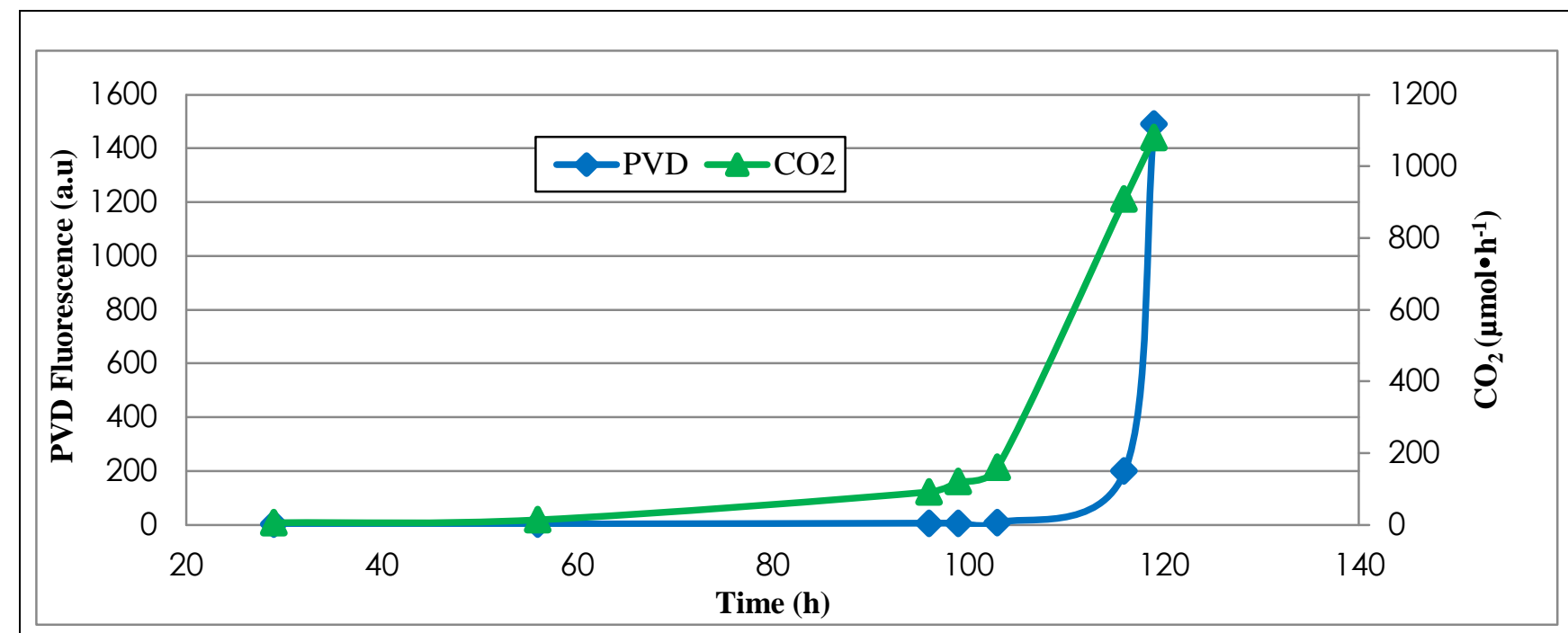

FIGURE 3. 2. REAL-TIME ANALYSIS OF PYOVERDINE SECRETION OF P. AERUGINOSA BIOFILM IN CEMS.

$P$. aeruginosa biofilm growth was analyzed through $\mathrm{CO}_{2}$ production in the Carbon Dioxide Evolution Measurement System (CEMS) (- Green). Pyoverdine (PVD) secretion into the effluent was concurrently measured ( - Blue). 


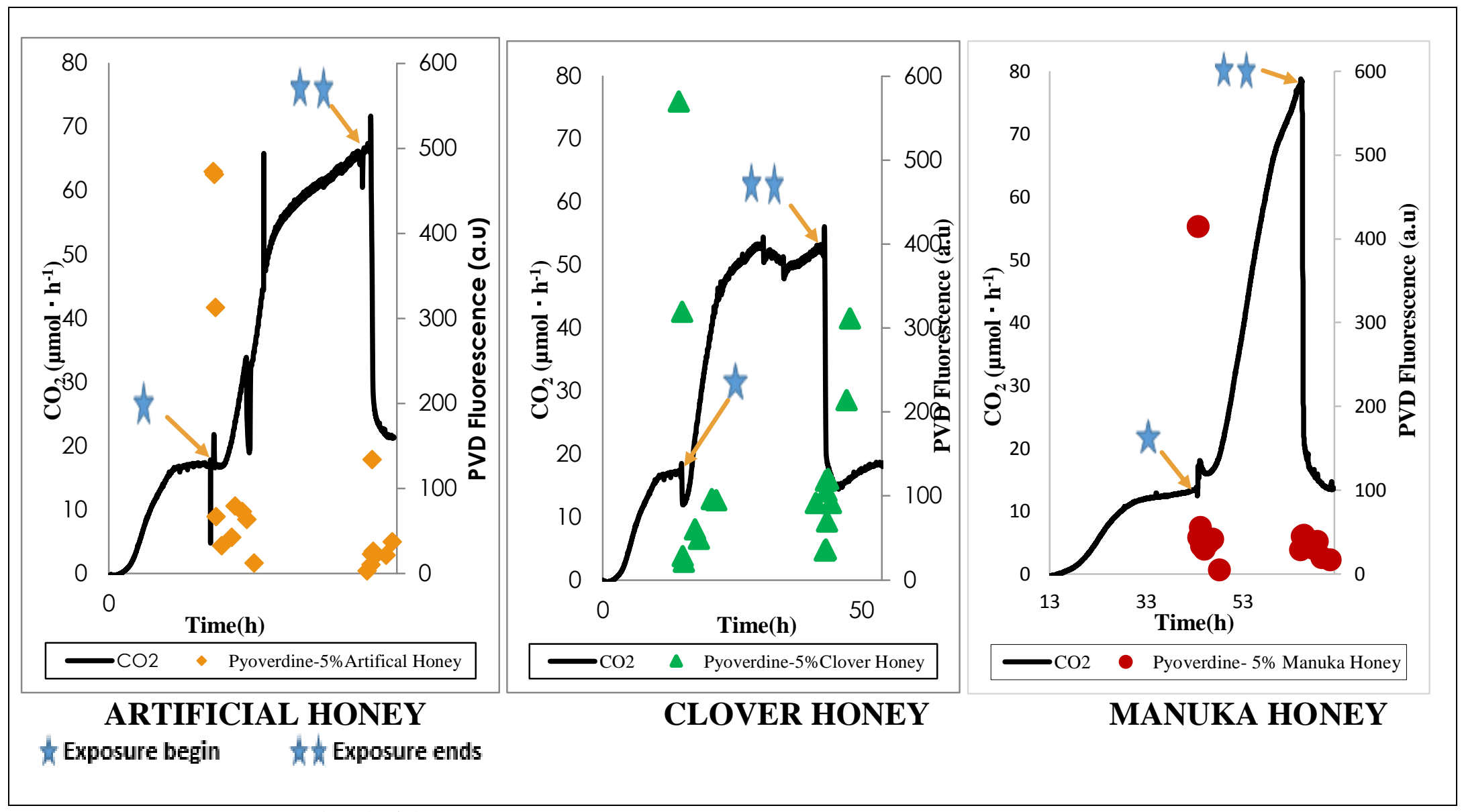

FIGURE 3. 3. EFFECT OF $5 \%(\mathrm{~W} / \mathrm{V})$ HONEY ON P. AERUGINOSA SIDEROPHORE PRODUCTION AND BIOFILM METABOLISM.

Stationary phase $P$. aeruginosa biofilm (- Black) incubated in CEMS at $25^{\circ} \mathrm{C}$, exposed to $5 \%(\mathrm{~g} / \mathrm{L})$ manuka honey, clover honey, and artificial honey for $24 \mathrm{~h}$. PVD secretion in the effluent was measured (- Red, Orange and Green) respectively. 


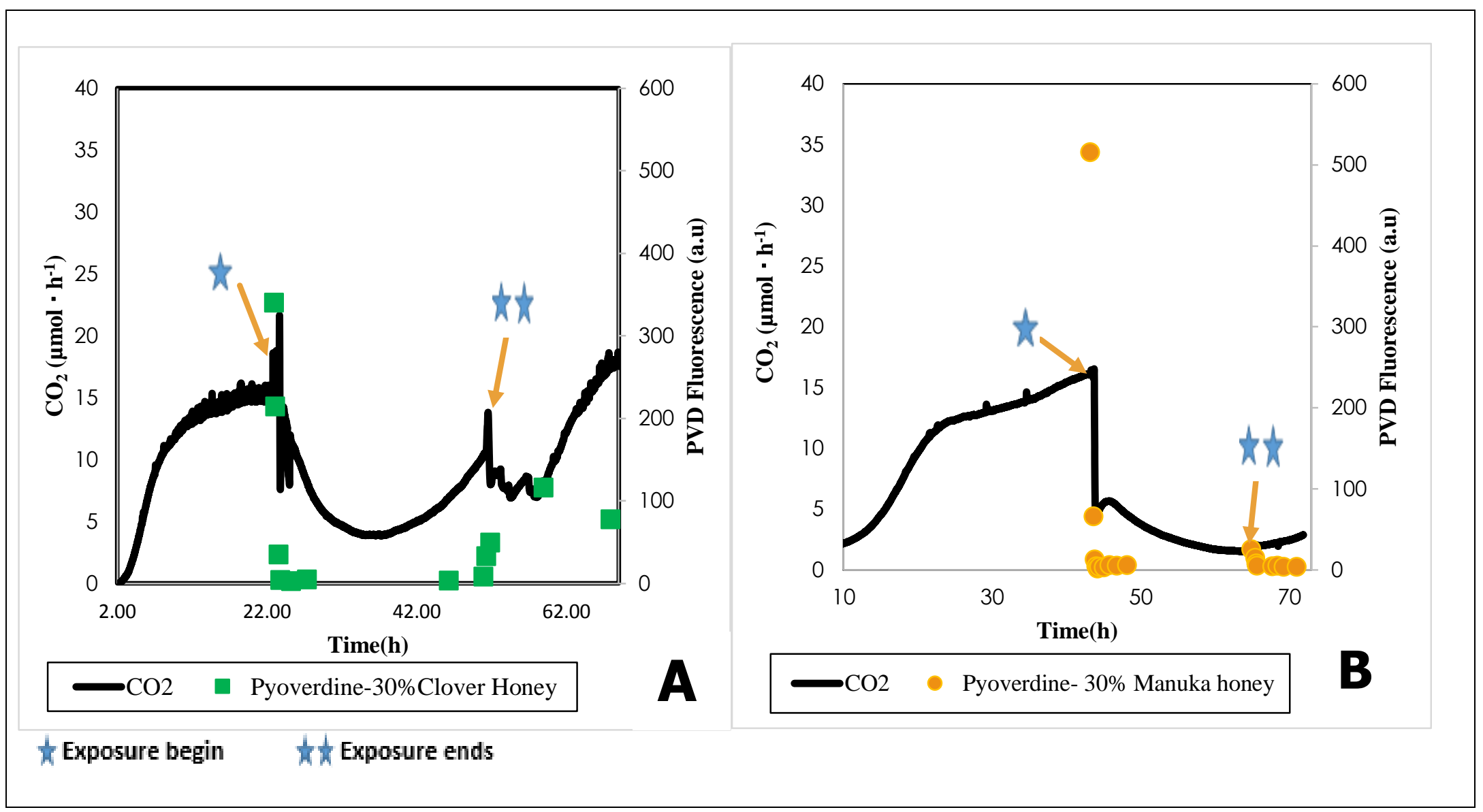

FIGURE 3. 4. EFFECT OF 24 HOUR EXPOSURE OF $30 \%$ (W/V) HONEY ON P. AERUGINOSA SIDEROPHORE PRODUCTION AND BIOFILM METABOLISM.

Stationary phase $P$. aeruginosa biofilm (- Black) incubated in CEMS at $25^{\circ} \mathrm{C}$, exposed to $30 \%$ (w/v) (A) Manuka honey and (B) Clover honey for $24 \mathrm{~h}$. PVD secretion in the effluent labeled (- Orange). 


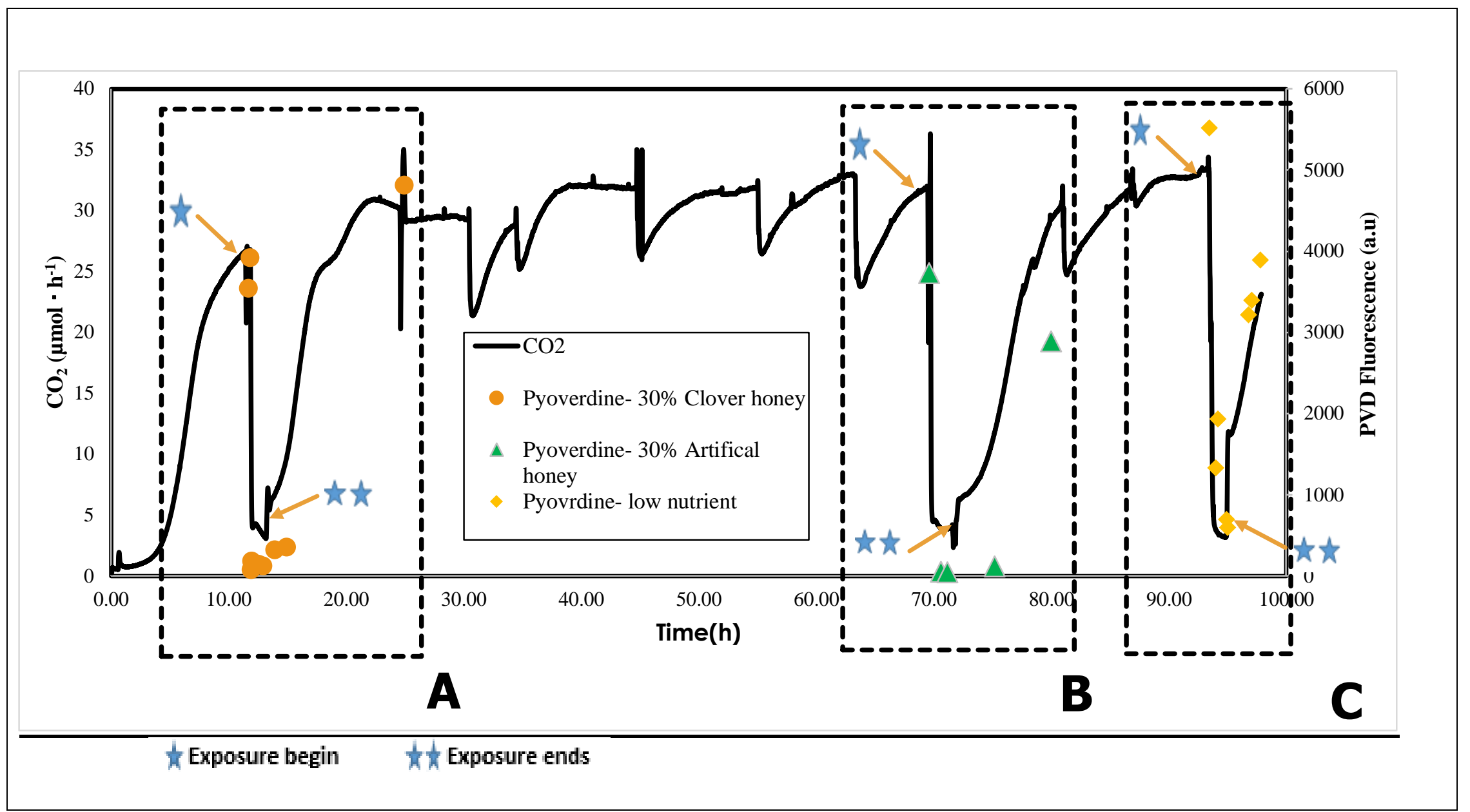

FIGURE 3. 5. EFFECT OF 2.5 HOUR EXPOSURE OF $30 \%$ (w/V) HONEY ON P. AERUGINOSA SIDEROPHORE PRODUCTION AND BIOFILM METABOLISM.

Stationary phase P.aeruginosa biofilm (- Black) incubated in CEMS at $25^{\circ} \mathrm{C}$, exposed to $30 \%$ (w/v) (A) Clover honey, (B) artificial honey $(\mathbf{C})$, and $0.003 \mathrm{~g} \cdot \mathrm{L}^{-1}$ tryptic soy broth medium for $2.5 \mathrm{~h}$. PVD secretion in the effluent (一red, green and yellow). 


\section{DISCUSSION}

Honey is an ancient remedy that gained renewed interest in modern medicine in the late 1950 's. This remedy has been previously used as preventative topical treatment for nosocomial infections (A-Jabari, 2005). Honey is primarily composed of various types of saccharides (Siddiqui, 1971; Roberts et al., 2012), enzymes (Bogdanov et al., 2008), and compounds that result in its antibacterial characteristics. Amongst all known types of honey studied, manuka honey is popular for its high antimicrobial properties in comparison to other types of honey (A-Jabari, 2005). An antimicrobial effect may benefit the infected host by killing or inhibiting the pathogen's metabolism and growth, or by reducing the production and excretion of pathogenic virulence factors. The exact antimicrobial action of honey is still not known, however, numerous studies demonstrated the sub-inhibitory effect of manuka honey and how it influences $P$. aeruginosa morphology (Henriques et al., 2011; Lu et al., 2013), promotes cell lysis (Roberts et al., 2012), impairs quorum sensing genes (thereby reducing expression of genes associated with virulence factors) (Wang et al., 2012) and inhibits bacterial growth (Roberts et al., 2012). A proper understanding of any antimicrobial compound's mechanisms of action will aid in developing appropriate application/dosage regimes and more effective combination therapies. This research was therefore designed to study bacterial biofilm responses, in particular metabolic response and siderophore secretion, upon exposure to honey to provide additional insight into the current literature's genetic and morphological knowledge. The increase in microbial resistance to current available antibiotics has necessitated the search for alternative ways of inhibiting pathogenic progression within the host and the development and administration of anti-virulent compounds (Cegelski et al., 2008).

\section{Pseudomonas aeruginosa as model organism}

$P$. aeruginosa is one of the most prevalent pathogens responsible for nosocomial infections, leading to morbidity and mortality of patients, highlighting the urgency for novel therapies to combat this species. This organism was chosen as a model Gram-negative opportunistic pathogen for its ability to secrete numerous virulence factors of which we measured the siderophore pyoverdine. The production of pyoverdine in a mouse pathogenesis model enhanced bacterial infection and virulence (Meyer et al., 1996). It is known from literature that $P$. 
aeruginosa possesses a strong ability to resist antimicrobial agents such as honey (Mandal et al., 2010).

The ability to accurately determine whether microbial cells are alive or dead (or something in between) at a particular time is not that well established (Davey, 2011). After any antibacterial exposure we can usually tell, in hindsight, if all bacteria were killed but if regrowth occurs at all it could either have been from a small percentage of survivors (while all other were killed) or the entire inoculum that went into a state of dormancy, followed by repair, restoration of growth (division) and metabolism once the stress has been removed. We measured $\mathrm{CO}_{2}$ as an indication of actively metabolizing cells and therefore our results cannot distinguish between dead or dormant cells. From the perspective of an infected host, however, it could be argued that both dead and/or dormant pathogens would allow host defensive strategies to overcome the infection. The measurement of pyoverdine (before, during and after exposure to honey) as a virulence factor was also central to this study. Through the CEMS (measuring the amount of $\mathrm{CO}_{2}$ produced from the biofilm as an indicator of biofilm growth) and LLABs (records the amount of transmitted light as an indication of biofilm biomass increase) systems, two independent real-time methods demonstrated the relationship between pyoverdine production and cell density.

\section{Response to 5\% honey}

Pyoverdine secretion can be influenced at a gene regulation level. It is known that honey can affect bacterial genetic regulatory systems, for example the quorum sensing pathway (e.g. impairing quorum sensing by reducing the expression of las and $r h l$ genes) which results in a reduction of gene expression associated with virulence factors (e.g. pyoverdine) (Starkey et al., 2012). These results were confirmed when reduced virulence factor production was demonstrated by exposing $P$. aeruginosa to 5\% (w/v) manuka honey (Kronda et al., 2013). It is also known that pyoverdine secretion and uptake in $P$. aeruginosa occurs through an ATP dependent manner and is thus a metabolically influenced pathway. The TonB complex is located on the inside of the periplasmic membrane and is controlled by the ExbB protein complex, which is responsible for transmitting energy of the protein motive force (Cornelis, 2010; Postle and Larsen, 2007). On the inner side of the cell membrane the ferric iron complex is transported to the cytoplasm of the cell through an ATP-binding cassette transporter (ABC) receptor (Heli et al., 2011). 
At 5\% honey exposure we observed an immediate decrease in pyoverdine excretion levels (figure 3.3). The 5\% honey also caused an increase in metabolism that is consistent with an increase in biomass (cell growth). From what is known currently, the reduced pyoverdine excretion can therefore be attributed to regulation at the gene level (and not the absence of available ATP) as ATP regeneration should have occurred at sufficient levels to sustain prolonged (around 24 hours) active cell mass increase. Metabolism and pyoverdine production was restored to preexposure levels immediately after honey was removed from the system.

Honey at 5\% apparently functioned as a nutrient (carbon) source as evidenced by the increase in biomass during exposure. These observations were previously reported in studies by Roberts et al. (2012) where P. aeruginosa growth was increased when manuka honey was diluted below the inhibitory levels.

\section{Response to $30 \%$ honey}

Upon $30 \%$ honey exposure, biofilm metabolism and pyoverdine excretion decreased immediately (figure 3.4). As mentioned before, a decrease in metabolism in our system can be interpreted as either cell killing and/or cell dormancy. The non-zero $\mathrm{CO}_{2}$ levels during the $30 \%$ exposure together with $\mathrm{CO}_{2}$ recovery curves (indicating regrowth after removal of the honey) suggested that a certain percentage of the cells remained alive and metabolically active (even during the entire 24 hours of exposure). Planktonic overnight $P$. aeruginosa cultures plated on agar containing different concentrations of honey showed that the cells were viable at concentrations of $5 \%$ and $15 \%(\mathrm{w} / \mathrm{v})$ but could not grow on plates containing $30 \%, 50 \%(\mathrm{w} / \mathrm{v})$ or more manuka honey.

\section{Comparing honey with sugars}

The biofilm responses in terms of changes in metabolic rate and pyoverdine excretion were similar when sugars (singularly or in combination) were added as compared to honey addition to equivalent final concentrations. Wang et al, has shown that sugar content in honey is responsible

for inhibition of the QS pathway (Wang et al., 2012), which is known to be an important pathway for regulation of biofilm virulence factors (Labbate et al., 2004; Wen and Burn, 2004; Irie and Parsek, 2008). 


\section{Biofilm response to $30 \%$ honey was mimicked under starvation conditions}

The biofilm response (in terms of changes in metabolism and pyoverdine excretion) to $30 \%$ honey was mimicked when the biofilm was exposed to starvation conditions (10 fold reduction in nutrient concentration). Similarity of this response to nutrient starvation condition can be explained through the bacterial stringent response, in which the biofilm undergoes a series of physiological and phenotypic changes that enables survival of some of the cells (Gilbert et al., 1990; Harder and Dijkhuizen, 1983; Azevedo et al., 2012). Studies have shown that metabolic states of the bacterium differ under nutrient starvation conditions. It is thought that this condition causes a rapid decrease in the rate of protein, RNA and cell wall synthesis and growth (Svitil et al., 1993; Van Delden et al., 2001). Therefore, the biofilm response to $30 \%$ (w/v) honey can be explained through the stringent response, where bacterial metabolism is shut down in harsh environments.

\section{Differences in honeys}

Different honeys (clover, manuka and artificial) resulted in qualitatively similar biofilm responses. However, exposure to $30 \%$ manuka honey seemed to have a residual effect resulting in more time needed for recovery (restoration of metabolism and pyoverdine excretion to preexposure levels). Planktonic $P$. aeruginosa cells that were exposed to $30 \%$ manuka honey also did not grow on agar plates 24 hours after plating (while cells incubated with 5\% and 15\% manuka honey for 24 hours did grow).

All three types of honey at $30 \%(\mathrm{w} / \mathrm{v})$ were capable of inhibiting biofilm metabolism. Decreases in biofilm metabolism occurred almost instantaneously with exposure to honey, but all biofilms recovered their metabolic activity within 24 hours after exposure.

Pyoverdine secretion was inhibited in the presence of all three types of honey (manuka, clover, artificial) and both concentrations (5\% and 30\%) tested. Additional experiments with glucose, sucrose and maltose (data not shown) further indicated that saccharides play an inhibitory role on siderophore production. However, while pyoverdine secretion recovered in all experiments after the removal of honey, the recovery rate both in terms of PVD and $\mathrm{CO}_{2}$ was faster after exposure to artificial honey compared to clover and manuka honey. The recovery of cell metabolism after removal of exposure to honey was also delayed in the case of manuka honey. 
The benefit of manuka honey as antimicrobial treatment compared to clover or artificial honey therefore seems to be limited to an increased duration of biofilm metabolic inhibition that might provide extra time to an infected host to launch a defense.

No formation of resistance to honey was observed when the same biofilms were repeatedly exposed to honey, as measured in terms of metabolic response and pyoverdine excretion. These results support those presented by Cooper et al., (2010) and Lerrer et al., (2007).

Honey will be beneficial to the host from a few perspectives, firstly, with reduced pathogenic virulence, the host defense system is able to initiate bacterial killing by the presence of iron chelating agents. Secondly, honey's inhibitory action on the biofilm will benefit the host defense mechanism as it inhibits the increase of pathogenic cells. Thirdly, Lerrer et al. (2007) have shown that the inhibitory action of honey can play a significant role in preventing establishment of $P$. aeruginosa biofilms by blocking bacterial sugar binding proteins.

The results presented here provide insights into honey as a remedy when used at appropriate concentrations and for sufficient durations to result in decreased bacterial metabolism. The choice of using a rich growth medium in this study was asymmetrical to the host blood. Through real-time non-destructive metabolic measurements used in this study we were able to gain insight into the antimicrobial mechanism of honey, indicating that dosage can play an important role in treatment of infections. For example in the case of 5\% manuka honey, the results gave a broad perspective of the effect of honey on the biofilm metabolism where pyoverdine was decreased, whereas growth and metabolism was increased during exposure. As an application this result might speak into dosage regimes because this means that failure to ensure high honey concentrations throughout treatment may harm the host by feeding the pathogens and providing them an opportunity to increase. 


\section{CHAPTER 4}

\section{The combined effect of honey and ethylenediamine tetraacetic acid disodium (EDTA) on biofilm metabolism}

\section{INTRODUCTION}

This chapter takes a step forward and examines the potential of honey as a combination therapy. In the previous chapter, it was demonstrated that honey inhibits $P$. aeruginosa virulence and metabolism. This chapter will look at biofilm response when honey is used under conditions simulating combination therapy.

Combination antibiotic therapy or polytherapy is based on the rationale of ensuring that pathogenic species are treated by more than one drug at a time, which will target one or more parts of the cell and therefore reduces the chance of formation of resistance (Cohen, 1992). Studies have shown that antibiotic combination therapy improves efficiency of treatment of infection by reducing dosage of antibiotics. Given the difficulty of treating multi-resistance bacteria, combination therapy has been shown to improve the process of treatment (Muller et al., 2013; Karayil et al., 1998).

Within the past decade, the use of honey combined with antibiotics on Gram-positive species such as MRSA has been studied extensively. In a recent study, MRSA growth was inhibited two fold when 5\% (w/v) manuka honey was combined with mupirocin, imipenem, tetracycline, rifampicin, and tazobactam antibiotics (Jenkins and Cooper, 2012; Karayil et al., 1998). Moreover, synergistic interaction between manuka honey and oxacillin has shown to reverse oxacillin resistance in MRSA, and result in down regulation of important genes in this species (Jenkins and Cooper, 2012). In addition, a similar study on S. aureus species has shown that no antibiotic resistance formed when rifampicin was combined with sub-inhibitory concentrations of manuka, whereas the use of this antibiotic alone resulted in emergence of resistance (Muller et al., 2013). Moreover, the synergistic effect of honey and antibiotics has been 
also observed in Gram-negative species, when 5\% manuka honey was combined with aminoglycoside antibiotics (Jenkins and Cooper, 2012).

As described in chapter 2, iron is a vital element that is essential for normal functioning and survival of all living organisms, and bacteria are not exceptions, especially as this element is known to play a role in the in vivo development of $P$. aeruginosa pathogenesis, biofilm formation and the defense against oxidative stress within its host (Vasil and Ochsner, 1999; Kim et al., 2003; Ratledge and Dover, 2000). Biofilm formation is strongly dependent on iron availability; therefore studies have indicated that chelating iron can be a promising new therapy for treatment of $P$. aeruginosa biofilms. Similar to the synergistic effect of honey and antibiotics, studies have reported that the combination of iron chelating agents with antibiotics initiates killing and biofilm dispersal (Moreau-Marquis et al., 2009).

This study investigated biofilm response in terms of metabolism and pyoverdine secretion to the combined effect of honey and an iron-chelating agent. The application of this study reflects biofilm response to the host system at the site of infection. In order to simulate application of combination therapy as occurring in wounds, a rich growth medium was used in this study, as is recommended for testing bacterial contaminants in cosmetics (Curry et al., 1993), food (Cunnif, 1995; US food and drug administration, 1995), and clinical applications (Murray et al., 1995).

\section{MATERIAL AND METHODS}

\section{Bacterial strain and growth conditions.}

Pseudomonas aeruginosa strain PAO1 $\left(\mathrm{ATCC}^{\circledR} 39324^{\mathrm{TM}}\right.$ ) was used in all experiments, as described in chapter 3.

Growth conditions in $A B$ defined Media. The overnight cultures for flow systems were prepared by growing PAO1 in $10 \mathrm{ml}$ broth medium containing $\mathrm{AB}$ defined medium supplemented with $10 \mathrm{mM}$ glucose in a test tube which was incubated for $24 \mathrm{~h}$ at $37^{\circ} \mathrm{C}$ in a shaking incubator at 250 rpm. $P$. aeruginosa biofilms were grown at $25^{\circ} \mathrm{C}$.

Growth conditions in Tryptic Soy Broth. The overnight cultures for flow systems (see below) were prepared by growing PAO1 in 10ml tryptic soy broth (TSB) at a concentration of $3 \mathrm{~g} / \mathrm{L}$ in $20 \mathrm{ml}$ 
test tubes, for $24 \mathrm{~h}$ at $37^{\circ} \mathrm{C}$ and at $250 \mathrm{rpm}$. P. aeruginosa biofilms were grown in $0.03 \mathrm{~g} / \mathrm{L}$ TSB under continuous flow (as described in chapter 3).

\section{Effect of iron depletion}

The influence of iron on pyoverdine production by $P$. aeruginosa biofilms were studied by inoculating PAO1 in CEMS in defined medium containing $0.001 \mathrm{mM} \cdot \mathrm{L}^{-1}$ iron, and $1 \mathrm{mM} \cdot \mathrm{L}^{-1}$ glucose as the primary carbon source. To illustrate the influence of iron on an established biofilm, the defined medium was switched to a medium depleted of iron for up to 24 hours. Pyoverdine secretion in the effluent was monitored continuously throughout and after the exposure.

The effect of iron on P. aeruginosa growth was studied through inoculating PAO1 in defined media void of iron. The biofilm was then exposed to $30 \%(\mathrm{w} / \mathrm{v})$ manuka honey in defined medium containing $1 \mathrm{mM}$ glucose as the carbon source for 24 hours.

\section{Effect of iron chelation}

In order to assess the influence of an iron-chelating agent on biofilm metabolism and pyoverdine secretion, EDTA was chosen for further study. The CEMS system was used to monitor biofilm growth; once biofilms reached a stationary phase, $0.001 \mathrm{mM}$ or $1 \mathrm{mM}$ EDTA was added to AB defined medium for $24 \mathrm{~h}$ under continuous flow (as described in chapter 3 ).

\section{Combined effect of manuka honey and EDTA}

P. aeruginosa was inoculated in CEMS with TSA as the growth medium. At stationary phase, biofilms were exposed to the media containing honey and EDTA for 24 hours. Combined treatment was studied using 5\% and $30 \%$ (w/v) manuka honey with $1 \mathrm{mM}$ EDTA both in AB defined growth media and TSB. 


\section{RESULTS AND DISCUSSION \\ Role of pyoverdine in biofilms}

In the present study, available iron in the growth medium was manipulated firstly by introducing an iron chelating agent and secondly by omitting iron from the growth medium. In the presence of an iron-chelating agent such as lactoferrin, $P$. aeruginosa is known to secrete pyoverdine to chelate iron from the environment (Cornelis and Dingemans, 2013). However, the results in this study showed that the addition of EDTA to P. aeruginosa biofilm caused a decrease in biofilm metabolism and an initial decrease in pyoverdine secretion (figure 4.1). An increase in pyoverdine secretion during EDTA exposure occurred after the initial drop. It is known that EDTA can initiate biofilm dispersal by disrupting extrapolymeric substance stability (Banin et al., 2006; Raad et al., 2003). However we did not observe an excessive sloughing of biofilm biomass upon EDTA introduction and the rapid increase in metabolism after EDTA removal suggests that the biofilm remained intact but was hindered in its ability to function at full capacity, as seen by the lowered metabolism.

In a low iron environment, $P$. aeruginosa biofilms secrete pyoverdine to chelate iron. However, in the case of depleting iron from the media, there was no effect on the amount of pyoverdine secreted (figure $4.2 \mathrm{~A}$ ). Switching from a medium containing iron to an iron depleted media resulted in a slight increase in biofilm metabolic activity while pyoverdine secretion dropped to slightly below the pre-exposure level (figure 4.2 B). Moreover, with addition of iron back into the medium, biofilm metabolism returned to pre-exposure level while pyoverdine secretion was not altered (figure $4.2 \mathrm{C}$ ). The results indicate that pyoverdine secretion is not directly related to iron concentration in the growth medium. Studies have also shown that pyoverdine synthesis can be highly influenced under different carbon conditions (Ponraj et al., 2013).

In addition, this study has shown that $P$. aeruginosa metabolic activity is low in an irondepleted medium (figure 4.3 A compared to B). Upon $30 \%$ honey exposure, P. aeruginosa metabolism and pyoverdine secretion decreased immediately. It was demonstrated that $P$. aeruginosa was metabolically active throughout exposure and the biofilm metabolism continuously increased during exposure whereas pyoverdine secretion remained low (figure 4.3 A). Moreover, switching back to an iron depleted medium, biofilm metabolism increased even 
further while pyoverdine secretion remained low and gradually increased in the biofilm. This response indicates that pyoverdine secretion is used for something other than only iron sequestration.

The response of $P$. aeruginosa biofilm to a combination of $30 \%$ manuka honey and EDTA in defined growth medium resulted in an immediate decrease in biofilm metabolic activity and pyoverdine secretion (figure 4.4) although the biofilm remained metabolically active throughout the exposure. Metabolism and pyoverdine secretion were restored when growth was switched back to the pre-exposure medium (figure 4.4). This unexpected response of $P$. aeruginosa indicates that a combination of drugs may have a reverse effect on biofilm activity, as our results have shown that the biofilm remained metabolically active throughout combination therapy but were metabolic inactive when exposed to honey alone (figure 3.4).

\section{Combination effect of honey and an iron chelator in rich growth medium}

In the previous chapter, honey at $5 \%$ was shown to function as a nutrient (carbon) source for the biofilm, as it resulted in an increase in P. aeruginosa biomass during exposure. However, combination of $5 \%(\mathrm{w} / \mathrm{v})$ honey and EDTA did not have this effect and was shown to cause an immediate decrease both in biofilm metabolism and pyoverdine section (figure $4.5 \mathrm{~A}$ ). This effect was diminished at the end of exposure where biofilm metabolic activity was returned to preexposure levels.

At $30 \%$ honey and EDTA exposure, a similar response to 5\% honey and EDTA was observed; the only difference being that biofilm metabolic activity and pyoverdine secretion was

delayed and did not recover immediately (figure $4.5 \mathrm{~B}$ ). As mentioned earlier in chapter 3 , a decrease in metabolism in the CEMS can be interpreted as either cell killing and/or cell dormancy. However, biofilm metabolic activity remained low for up to 24 hours after honey and EDTA was removed from the system (figure $4.5 \mathrm{~B}$ ), indicating that presence of chelator and honey could have an important effect on $P$. aeruginosa biofilms. 


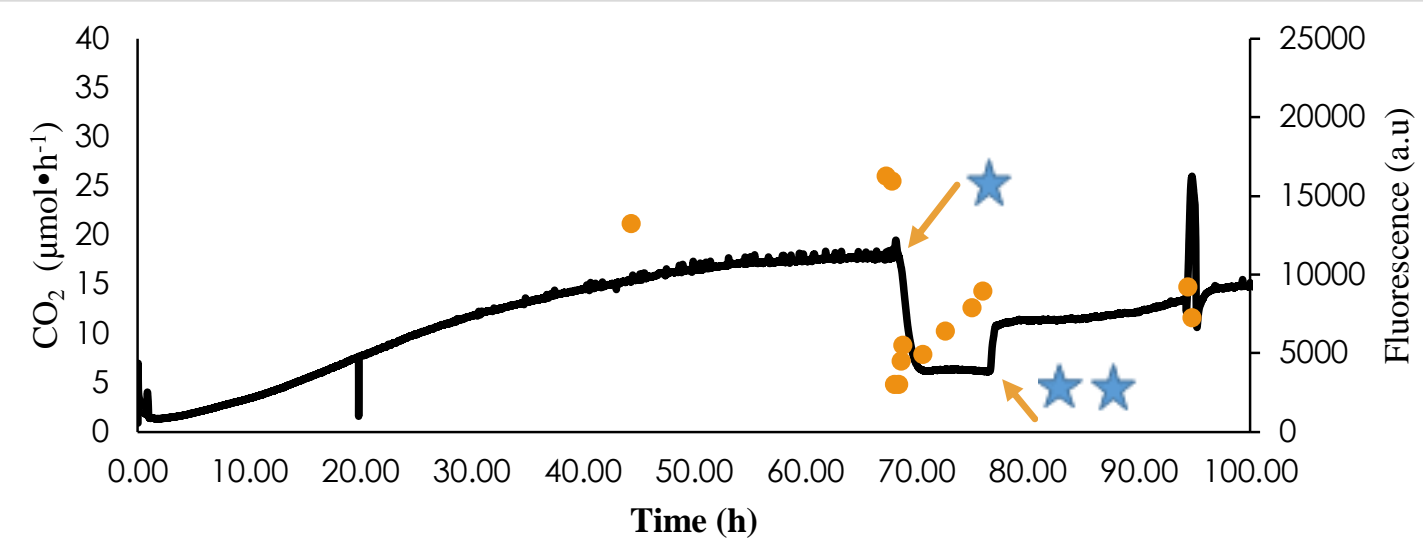

$\longrightarrow \mathrm{CO} 2 \bigcirc$ Pyoverdine- 1mM EDTA

$\downarrow$ Exposure begin $\downarrow \hbar$ Exposure ends

FIGURE 4. 1._EFFECT OF EDTA ON $P$. AERUGINOSA $\mathrm{CO}_{2}$ PRODUCTION AND SIDEROPHORE SECRETION.

$P$. aeruginosa biofilm incubated in defined medium containing $0.001 \mathrm{mM}$ iron and $1 \mathrm{mM}$ glucose in CEMS at $25^{\circ} \mathrm{C}$, exposed to $1 \mathrm{mM}$ EDTA for $6 \mathrm{~h}$. 


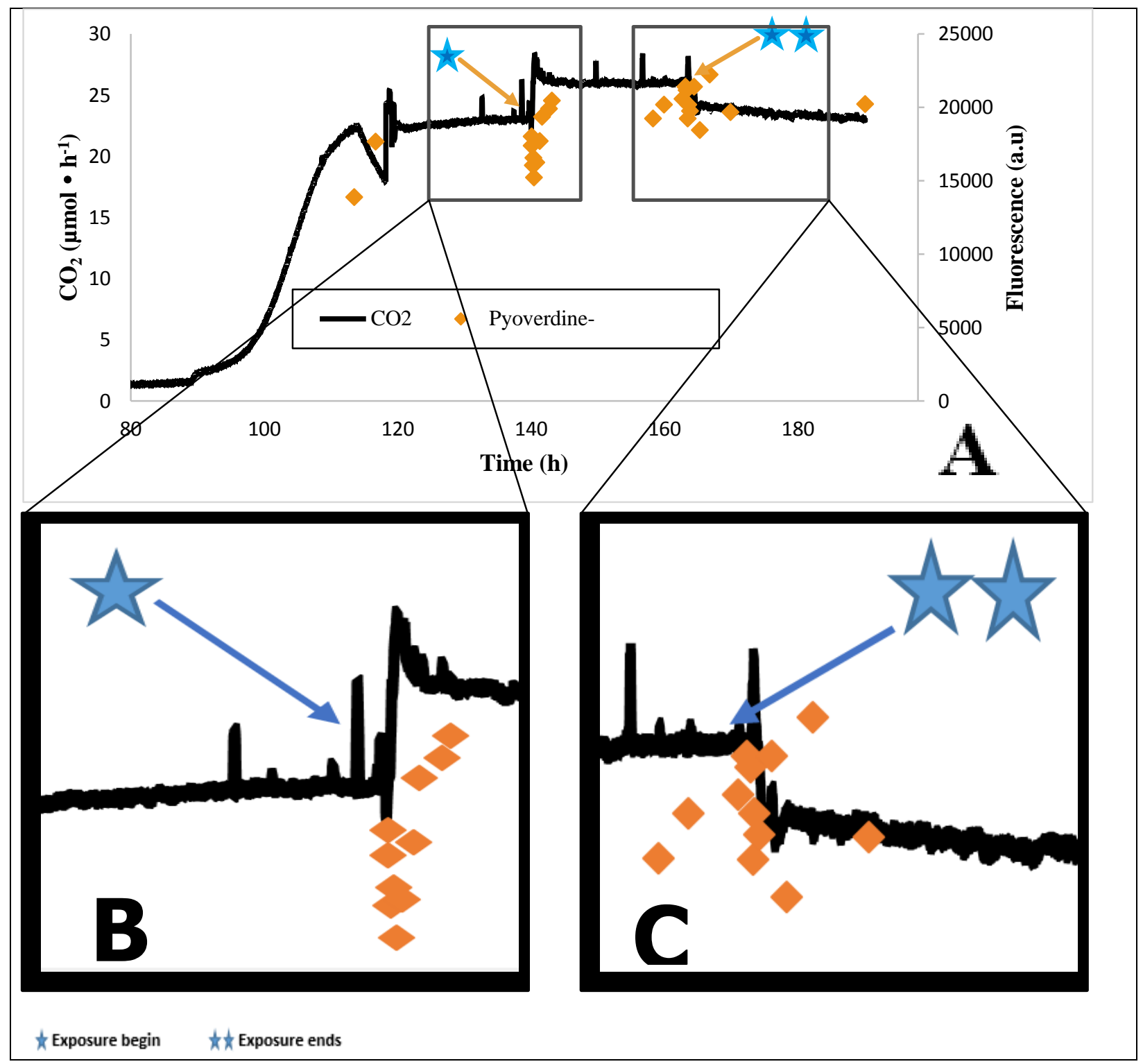

FIGURE 4. 2. EFFECT OF IRON DEPLETED ENVIRONMENT ON P. AERUGINOSA METABOLISM.

(A) Mature $P$. aeruginosa biofilm (- Black) incubated in defined media containing $0.001 \mathrm{mM}$ iron and $1 \mathrm{mM}$ glucose in the CEMS at $25^{\circ} \mathrm{C}$, exposed to media depleted of iron for 24 h. (B) exposure of biofilm to an iron depleted medium. (C) Switch from an iron depleted medium to the pre-exposure medium. Pyoverdine did not change when the medium, was switched back to a defined medium containing iron. The changes in the medium was sensed by the species and resulted in an increase in $\mathrm{CO}_{2}$ production as well as pyoverdine secretion. Results indicate that absence of iron in the environment did not have a significant effect on an established mature biofilm. 


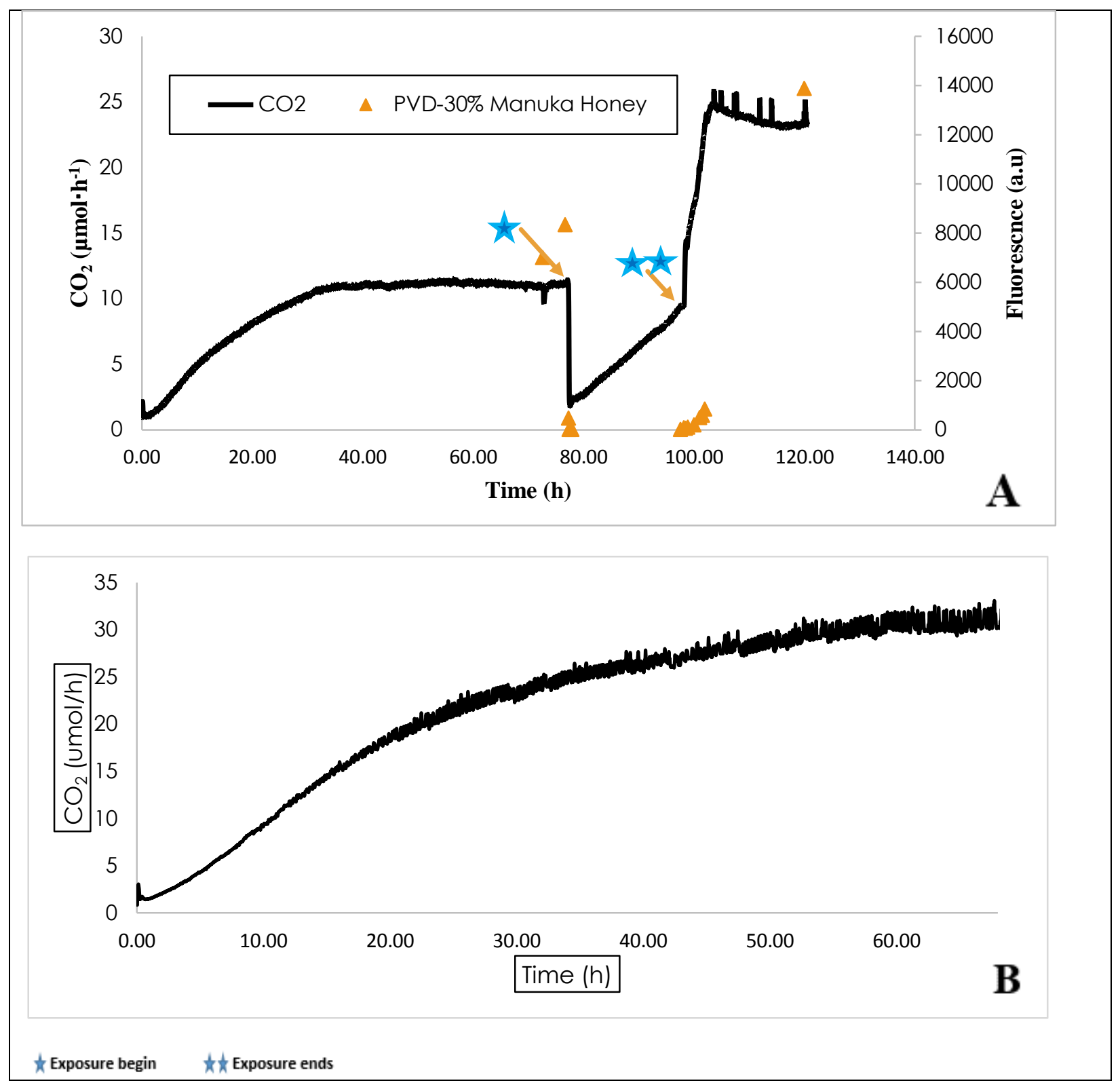

FIGURE 4. 3. EFFECT OF HONEY ON P. AERUGINOSA BIOFILM UNDER IRON DEPLETED CONDITIONS.

Mature $P$. aeruginosa biofilm ( - Black) incubated in defined growth medium containing $1 \mathrm{mM}$ glucose which was void of iron was exposed to $30 \%$ manuka honey for $20 \mathrm{~h}(\mathbf{A})$. The presence of honey caused an increase in $\mathrm{CO}_{2}$ production during the exposure indicating biofilm activity. Biofilm $\mathrm{CO}_{2}$ production was increased after removal of honey from the growth medium. The level of $\mathrm{CO}_{2}$ production in (A) was compared to (B) which the same culture was inoculated in growth media containing $0.001 \mathrm{mM}$ iron and not exposed to honey. 


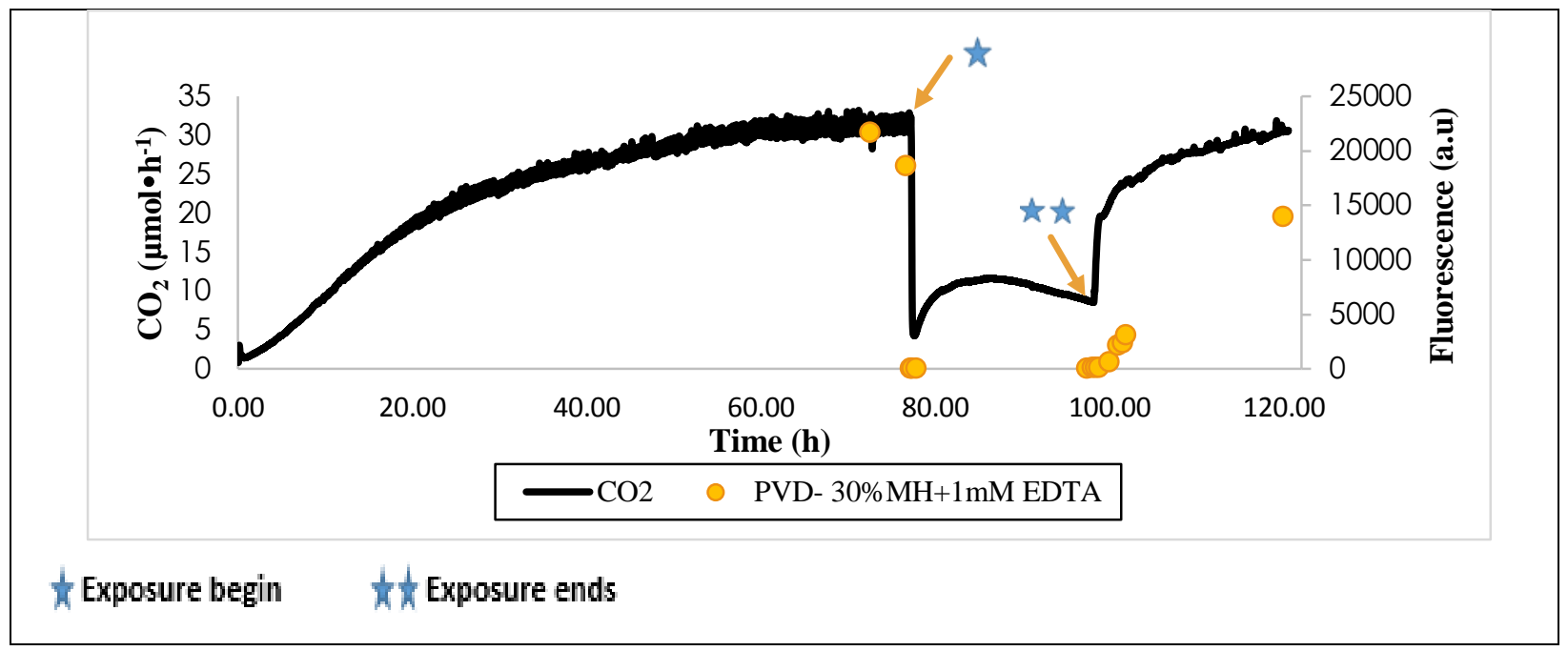

FIGURE 4. 4. THE COMBINED EFFECT OF $30 \%$ HONEY AND EDTA ON P. AERUGINOSA IN A DEFINED GROWTH MEDIUM.

Stationary phase $P$. aeruginosa biofilm (- Black) incubated in CEMS at $25^{\circ} \mathrm{C}$ in defined growth media was exposed to $30 \%$ (w/v) Manuka honey and $1 \mathrm{mM}$ EDTA for $24 \mathrm{~h}$. After $24 \mathrm{~h}$ treatment, media was switched to pre-exposure growth medium. 


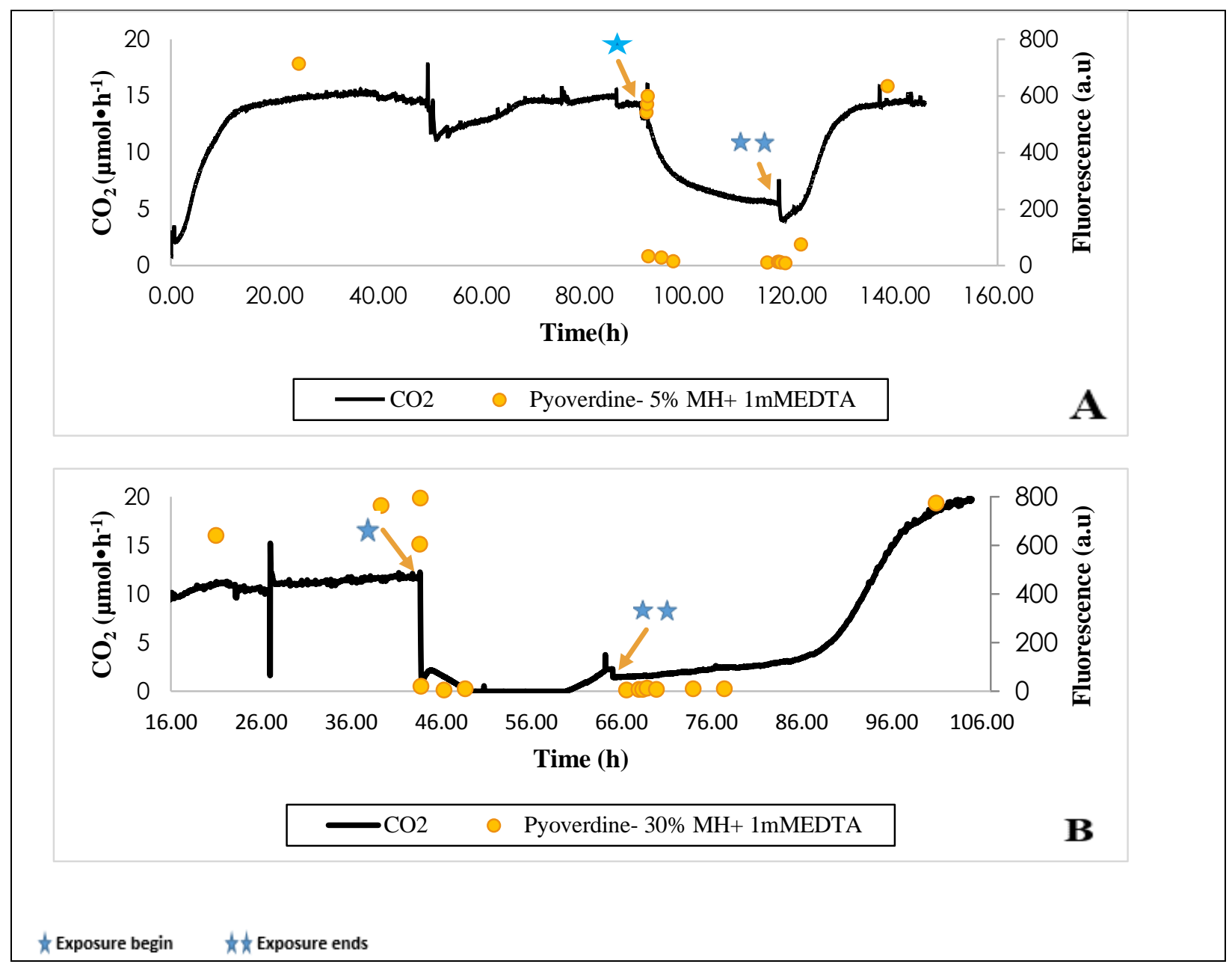

FigurE 4. 5. THE COMBINED EFFECT OF HONEY AND EDTA ON P. AERUGINOSA IN RICH GROWTH MEDIUM.

Stationary phase $P$. aeruginosa biofilm (- Black) incubated in rich growth media $\left(0.3 \mathrm{~g} \cdot \mathrm{L}^{-1}\right.$ tryptic soy broth) in CEMS at $25^{\circ} \mathrm{C}$ was exposed to (A) $5 \%(\mathrm{w} / \mathrm{v})$ Manuka honey and $1 \mathrm{mM}$ EDTA (B) 30\% (w/v) Manuka honey containing $1 \mathrm{mM}$ EDTA for $24 \mathrm{~h}$. After $24 \mathrm{~h}$ treatment, media was switched to pre-exposure growth medium. 


\section{CHAPTER 5}

\section{CONCLUSION AND FUTURE WORK}

The findings presented in this research will contribute to a better understanding of honey as a natural remedy and its abilities to counter bacterial metabolism and virulence. Through nondestructive metabolic measurement it was possible to explore, in real-time, the effect of honey on bacterial metabolism both in terms of response to exposure as well as recovery under different environmental conditions. As, described in chapter 3, it was noted that the antimicrobial effect of honey is highly dependent on the dosage used and can have a significant role in biofilm inhibition and therefore potentially also in the treatment of infections. For example in the case of 5\% manuka honey, the results gave a broad perspective of the effect of honey on the biofilm metabolism where pyoverdine was decreased, whereas growth and metabolism was increased during exposure. When applied at 30\%, manuka honey caused a decrease in both pyoverdine secretion and metabolism. In an applied sense, this result might speak into dosage regimes because this means that failure to ensure high honey concentrations throughout treatment may harm the host by feeding the pathogens and providing them an opportunity to increase.

In addition, the results obtained from defined growth medium indicated that pyoverdine production in $P$. aeruginosa was unrelated to iron availability. This is an indication that pyoverdine is possibly produced for other purposes in the biofilm, which requires further investigation. Biofilm behavior in response to combination treatment showed surprising results. For example, treatment of honey and EDTA in rich growth medium decreased biofilm metabolic activity and increased biofilm recovery time whereas, similar treatment in defined medium did not have such effects.

Studies on honey and its role on biofilm metabolism require further research. Although biofilm metabolic activity was measured with the CEMS system in this project, it is proposed that the effect of honey on biofilm metabolism should be also tested in the presence of compounds that target bacterial metabolism. Colistin is a good example of such a compound that is responsible for targeting cells with low metabolic active. It is hypothesized that at $5 \%$ honey the presence of colistin will inhibit metabolism, which can be determined at different concentrations of honey. 
This will also demonstrate if exposure to honey can initiate formation of dormant cells. In $P$. aeruginosa, colistin has proven to be effective against inactive cells in the deep layers of biofilm, induce expression of pmr-LPS modification system and inhibition of MexAB-OprM efflux pump (Harsmen et al., 2010; Pamp et al., 2008). Overall, the application of understanding the mechanism of honey that influence metabolism will help in better design of therapies. 


\section{REFERENCES}

Abdallah, N.M.A., Elsayed, S.B., Yassin, M.M., \& El-gohary, G.M (2011). Biofilm forming bacteria isolated from urinary tract infection, relation to catherterization and susceptibility to antibiotic. International Journal for Biotechnology and Molecular Biology Research, 2 (10), 172-178.

Abergel, R. J., Wilson, M. K., Arceneaux, J. E., Hoette, T. M., Strong, R. K., Byers, B. R., \& Raymond, K. N. (2006). Anthrax pathogen evades the mammalian immune system through stealth siderophore production. Proceedings of the National Academy of Sciences, 103(49), 18499-18503.

Adlerova, L., Bartoskova, A., \& Faldyna, M. (2008). Lactoferrin: a review. Veterinarni Medicina, 53(9), 457-468.

Adonizio, A., Kong, K. F., \& Mathee, K. (2008). Inhibition of quorum sensing-controlled virulence factor production in Pseudomonas aeruginosa by South Florida plant extracts. Antimicrobial agents and chemotherapy, 52(1), 198-203.

Ahmas A., Azim MK, Mesaik MA. Nazimuddin \& khan RA. (2008). Natural honey modulates physiological glycemic response compared to simulated honey and D-glucose. Journal of food Science, 73, 165-167.

Ahmed I. \& Aqil, F. (2008). New strategies combating bacterial infection. John Wily \& Sons. P264.

Ahmed, A., Alamkhan, R., Azim, M.K., Saeed, S.A., Mesaik, M.A.,Ahmed, S., \& Imran, I., (2011). Effect of Natural Honey on Human platelets and blood coagulation protein. Journal of pharmaceutical science, 24(3), 389-397.

Alandejani, T., Marsen, J., Ferris, W., Slinger, R., \& Chan, F., (2009). Effectiveness of honey on Staphylococcus aureus and Pseudomonas aeruginosa biofilm. Otolaryngology-Head and Neck Surgery, 141, 114-118.

Allen, K. L., Molan, P. C., \& Reid, G. M. (1991). A survey of the antibacterial activity of some New Zealand honeys. Journal of pharmacy and pharmacology, 43(12), 817-822.

Alvarez-Suarez, J. M., Tulipani, S., Díaz, D., Estevez, Y., Romandini, S., Giampieri, F., ... \& Battino, M. (2010). Antioxidant and antimicrobial capacity of several monofloral Cuban honeys and their correlation with color, polyphenol content and other chemical compounds. Food and Chemical Toxicology, 48(8), 2490-2499.

Al-Waili, N. S. (2004). Investigating the antimicrobial activity of natural honey and its effects on the pathogenic bacterial infections of surgical wounds and conjunctiva. Journal of medicinal food, 7(2), 210-222.

Al-Waili, N. S. (2005). Effects of honey on the urinary total nitrite and prostaglandins concentration. International urology and nephrology, 37(1), 107-111.

Al-Waili, N. S., \& Saloom, K. Y. (1999). Effects of topical honey on post-operative wound infections due to gram positive and gram negative bacteria following caesarean sections and hysterectomies. European journal of medical research, 4(3), 126. 
Al-Waili, N., Akmal, M., Al-Waili, F.S., Saloom, K.Y., \& Ali, A., (2005). The antimicrobial potential of honey from United Arab Emirates on some microbial isolates. Med Science Monitoring, 11(12), BR433-438.

AL-Waili, N., Al Ghamdi, A., Ansari, M. J., Al-Attar, Y., Osman, A., \& Salom, K. (2013). Differences in Composition of Honey Samples and Their Impact on the Antimicrobial Activities against Drug Multiresistant Bacteria and Pathogenic Fungi. Archives of medical research, 44, 307-316.

Al-Waili, N.S. (2003). Intravenous and Intrapulmonary Administration of Honey Solution to Healthy Sheep: Effects on Blood Sugar, Renal and Liver Function Tests, Bone Marrow Function, Lipid Profile, and Carbon Tetrachloride-Induced Liver Injury. Journal of Medicinal Food, 6(3), 231-247.

Al-Waili, N.S., Salom, K., Butler, G., \& Al Ghamdi, A.A., (2011). Honey and Microbial Infections: A Review supporting the use of honey for microbial control. Journal of Medicinal Food, 14(10), 1079-1096.

Ammons, M. C. B., Ward, L. S., \& James, G. A. (2011). Anti-biofilm efficacy of a lactoferrin/xylitol wound hydrogel used in combination with silver wound dressings. International Wound Journal, 8(3), 268-273.

Ammons, M.C.B. (2010). Anti-Biofilm Strategies and the Need for Innovation in Wounds Care. Recent Patents on Ant-infective Drug Discover. 5(1):10-17.

Andrews, S. C., Robinson, A. K., \& Rodríguez-Quiñones, F. (2003). Bacterial iron homeostasis. FEMS microbiology reviews, 27(2-3), 215-237.

Ankenbauer, R. O. B. E. R. T., Sriyosachati, S. O. M. P. O. R. N., \& Cox, C. D. (1985). Effects of siderophores on the growth of Pseudomonas aeruginosa in human serum and transferrin. Infection and immunity, 49(1), 132-140.

Annapoorani, A., Umamageswaran, V., Parameswari, R., Pandian, S. K., \& Ravi, A. V. (2012). Computational discovery of putative quorum sensing inhibitors against LasR and RhlR receptor proteins of Pseudomonas aeruginosa. Journal of Computer-Aided Molecular Design, 26(9), 1067-1077.

Arribas-Lorenzo, G., \& Morales, F. J. (2010). Analysis, distribution, and dietary exposure of glyoxal and methylglyoxal in cookies and their relationship with other heat-induced contaminants. Journal of agricultural and food chemistry, 58 (5), 2966-2972.

Azeredo, L. D. C., Azeredo, M. A. A., De Souza, S. R., \& Dutra, V. M. L. (2003). Protein contents and physicochemical properties in honey samples of Apis mellifera of different floral origins. Food Chemistry, 80(2), 249-254.

Azevedo, N., Bragança, S., Simões, L., Cerqueira, L., Almeida, C., Keevil, C., \& Vieira, M. (2012). Proposal for a method to estimate nutrient shock effects in bacteria. BMC research notes, 5(1), 422.

Badet, C. \& Quero, F., (2011). The in vitro effect of manuka honey on growth and adherence of oral bacteria. Journal of Anaerobe, 17, 19-22.

Balaban, N. (2008). Control of biofilm infections by signal manipulation. Volume II. Springer Publication. Netherland. P64.

Bang, L. M., Buntting, C., \& Molan, P. (2003). The effect of dilution on the rate of hydrogen peroxide production in honey and its implications for wound healing. The Journal of Alternative \& Complementary Medicine, 9(2), 267-273. 
Banin, E., Brady, K. M., \& Greenberg, E. P. (2006). Chelator-induced dispersal and killing of Pseudomonas aeruginosa cells in a biofilm. Applied and environmental microbiology, 72(3), 2064-2069.

Banin, E., Vasil, M. L., \& Greenberg, E. P. (2005). Iron and Pseudomonas aeruginosa biofilm formation. Proceedings of the National Academy of Sciences of the United States of America, 102(31), 11076-11081.

Barker, K. D., Barkovits, K., \& Wilks, A. (2012). Metabolic flux of extracellular heme uptake in Pseudomonas aeruginosa is driven by the iron-regulated heme oxygenase (HemO). Journal of Biological Chemistry, 287(22), 18342-18350.

Barrett, A.D.T. \& Stanberry, L.R., (2009). Vaccines for biodefense and Emerging ad Neglected Diseases. Academic Press. P 946.

Bhakta, M. N., \& Wilks, A. (2006). The mechanism of heme transfer from the cytoplasmic heme binding protein PhuS to the $\delta$-regioselective heme oxygenase of Pseudomonas aeruginosa. Biochemistry, 45(38), 11642-11649.

Bhimani, R. S., Vendrov, Y., \& Furmanski, P. (1999). Influence of lactoferrin feeding and injection against systemic staphylococcal infections in mice. Journal of applied microbiology, 86(1), 135-144.

Bjarnsholt, T., \& Givskov, M., (2007). Quorum-sensing blockade as a strategy for enhancing host defenses against bacterial pathogens. Phylosophical transactions of the Royal Society, 362, 1213-1222.

Bjarnsholt, T., Tolker-Nielsen, T., Høiby, N., \& Givskov, M. (2010). Interference of Pseudomonas aeruginosa signalling and biofilm formation for infection control. Expert Rev. Mol. Med, 12 , e11.

Blair, S. E., \& Carter, D. A. (2005). The potential for honey in the management of wounds and infection. Healthcare Infection, 10(1), 24-31.

Blair, S. E., Cokcetin, N. N., Harry, E. J., \& Carter, D. A. (2009). The unusual antibacterial activity of medical-grade Leptospermum honey: antibacterial spectrum, resistance and transcriptome analysis. European journal of clinical microbiology \& infectious diseases, 28(10), 1199-1208.

Bogdanov, S., Jurendic, T., Sieber, R., \& Gallmann, P. (2008). Honey for nutrition and health: a review. Journal of the American College of Nutrition, 27(6), 677-689.

Brackman, G., Hillaert, U., Van Calenbergh, S., Nelis, H. J., \& Coenye, T. (2009). Use of quorum sensing inhibitors to interfere with biofilm formation and development in Burkholderia multivorans and Burkholderia cenocepacia. Research in microbiology, 160(2), 144-151.

Brandel, J., Humbert, N., Elhabiri, M., Schalk, I. J., Mislin, G. L., \& Albrecht-Gary, A. M. (2012). Pyochelin, a siderophore of Pseudomonas aeruginosa: physicochemical characterization of the iron (III), copper (II) and zinc (II) complexes. Dalton Transactions, 41(9), 28202834.

Braud, A., Hannauer, M., Mislin, G. L., \& Schalk, I. J. (2009). The Pseudomonas aeruginosa pyochelin-iron uptake pathway and its metal specificity. Journal of bacteriology, 191(11), 3517-3525.

Braud, A., Hoegy, F., Jezequel, K., Lebeau, T., \& Schalk, I. J. (2009). New insights into the metal specificity of the Pseudomonas aeruginosa pyoverdine-iron uptake pathway. Environmental microbiology, 11(5), 1079-1091.

Braun, V., \& Killmann, H. (1999). Bacterial solutions to the iron-supply problem. Trends in biochemical sciences, 24(3), 104-109. 
Braun, V., Hantke, K., \& Cornelis, P. (Eds.). (2013). Iron Uptake in Bacteria with Emphasis on $E$. coli and Pseudomonas. Springer. P 6, DOI: 10.1007/978-94-007-6088-2

Briskot, G., Taraz, K., \& Budzikiewic, H. (1989). Pyoverdine-type siderophores from Pseudomonas aeruginosa. Liebigs Ann Chem, 375-384.

Britigan, B. E., Hayek, M. B., Doebbeling, B. N., \& Fick, R. B. (1993). Transferrin and lactoferrin undergo proteolytic cleavage in the Pseudomonas aeruginosa-infected lungs of patients with cystic fibrosis. Infection and immunity, 61(12), 5049-5055.

Britigan, B. E., Rasmussen, G. T., \& Cox, C. D. (1997). Augmentation of oxidant injury to human pulmonary epithelial cells by the Pseudomonas aeruginosa siderophore pyochelin. Infection and immunity, 65(3), 1071-1076.

Britigan, B. E., Roeder, T. L., Rasmussen, G. T., Shasby, D. M., McCormick, M. L., \& Cox, C. D. (1992). Interaction of the Pseudomonas aeruginosa secretory products pyocyanin and pyochelin generates hydroxyl radical and causes synergistic damage to endothelial cells. Implications for Pseudomonas-associated tissue injury. Journal of Clinical Investigation, 90(6), 2187.

Buckett, W. M., Luckas, M. J., Gazvani, M. R., Aird, I. A., \& Lewis-Jones, D. (1997). Seminal plasma lactoferrin concentrations in normal and abnormal semen samples. Journal of andrology, 18(3), 302-304.

Carnwath, R., Graham, E. M., Reynolds, K., \& Pollock, P. J. (2014). The antimicrobial activity of honey against common equine wound bacterial isolates. The Veterinary Journal, 199(1), 110-114.

Cegelski, L., Marshall, G. R., Eldridge, G. R., \& Hultgren, S. J. (2008). The biology and future prospects of antivirulence therapies. Nature Reviews Microbiology, 6(1), 17-27.

Choo, J. H., Rukayadi, Y., \& Hwang, J. K. (2006). Inhibition of bacterial quorum sensing by vanilla extract. Letters in applied microbiology, 42(6), 637-641.

Clatworthy, A. E., Pierson, E., \& Hung, D. T. (2007). Targeting virulence: a new paradigm for antimicrobial therapy. Nature chemical biology, 3(9), 541-548.

Clutterbuck, A. L., Woods, E. J., Knottenbelt, D. C., Clegg, P. D., Cochrane, C. A., \& Percival, S. L. (2007). Biofilms and their relevance to veterinary medicine. Veterinary microbiology, 121(1), 1-17.

Coenye, T. \& Nelis, H.J., (2010). In vitro and in vivo model systems to study microbial biofilm formation. Journal of Microbiological Methods, 83(2), 89-105.

Coffman, T. J., Cox, C. D., Edeker, B. L., \& Britigan, B. E. (1990). Possible role of bacterial siderophores in inflammation. Iron bound to the Pseudomonas siderophore pyochelin can function as a hydroxyl radical catalyst. Journal of Clinical Investigation, 86(4), 1030.

Cohen, M. L. (1992). Epidemiology of drug resistance: implications for a post-antimicrobial era. Science, 257(5073), 1050-1055.

Collier, D. N., Hager, P. W., \& Phibbs Jr, P. V. (1996). Catabolite repression control in the Pseudomonads. Research in microbiology, 147(6), 551-561.

Cooper, R. A., Jenkins, L., Henriques, A. F. M., Duggan, R. S., \& Burton, N. F. (2010). Absence of bacterial resistance to medical-grade manuka honey. European journal of clinical microbiology \& infectious diseases, 29(10), 1237-1241.

Cooper, R. A., Molan, P. C., \& Harding, K. G. (1999). Antibacterial activity of honey against strains of Staphylococcus aureus from infected wounds. Journal of the Royal Society of Medicine, 92(6), 283. 
Cooper, R. A., Molan, P. C., \& Harding, K. G. (2002). The sensitivity to honey of Gram-positive cocci of clinical significance isolated from wounds. Journal of Applied Microbiology, 93(5), 857-863.

Cornelis, P. (2010). Iron uptake and metabolism in pseudomonads. Applied microbiology and biotechnology, 86(6), 1637-1645.

Cornelis, P., \& Dingemans, J. (2013). Pseudomonas aeruginosa adapts its iron uptake strategies in function of the type of infections. Frontier in Cellular and Infection Microbiology. 3, 75. Doi: $10.3389 /$ fcimb.2013.0075

Costerton, J. W., Stewart, P. S., \& Greenberg, E. P. (1999). Bacterial biofilms: a common cause of persistent infections. Science, 284(5418), 1318-1322.

Cox, C. D. (1980). Iron uptake with ferripyochelin and ferric citrate by Pseudomonas aeruginosa. Journal of bacteriology, 142(2), 581-587.

Cox, C. D. (1986). Role of pyocyanin in the acquisition of iron from transferrin. Infection and immunity, 52(1), 263-270.

Cox, C. D., Rinehart, K. L., Moore, M. L., \& Cook, J. C. (1981). Pyochelin: novel structure of an iron-chelating growth promoter for Pseudomonas aeruginosa. Proceedings of the National Academy of Sciences, 78(7), 4256-4260.

Cox, C.D. (1982). Effect of phyochelin on the virulence of Pseudomonas aeruginosa. Infections in immunity. 36:17-23

Croguennec, T., Li, N., Phelebon, L., Garnier-Lambrouin, F., \& Gésan-Guiziou, G. (2012). Interaction between lactoferrin and casein micelles in skimmed milk. International Dairy Journal.

Cunnif, P. 1995. Official methods of analysis AOAC International, $16^{\text {th }}$ ed. AOAC International, Arlington, VA.

Curry, A. S., G. G. Joyce, \& G. N. McEwen, Jr. 1993. CTFA Microbiology guidelines. The Cosmetic, Toiletry, and Fragrance Association, Inc. Washington, D.C.

Da Silva Ferreira, A. C., Reis, S., Rodrigues, C., Oliveira, C., \& De Pinho, P. G. (2007). Simultaneous determination of ketoacids and dicarbonyl compounds, key Maillard intermediates on the generation of aged wine aroma. Journal offood science, 72(5), S314S318.

Daglia, M., Amoroso, A., Rossi, D., Mascherpa, D., \& Maga, G. (2013). Identification and quantification of $\alpha$-dicarbonyl compounds in balsamic and traditional balsamic vinegars and their cytotoxicity against human cells. Journal of Food Composition and Analysis, 31 (1), 67-74.

Daglia, M., Ferrari, D., Collina, S., \& Curti, V. (2013). Influence of in Vitro Simulated Gastroduodenal Digestion on Methylglyoxal Concentration of Manuka (Lectospermum scoparium) Honey. Journal of agricultural and food chemistry, 61(9), 2140-2145.

Damiens, E., El Yazidi, I., Mazurier, J., Duthille, I., Spik, G., \& Boilly-Marer, Y. (1999). Lactoferrin inhibits G1 cyclin-dependent kinases during growth arrest of human breast carcinoma cells. Journal of cellular biochemistry, 74(3), 486-498.

Davies, D. G., Parsek, M. R., Pearson, J. P., Iglewski, B. H., Costerton, J. W., \& Greenberg, E. P. (1998). The involvement of cell-to-cell signals in the development of a bacterial biofilm. Science, 280(5361), 295-298.

de Ungria, M., Rao, R., Wobken, J. D., Luciana, M., Nelson, C. A., \& Georgieff, M. K. (2000). Perinatal iron deficiency decreases cytochrome c oxidase (CytOx) activity in selected regions of neonatal rat brain. Pediatric research, 48(2), 169-176. 
Dhur, A., Galan, P., \& Hercberg, S. (1989). Effects of different degrees of iron deficiency on cytochrome $\mathrm{P} 450$ complex and pentose phosphate pathway dehydrogenases in the rat. The Journal of nutrition, 119(1), 40.

Donlan, R.M. \& Costerton, J.W. (2002). Biofilms: Survival mechanisms of clinically relevant microorganisms. Clinical microbiology review, 167-193

Drake, E. J., \& Gulick, A. M. (2011). Structural characterization and high-throughput screening of inhibitors of PvdQ, an NTN hydrolase involved in pyoverdine synthesis. ACS chemical biology, 6(11), 1277-1286.

Drusano, G. L. (2004). Antimicrobial pharmacodynamics: critical interactions of bug and drug'. Nature Reviews Microbiology, 2(4), 289-300.

Dumas, Z., Ross-Gillespie, A., \& Kümmerli, R. (2013). Switching between apparently redundant iron-uptake mechanisms benefits bacteria in changeable environments. Proceedings of the Royal Society B: Biological Sciences, 280(1764).

Ellison, R. D., Giehl, T. J., \& LaForce, F. M. (1988). Damage of the outer membrane of enteric gram-negative bacteria by lactoferrin and transferrin. Infection and Immunity, 56(11), 2774-2781.

Elrod R. P. \& Braun, A.C. (1942). Pseudomonas aeruginosa: its role as a plant pathogen. Journal of Bacteriology, 44(6), 633-645.

Erejuwa, O. O., Sulaiman, S. A., \& Ab Wahab, M. S. (2012). Honey: a novel antioxidant. Molecules, 17(4), 4400-4423.

Escaich, S. (2008). Antivirulence as a new antibacterial approach for chemotherapy. Current opinion in chemical biology, 12(4), 400-408.

Escaich, S., (2010). Noval agents to inhibit microbial virulence and pathogenicity. Reviews. 20(10):1401-1418. 58

Evans, S. A., Turner, S. M., Bosch, B. J., Hardy, C. C., \& Woodhead, M. A. (1996). Lung function in bronchiectasis: the influence of Pseudomonas aeruginosa. European Respiratory Journal, 9(8), 1601-1604.

Fidaleo, M., Zuorro, A., \& Lavecchia, R., (2010). Methylglyoxal: A new Waepon against Staphylococcal Wound Infections? The Chemical Society of Japan, 39, 322-323.

Finkelstein, R. A., Sciortino, C. V., \& McIntosh, M. A. (1983). Role of iron in microbe-host interactions. Review of Infectious Diseases, 5(Supplement 4), S759-S777.

Fjallman AHM. Production of dental health using honey with high antimicrobial activity. University of Waikato. 2000, MSc, Doctoral thesis.

Fluckinger, M., Haas, H., Merschak, P., Glasgow, B. J., \& Redl, B. (2004). Human tear lipocalin exhibits antimicrobial activity by scavenging microbial siderophores. Antimicrobial agents and chemotherapy, 48(9), 3367-3372.

Francis, J. (2008). Global Encyclopedia of Environmental Science, Technology and Management. Global Vision Publishing, New Delhi, India. P 139.

Frieden, T., (2013). Antibiotic Resistance threats in the United States, 2013. U.S. Department of Health and Human Services: Centers for Disease control and prevention. P68-69. www.cdc.gov/drugresistance/threat-report.../ar-threats-2013-508.pdf

Gessard C. Classics in infectious diseases. On the blue and green coloration that appears on bandages. By Carle Gessard (1850-1925). Rev Infect Dis 1984:6. Suppl 3:S775-6.

Ghysels, B., Dieu, B. T. M., Beatson, S. A., Pirnay, J. P., Ochsner, U. A., Vasil, M. L., \& Cornelis, P. (2004). FpvB, an alternative type I ferripyoverdine receptor of Pseudomonas aeruginosa. Microbiology, 150(6), 1671-1680. 
Gilbert, P. E. T. E. R., Collier, P. J., \& Brown, M. R. (1990). Influence of growth rate on susceptibility to antimicrobial agents: biofilms, cell cycle, dormancy, and stringent response. Antimicrobial agents and chemotherapy, 34(10), 1865.

González-Chávez, S. A., Arévalo-Gallegos, S., \& Rascón-Cruz, Q. (2009). Lactoferrin: structure, function and applications. International journal of antimicrobial agents, 33(4), 301-e1.

Goring, R.V. and Mims, C.A. (2012). Mims' Medical Microbiology. Elsevier Health Sciences publication. P. 472

Görke, B., \& Stülke, J. (2008). Carbon catabolite repression in bacteria: many ways to make the most out of nutrients. Nature Reviews Microbiology, 6(8), 613-624.

Gould, I, M. \& Van-Der-Meer, J. (2007). Antibiotic policies: fighting resistance. Springer Science publication. New York, United States. P 162.

Grady, N.P.O., Alexander, M., Burns, L.A., Dellinger, P. E., Garland, J., Heard, S.O., Lipsett, P.A., Masur, H., Mermel, L.A., Pearson, M.L., Raad, I.I., Randolph, A.G., Rupp, M.E., \& Saint, S. (2011). Summary of Recommendations: Guidelines for prevention of Intravascular Catheter-related Infection. Clinical Infectious Diseases, 52(9), 1087-1099.

Gregoire, N., Raherison, S., Grignon, C., Comets, E., Marliat, M., Poly, M.C., \& Couet, W. (2010). Semimechanic pharmacokineticpharmacodynamic model with adaptation development for Time-Kill experiments of Ciprofloxacin against Pseudomonas aeruginosa. Antimicrobial agents and Chemotherapy, 54 (6), 2379-2384.

Gross, H., \& Loper, J. E. (2009). Genomics of secondary metabolite production by Pseudomonas spp. Natural product reports, 26(11), 1408-1446.

Hannauer, M., Schäfer, M., Hoegy, F., Gizzi, P., Wehrung, P., Mislin, G. L., ... \& Schalk, I. J. (2012). Biosynthesis of the pyoverdine siderophore of Pseudomonas aeruginosa involves precursors with a myristic or a myristoleic acid chain. FEBS letters, 586(1), 96-101.

Harada, E., Itoh, Y., Sitizyo, K., Takeuchi, T., Araki, Y., \& Kitagawa, H. (1999). Characteristic transport of lactoferrin from the intestinal lumen into the bile via the blood in piglets. Comparative Biochemistry and Physiology Part A: Molecular \& Integrative Physiology, 124(3), 321-327.

Harder, W., \& Dijkhuizen, L. (1983). Physiological responses to nutrient limitation. Annual Reviews in Microbiology, 37(1), 1-23.

Harding, R. A., \& Royt, P. W. (1990). Acquisition of iron from citrate by Pseudomonas aeruginosa. Journal of general microbiology, 136(9), 1859-1867.

Harjai, K., Khandwaha, R.K., Mittal, R., Yadav, V., Gupta, V., \& Sharma, S., (2005). Effect of $\mathrm{pH}$ on production of Virulence Factors by biofilm cells of Pseudomonas aeruginosa. Folia Microbiologica, 50(29), 99-102

Harmsen, M., Yang, L., Pamp, S. J., \& Tolker-Nielsen, T. (2010). An update on Pseudomonas aeruginosa biofilm formation, tolerance, and dispersal. FEMS Immunology \& Medical Microbiology, 59(3), 253-268.

Harrison, J.J., Ceri, H. \& Turner, R.J. (2007) Multimetal resistance and tolerance in microbial biofilms. Nature reviews in microbiology, 5, 928-938.

Hayen, H., \& Volmer, D. A. (2006). Different iron-chelating properties of pyochelin diastereoisomers revealed by LC/MS. Analytical and bioanalytical chemistry, 385(3), 606611.

Heli, H., Mirtorabi, S., \& Karimian, K. (2011). Advances in iron chelation: an update. Expert opinion on therapeutic patents, 21(6), 819-856. 
Henriques, A. F., Jenkins, R. E., Burton, N. F., \& Cooper, R. A. (2011). The effect of manuka honey on the structure of Pseudomonas aeruginosa. European Journal of Clinical Microbiology \& Infectious Diseases, 30(2), 167-171.

Henriques, A. F., Jenkins, R. E., Burton, N. F., \& Cooper, R. A. (2010). The intracellular effects of manuka honey on Staphylococcus aureus. European journal of clinical microbiology \& infectious diseases, 29(1), 45-50.

Hentzer, M., Wu, H., Andersen, J. B., Riedel, K., Rasmussen, T. B., Bagge, N., ... \& Givskov, M. (2003). Attenuation of Pseudomonas aeruginosa virulence by quorum sensing inhibitors. The EMBO Journal, 22(15), 3803-3815.

Hester, K. L., Madhusudhan, K. T., \& Sokatch, J. R. (2000). Catabolite repression control by crc in $2 \mathrm{xYT}$ medium is mediated by posttranscriptional regulation of bkdR expression in Pseudomonas putida. Journal of bacteriology, 182(4), 1150-1153.

Hidron, A. I., Edwards, J. R., Patel, J., Horan, T. C., Sievert, D. M., Pollock, D. A., \& Fridkin, S. K. (2008). Antimicrobial-resistant pathogens associated with healthcare-associated infections: annual summary of data reported to the National Healthcare Safety Network at the Centers for Disease Control and Prevention, 2006-2007. infection control and hospital epidemiology, 29(11), 996-1011.

Hoegy, F., Celia, H., Mislin, G. L., Vincent, M., Gallay, J., \& Schalk, I. J. (2005). Binding of ironfree siderophore, a common feature of siderophore outer membrane transporters of Escherichia coli and Pseudomonas aeruginosa. Journal of Biological Chemistry, 280(21), 20222-20230.

Hohnadel, D. A. N. Y., \& Meyer, J. M. (1988). Specificity of pyoverdine-mediated iron uptake among fluorescent Pseudomonas strains. Journal of bacteriology, 170(10), 4865-4873.

Hunt, S. M., Werner, E. M., Huang, B., Hamilton, M. A., \& Stewart, P. S. (2004). Hypothesis for the role of nutrient starvation in biofilm detachment. Applied and environmental microbiology, 70(12), 7418-7425.

Ingle, J.I., Bakland, L.K. \& Baumgartner, J.C. (2008). Ingle's endodontics 6. Sixth edition. BCDecker Inc. Hamilton, Canada. P 276.

Irie, Y., \& Parsek, M. R. (2008). Quorum sensing and microbial biofilms. In Bacterial biofilms (pp. 67-84). Springer Berlin Heidelberg.

Israili, Z. H. (2013). Antimicrobial Properties of Honey. American Journal of Therapeutics. doi: 10.1097/MJT.0b013e318293b09b

Jakubovics, N. S., \& Jenkinson, H. F. (2001). Out of the iron age: new insights into the critical role of manganese homeostasis in bacteria. Microbiology, 147(7), 1709-1718.

Jenkins, R. E., \& Cooper, R. (2012). Synergy between oxacillin and manuka honey sensitizes methicillin-resistant Staphylococcus aureus to oxacillin. Journal of antimicrobial chemotherapy, 67(6), 1405-1407.

Jenkins, R., \& Cooper, R. (2012). Improving antibiotic activity against wound pathogens with manuka honey in vitro. PloS one, 7(9), e45600.

Jenkins, R., Burton, N., \& Cooper, R. (2011). Effect of manuka honey on the expression of universal stress protein A in meticillin-resistant Staphylococcus aureus. International journal of antimicrobial agents, 37(4), 373-376.

Jensen, O. L., Gluud, B. S., \& Birgens, H. S. (1986). The concentration of lactoferrin in tears of normals and of diabetics. Acta Ophthalmologica, 64(1), 83-87. 
Jervis-Bardy, J., Foreman, A., \& Bray, S., (2011). Methyglyoxal-Infused Honey Mimics the AntiStaphylococcus aureus Biofilm Activity of Manuka Honey: Potential Implication in Chronic Rhnosinisitis. The American Laryngological and Otological Soceity. 121, 11041107.

Jung, K. (2011). Microbiology: Tuning communication fidelity. Nature Chemical Biology, 7(8), $502-503$.

Jurtshuk P Jr. (1996). Bacterial Metabolism. In: Baron S, editor. Medical Microbiology. 4th edition. Galveston (TX): University of Texas Medical Branch at Galveston. Chapter 4. Available from: http://www.ncbi.nlm.nih.gov/books/NBK7919/

Karatan, E. \& Watnick, P. (2009). Signals, Regulatory networks, and materials that build and break bacterial biofilm. Microbiology and Molecular biology Reviews, 73(2), 310-347.

Karayil, S., Deshpande, S. D., \& Koppikar, G. V. (1998). Effect of honey on multidrug resistant organisms and its synergistic action with three common antibiotics. Journal of postgraduate medicine, 44(4), 93.

Kerem, E., Corey, M., Gold, R., \& Levison, H. (1990). Pulmonary function and clinical course in patients with cystic fibrosis after pulmonary colonization with Pseudomonas aeruginosa. The Journal of pediatrics, 116(5), 714-719.

Kim, E. J., Sabra, W., \& Zeng, A. P. (2003). Iron deficiency leads to inhibition of oxygen transfer and enhanced formation of virulence factors in cultures of Pseudomonas aeruginosa PAO1. Microbiology, 149(9), 2627-2634.

Kirchman, D. L., Meon, B., Cottrell, M. T., Hutchins, D. A., Weeks, D., \& Bruland, K. W. (2000). Carbon versus iron limitation of bacterial growth in the California upwelling regime. Limnology and Oceanography, 45(8), 1681-1688.

Klausen, M., Aaes-Jørgensen, A., Molin, S., \& Tolker-Nielsen, T. (2003). Involvement of bacterial migration in the development of complex multicellular structures in Pseudomonas aeruginosa biofilms. Molecular microbiology, 50(1), 61-68.

Kluyver, A. J., \& Van Niel, C. B. (1956). The microbe's contribution to biology (p. 5). Cambridge, MA: Harvard University Press.

Koch, C. and Hoiby, N., (1993). Pathogenisis of Cystic fibrosis. Lsncet, 341, 1065-1069.

Kronda, J. M., Cooper, R. A., \& Maddocks, S. E. (2013). Manuka honey inhibits siderophore production in Pseudomonas aeruginosa. Journal of applied microbiology.

Kroukamp, O., \& Wolfaardt, G. M. (2009). CO2 production as an indicator of biofilm metabolism. Applied and environmental microbiology, 75(13), 4391-4397.

Labbate, M., Queck, S. Y., Koh, K. S., Rice, S. A., Givskov, M., \& Kjelleberg, S. (2004). Quorum sensing-controlled biofilm development in Serratia liquefaciens MG1. Journal of bacteriology, 186(3), 692-698.

Lambert, R.J.W. \& Pearson, J. (2000), Susceptibility testing: accurate and reproducible minimum inhibitory concentration (MIC) and non-inhibitory concentration (NIC) values. Journal of Applied Microbiology, 88, 784-790. doi: 10.1046/j.1365-2672.2000.01017.x

Lamont, I. L., Beare, P. A., Ochsner, U., Vasil, A. I., \& Vasil, M. L. (2002). Siderophore-mediated signaling regulates virulence factor production in Pseudomonas aeruginosa. Proceedings of the National Academy of Sciences, 99(10), 7072-7077.

Lee, J. H., Park, J. H., Kim, J. A., Neupane, G. P., Cho, M. H., Lee, C. S., \& Lee, J. (2011). Low concentrations of honey reduce biofilm formation, quorum sensing, and virulence in Escherichia coli O157: H7. Biofouling, 27(10), 1095-1104. 
Lerrer, B., Zinger-Yosovich, K. D., Avrahami, B., \& Gilboa-Garber, N. (2007). Honey and royal jelly, like human milk, abrogate lectin-dependent infection-preceding Pseudomonas aeruginosa adhesion. The ISME journal, 1(2), 149-155.

Levin, M.H., Olson, B., Nathan, C., Kabins, S.A., \& Weinstein, R.A. (1984). Pseudomonas in the sinks in an intensive care unit: relation to patients. Journal of Clinical Pathology, 37 (4), 424-427.

Liu, P. V., \& Shokrani, F. A. T. E. M. E. H. (1978). Biological activities of pyochelins: ironchelating agents of Pseudomonas aeruginosa. Infection and immunity, 22(3), 878-890.

Lu, J., Carter, D. A., Turnbull, L., Rosendale, D., Hedderley, D., Stephens, J., ... \& Harry, E. J. (2013). The Effect of New Zealand Kanuka, Manuka and Clover Honeys on Bacterial Growth Dynamics and Cellular Morphology Varies According to the Species. PloS one, $8(2)$, e55898.

Lusby, P. E., Coombes, A. L., \& Wilkinson, J. M. (2005). Bactericidal activity of different honeys against pathogenic bacteria. Archives of medical research, 36(5), 464-467.

Macor, J. E. (2011). Annual Reposts in Medicinal Chemistry. Vol 46. Elsevier Science. Academic Press. P245. DOI:10.1016/B978-0-12-386009-5.00012-6

Maddocks, S. E., \& Jenkins, R. E. (2013). Honey: a sweet solution to the growing problem of antimicrobial resistance?. Future microbiology, 8(11), 1419-1429.

Maddocks, S.E., Lopez, M.S., Rowlands, R.S., \& Cooper, R.A., (2012). Manuka honey inhibits the development of Streptococcus pyogenes biofilms and causes reduced expression of two fibronectin bindhing proteins. Journal of Microbiology, 158, 781-790.

Magasanik, B. (1970). Chapter IX: Glucose Effects: Inducer Exclusion and Repression. Cold Spring Harbor Monograph Archive, 1, 189-219.

Mah, T. F., Pitts, B., Pellock, B., Walker, G. C., Stewart, P. S., \& O'Toole, G. A. (2003). A genetic basis for Pseudomonas aeruginosa biofilm antibiotic resistance. Nature, 426(6964), 306310.

Majtan, J., Bohova, J., Prochazka, E., \& Klaudiny, J. (2013). Methylglyoxal May Affect Hydrogen Peroxide Accumulation in Manuka Honey Through the Inhibition of Glucose Oxidase. Journal of medicinal food, 17(12), 290-293. doi: 10.1089/jmf.2012.0201

Mandal, S., DebMandal, M., Pal, N. K., \& Saha, K. (2010). Antibacterial activity of honey against clinical isolates of Escherichia coli, Pseudomonas aeruginosa and Salmonella enterica serovar Typhi. Asian Pacific Journal of Tropical Medicine, 3(12), 961-964.

Marshall, B., Stintzi, A., Gilmour, C., Meyer, J. M., \& Poole, K. (2009). Citrate-mediated iron uptake in Pseudomonas aeruginosa: involvement of the citrate-inducible FecA receptor and the FeoB ferrous iron transporter. Microbiology, 155(1), 305-315.

Martin, L. W., Reid, D. W., Sharples, K. J., \& Lamont, I. L. (2011). Pseudomonas siderophores in the sputum of patients with cystic fibrosis. Biometals, 24(6), 1059-1067.

Mavric, E., Wittmann, S., Barth, G., \& Henle, T. (2008). Identification and quantification of methylglyoxal as the dominant antibacterial constituent of Manuka (Leptospermum scoparium) honeys from New Zealand. Molecular nutrition \& food research, 52(4), 483489.

McDonnell, G., \& Russell, A.D. (1999) Antiseptics and disinfectants: Activity, action and resistance. Clinical Microbiology, 12, 147-179.

McLean, R. J., Whiteley, M., Stickler, D. J., \& Fuqua, W. C. (1997). Evidence of autoinducer activity in naturally occurring biofilms. FEMS microbiology letters, 154(2), 259-263. 
Medoff, G., Comfort, M., \& Kobayashi, G. S. (1971). Synergistic action of amphotericin B and 5fluorocytosine against yeast-like organisms. Experimental Biology and Medicine, 138(2), 571-574.

Merckoll, P., Jonassen, T. Ø., Vad, M. E., Jeansson, S. L., \& Melby, K. K. (2009). Bacteria, biofilm and honey: a study of the effects of honey on 'planktonic' and biofilm-embedded chronic wound bacteria. Scandinavian journal of infectious diseases, 41(5), 341-347.

Mesaik, M. A., Azim, M. K., \& Mohiuddin, S. (2008). Honey modulates oxidative burst of professional phagocytes. Phytotherapy Research, 22(10), 1404-1408.

Meyer, J. M., \& Hohnadel, D. (1992). Use of nitrilotriacetic acid (NTA) by Pseudomonas species through iron metabolism. Applied microbiology and biotechnology, 37(1), 114-118.

Miller, J. K., Brantner, J. S., Clemons, C., Kreider, K. L., Milsted, A., Wilber, P., ... \& Wagers, P. O. (2013). Mathematical modelling of Pseudomonas aeruginosa biofilm growth and treatment in the cystic fibrosis lung. Mathematical Medicine and Biology.

Molan, P. C. (1992). The antibacterial activity of honey: 2. Variation in the potency of the antibacterial activity. Bee world, 73, 59-76.

Molan, P. C. (2006). The evidence supporting the use of honey as a wound dressing. The International Journal of Lower Extremity Wounds, 5(1), 40-54.

Morales, G., Linares, J. F., Beloso, A., Albar, J. P., Martínez, J. L., \& Rojo, F. (2004). The Pseudomonas putida $\mathrm{Crc}$ global regulator controls the expression of genes from several chromosomal catabolic pathways for aromatic compounds. Journal of bacteriology, 186(5), 1337-1344.

Moreau-Marquis, S., O'Toole, G. A., \& Stanton, B. A. (2009). Tobramycin and FDA-approved iron chelators eliminate Pseudomonas aeruginosa biofilms on cystic fibrosis cells. American journal of respiratory cell and molecular biology, 41(3), 305.

Mossialos, D., Ochsner, U., Baysse, C., Chablain, P., Pirnay, J. P., Koedam, N., ... \& Cornelis, P. (2002). Identification of new, conserved, non-ribosomal peptide synthetases from fluorescent pseudomonads involved in the biosynthesis of the siderophore pyoverdine. Molecular microbiology, 45(6), 1673-1685.

Müller, P., Alber, D. G., Turnbull, L., Schlothauer, R. C., Carter, D. A., Whitchurch, C. B., \& Harry, E. J. (2013). Synergism between Medihoney and Rifampicin against MethicillinResistant Staphylococcus aureus (MRSA). PloS one, 8(2), e57679.

Murata, M., Wakabayashi, H., Yamauchi, K., \& Abe, F. (2013). Identification of milk proteins enhancing the antimicrobial activity of lactoferrin and lactoferricin. Journal of Dairy Science, 96(8), 4891- 4898.

Murray, P. R., E. J. Baron, M. A. Pfaller, F. C. Tenover, \& R. H. Yolken (eds). 1995. Manual of clinical microbiology, $6^{\text {th }}$ ed. American Society for Microbiology, Washington, D.C

Musthafa, K., Ravi, A., Annapoorani, A., Packiavathy, I. V., \& Pandian, S. (2010). Evaluation of anti-quorum-sensing activity of edible plants and fruits through inhibition of the N-acylhomoserine lactone system in Chromobacterium violaceum and Pseudomonas aeruginosa. Chemotherapy, 56(4), 333-339.

Nassar, H. M., Li, M., \& Gregory, R. L. (2012). Effect of honey on Streptococcus mutans growth and biofilm formation. Applied and environmental microbiology, 78(2), 536-540.

Neilands, J.B., Konopka, K., Schwyn, B., Coy, M, Francis, R.T., Paw, B.H, \& Bagg, A. (1987). 1. Comparative Biochemistry of Microbial Iron Assimilation. In: Winkelmann,G.; van der 
Helm, D.; Neilands, J.B. (eds.) 1987. Iron Transport in Microbes, Plants and Animals.VCH Publishers.

Niederkom, J.Y. \& Kaplan, H. J., (2007). Immune Response and the Eye: Vol92- Chemical immunology and allergy. Karger Medical and Scientific Publisher. P185.

O’Toole, A.G. \& Ghannoum, M.A. (2004). Microbial biofilms. American Society for Microbiology, Washington, USA. P 20, 43, 44 \& 46.

Oexle, H., Gnaiger, E., \& Weiss, G. (1999). Iron-dependent changes in cellular energy metabolism: influence on citric acid cycle and oxidative phosphorylation. Biochimica et Biophysica Acta (BBA)-Bioenergetics, 1413(3), 99-107.

O'Neill, M. J., Bhakta, M. N., Fleming, K. G., \& Wilks, A. (2012). Induced fit on heme binding to the Pseudomonas aeruginosa cytoplasmic protein (PhuS) drives interaction with heme oxygenase (HemO). Proceedings of the National Academy of Sciences, 109(15), 56395644.

Ongena, M., Jacques, P., Delfosse, P., \& Thonart, P. (2002). Unusual traits of the pyoverdinmediated iron acquisition system in Pseudomonas putida strain BTP1. Biometals, 15(1), $1-13$.

Pamp SJ, Gjermansen M, Johansen HK \& Tolker-Nielsen T (2008). Tolerance to the antimicrobial peptide colistin in Pseudomonas aeruginosa biofilms is linked to metabolically active cells, and depends on the pmr and mexAB-oprM genes. Mol Microbiol, 68, 223-240.

Pan, Y., Sonn, G. A., Sin, M. L., Mach, K. E., Shih, M. C., Gau, V., ... \& Liao, J. C. (2010). Electrochemical immunosensor detection of urinary lactoferrin in clinical samples for urinary tract infection diagnosis. Biosensors and Bioelectronics, 26(2), 649-654.

Papaioannou, E., Wahjudi, M., Nadal-Jimenez, P., Koch, G., Setroikromo, R., \& Quax, W. J. (2009). Quorum-quenching acylase reduces the virulence of Pseudomonas aeruginosa in a Caenorhabditis elegans infection model. Antimicrobial agents and chemotherapy, 53(11), 4891-4897.

Parsek, M.R. \& Tolker- Nielsen, T. (2008). Pattern formation in Pseudomonas aeruginosa biofilm. Journal of Elsevier Science direct, 11, 560-566.

Patriquin, G. M., Banin, E., Gilmour, C., Tuchman, R., Greenberg, E. P., \& Poole, K. (2008). Influence of quorum sensing and iron on twitching motility and biofilm formation in Pseudomonas aeruginosa. Journal of bacteriology, 190(2), 662-671.

Pearson, J. P., Feldman, M., Iglewski, B. H., \& Prince, A. (2000). Pseudomonas aeruginosa cellto-cell signaling is required for virulence in a model of acute pulmonary infection. Infection and immunity, 68(7), 4331-4334.

Perez, L.M., Alvarez, B.L., Codony, F., Fittipaldi, M., Adrados, B., Penuela, G. \& Morato, J. (2010). A new microtitre plate screening method for evaluating the viability of aerobic respiring bacteria in high surface biofilms. Letters in Applied Microbiology, 51,331-337.

Pessi, G., Williams, F., Hindle, Z., Heurlier, K., Holden, M. T., Cámara, M., ... \& Williams, P. (2001). The Global Posttranscriptional Regulator RsmA Modulates Production of Virulence Determinants and N-Acylhomoserine Lactones in Pseudomonas aeruginosa. Journal of bacteriology, 183(22), 6676-6683.

Pexi, A., Ramirez- Bahena, M.H. \& Velazquez, E. (2009). Historical evolution and current status of the taxonomy of genus Pseudomonas. Infection, Genetics \& evolution, 9, 1132-1147.

Pillay, K., Coutsoudis, A., Agadzi-Naqvi, A. K., Kuhn, L., Coovadia, H. M., \& Janoff, E. N. (2001). Secretory leukocyte protease inhibitor in vaginal fluids and perinatal human 
immunodeficiency virus type 1 transmission. Journal of Infectious Diseases, 183(4), 653656.

Ponka, P. (1997). Tissue-specific regulation of iron metabolism and heme synthesis: distinct control mechanisms in erythroid cells. Blood, 89(1), 1-25.

Ponraj, P., Shankar, M., Ilakkiam, D., Rajendhran, J., \& Gunasekaran, P. (2013). Influence of periplasmic oxidation of glucose on pyoverdine synthesis in Pseudomonas putida S11. Applied microbiology and biotechnology, 97(11), 5027-5041.

Poole, K. E. I. T. H., Young, L. I. S. A., \& Neshat, S. H. A. D. I. (1990). Enterobactin-mediated iron transport in Pseudomonas aeruginosa. Journal of bacteriology, 172(12), 6991-6996.

Poole, K., \& McKay, G. A. (2003). Iron acquisition and its control in Pseudomonas aeruginosa: many roads lead to Rome. Front. Biosci, 8, d661-d686.

Postle, K., \& Larsen, R. A. (2007). TonB-dependent energy transduction between outer and cytoplasmic membranes. Biometals, 20(3-4), 453-465.

Raad, I., Chatzinikolaou, I., Chaiban, G., Hanna, H., Hachem, R., Dvorak, T., ... \& Costerton, W. (2003). In vitro and ex vivo activities of minocycline and EDTA against microorganisms embedded in biofilm on catheter surfaces. Antimicrobial agents and chemotherapy, 47(11), 3580-3585.

Racker, E., \& Krimsky, I. (1947). Relation of iron salts to inhibition of glycolysis by Theiler FA virus of mouse encephalomyelitis. The Journal of experimental medicine, 85(6), 715.

Rahme, R.G., Ausubel, M.F, Cao, H., Drenkard, E., Goumnerov, B.C., Lau, G. W., MahajanMiklos, S., Plotnikova, J., Tan, M.W., Tsongalis, J., Walendziewicz, C. L. \& Tompkins,R.G. (2000). Plants and animals share functionally common bacterial virulence factors. PNAS, 97(16), 8815-8821.

Rana, T. M., \& Meares, C. F. (1991). Iron chelate mediated proteolysis: protein structure dependence. Journal of the American Chemical Society, 113(5), 1859-1861.

Rasko, D. A., \& Sperandio, V. (2010). Anti-virulence strategies to combat bacteria-mediated disease. Nature Reviews Drug Discovery, 9(2), 117-128.

Ratledge, C., \& Dover, L. G. (2000). Iron metabolism in pathogenic bacteria. Annual Reviews in Microbiology, 54(1), 881-941.

Rice, L. B. (2008). Federal funding for the study of antimicrobial resistance in nosocomial pathogens: no ESKAPE. Journal of Infectious Diseases, 197(8), 1079-1081.

Richard, G., Wunderink, R. D., \& Wundrink, J.R. (2001). Ventilator Associated Pneumonia. Springer publication. $\mathrm{P} 45$.

Roberts RR, Hota B, Ahmad I, Scott RD, II, Foster SD, \& Abbasi F. (2009). Hospital and societal costs of antimicrobial resistant infections in a Chicago teaching hospital: implications for antibiotic stewardship. Clin Infect Dis.49:1175-84 http://www.tufts.edu/med/apua/consumers/personal_home_5_1451036133.pdf

Roberts, A. E., Maddocks, S. E., \& Cooper, R. A. (2012). Manuka honey is bactericidal against Pseudomonas aeruginosa and results in differential expression of oprF and algD. Microbiology, 158(Pt 12), 3005-3013.

Rojo, F. (2010). Carbon catabolite repression in Pseudomonas: optimizing metabolic versatility and interactions with the environment. FEMS microbiology reviews, 34(5), 658-684.

Sadfar, A. (2011). Principles and practice of Cancer infectious diseases: Current clinical Oncology. Springer publication, P 113.

Schaechter, M., Engleberg, N. C., DiRita, V.J., \& Dermody, T., (2007). Schaechter's Mechanisms of Microbial Diseases. Lippincott Williams \& Wilkins Publications. P 58. 
Schalk, I. J., \& Guillon, L. (2012). Pyoverdine biosynthesis and secretion in Pseudomonas aeruginosa: implications for metal homeostasis. Environmental microbiology. doi:10.1111/1462-2920.12013

Sekhri, K., (2013). Antimicrobial resistance: understanding solutions and future developments. International Journal of Pharma and Bio sciences, 4(2), 338-343.

Shrout, J. D., Chopp, D. L., Just, C. L., Hentzer, M., Givskov, M., \& Parsek, M. R. (2006). The impact of quorum sensing and swarming motility on Pseudomonas aeruginosa biofilm formation is nutritionally conditional. Molecular microbiology, 62(5), 1264-1277.

Singh, P. K., Parsek, M. R., Greenberg, E. P., \& Welsh, M. J. (2002). A component of innate immunity prevents bacterial biofilm development. Nature, 417(6888), 552-555.

Singh, P. K., Schaefer, A. L., Parsek, M. R., Moninger, T. O., Welsh, M. J., \& Greenberg, E. P. (2000). Quorum-sensing signals indicate that cystic fibrosis lungs are infected with bacterial biofilms. Nature, 407(6805), 762-764.

Sio, C. F., Otten, L. G., Cool, R. H., Diggle, S. P., Braun, P. G., Bos, R., ... \& Quax, W. J. (2006). Quorum quenching by an N-acyl-homoserine lactone acylase from Pseudomonas aeruginosa PAO1. Infection and immunity, 74(3), 1673-1682.

Spoering, A.L. \& Lewis, K. (2001). Biofilms and planktonic cells of Pseudomonas aeruginosa have similar resistance to killing by antimicrobials. Journal of Bacteriology, 183(23), 6746-6751.

Starkey, M., Wang, R., Hazan, R. N., \& Rahme, L. G. (2012). Honey's Ability to Counter Bacterial Infections Arises from Both Bactericidal Compounds and QS Inhibition. 3,144. doi: 10.3389/fmicb.2012.00144

Stephen, H.G., and Hawkey M.P. (2006). Principles and practice of Clinical bacteriology, 2nd edition. John Wiley and Sons. Ltd. P.427-443.

Storz, G. and Hengge-Aronis, R. (2000). Bacterial stress responses. ASM Press, Washington. P 330.

Stover, C. K., Pham, X. Q., Erwin, A. L., Mizoguchi, S. D., Warrener, P., Hickey, M. J., and Olson, M. V. (2000). Complete genome sequence of Pseudomonas aeruginosa PAO1, an opportunistic pathogen. Nature, 406(6799), 959-964.

Svitil, A. L., Cashel, M., \& Zyskind, J. W. (1993). Guanosine tetraphosphate inhibits protein synthesis in vivo. A possible protective mechanism for starvation stress in Escherichia coli. Journal of Biological Chemistry, 268(4), 2307-2311.

Tang H. B., Dimango, E. Bryan, R., Gambello, M., Iglewski, B.H., Goldberg, J.B., \& Prince, A. (1996). Contributions of specific Pseudomonas aeruginosa virulence factor to pathogenisis of pneumonia in a neonatal mouse model of infection. Infections in immunity, 64, 37-43.

Truchado, P., Gil-Izquierdo, F., Barberan, T., \& Allende, A., (2009). Inhibition by Chestnut Honey of N-Acyl-L-homoserine Lactones and Biofilm Formation in Erwinia carotovora, Yersinnia enterocoltiica, and Aeromonas ydrophila. Journal of Agricultural food Chemistry, 57, 11186-11193.

Truchado, P., Lopes-Galvez, F., Gil, M.I., Tomas-Barberan, F.A., \& Allende, A. (2009). Quorum sensing inhibitory and antimicrobial activities of honey and the relationship with individual phenolics. Food Chemistry, 115, 1337-13344.

Tur, E., Bolton, L., \& Constantine, B. E. (1995). Topical hydrogen peroxide treatment of ischemic ulcers in the guinea pig: blood recruitment in multiple skin sites. Journal of the American Academy of Dermatology, 33(2), 217-221. 
U.S. Food and Drug Administration. 1995. Bacteriological analytical manual, 8thed. AOAC International, Gaithersburg, MD.

Van Delden, C., Comte, R., \& Bally, M. (2001). Stringent Response Activates Quorum Sensing and Modulates Cell Density-Dependent Gene Expression in Pseudomonas aeruginosa. Journal of bacteriology, 183(18), 5376-5384.

Van der Strate, B. W. A., Beljaars, L., Molema, G., Harmsen, M. C., \& Meijer, D. K. F. (2001). Antiviral activities of lactoferrin. Antiviral research, 52(3), 225-239.

Vasil, M. L., Graham, L.M., Ostroff, R.M., Shortridge, V.D., \& Vasil, A.I. (1991). Phospholipase C: Molecular biology and contribution to pathogenisis of Pseudomonas aeruginosa. Antibiotic Chemotherapy, 44, 34-47

Vasil, M.L., Grant, C.C., \& Prince, R.W. (1989). Regulation of exotoxin A synthesis in Pseudomonas aeruginosa: characterization of toxA-lacZ fusion in wild-type and mitant strain. Molecular Microbiology, 3, 371-381.

Verrases, C., Boxstael, S.V., Meervenne, V., Coillie, V., Butaye, P., Catry, B., Schaetzen, M-A., Huffel, X.V., Imberechts, H., Dierich, K., Daube, G., Saegermanm C., Block, J.D., Dewulf, J., \& Hvrman, L. (2013). Antibiotic resistance in food chain: A review. International Journal of environmental Research and public health, 10, 2643-2669.

Visca, P. A. O. L. O., Colotti, G., Serino, L., Verzili, D., Orsi, N., \& Chiancone, E. (1992). Metal regulation of siderophore synthesis in Pseudomonas aeruginosa and functional effects of siderophore-metal complexes. Applied and environmental microbiology, 58(9), 28862893.

Wahjudi, M., Murugappan, S., van Merkerk, R., Eissens, A. C., Visser, M. R., Hinrichs, W. L., \& Quax, W. J. (2013). Development of a dry, stable and inhalable acyl-homoserine-lactoneacylase powder formulation for the treatment of pulmonary Pseudomonas aeruginosa infections. EUROPEAN JOURNAL OF PHARMACEUTICAL SCIENCES, 48(4-5), 637643.

Wang, R., Starkey, M., Hazan, R., \& Rahme, L. G. (2012). Honey’s ability to counter bacterial infections arises from both bactericidal compounds and QS inhibition. Frontiers in microbiology, 3 .

Weinberg, E. D. (2009). Iron availability and infection. Biochimica et Biophysica Acta (BBA)General Subjects, 1790(7), 600-605.

Weinberg, E.D, (2001). Human lactoferrin: a novel therapeutic with broad spectrum potential. Journal of pharmacy and pharmacology, 53, 1303-1310.

Wen, Z. T., \& Burne, R. A. (2004). LuxS-mediated signaling in Streptococcus mutans is involved in regulation of acid and oxidative stress tolerance and biofilm formation. Journal of bacteriology, 186(9), 2682-2691.

White Jr, J. W., Subers, M. H., \& Schepartz, A. I. (1963). The identification of inhibine, the antibacterial factor in honey, as hydrogen peroxide and its origin in a honey glucoseoxidase system. Biochimica et Biophysica Acta (BBA)-Specialized Section on Enzymological Subjects, 73(1), 57-70.

Wiehlmann, L., Wagner, G., Cramer, N., Siebert, B., Gudowius, P., Morales, G., Kohler, T., Delden, C.V., Weinel, C., Slickers,P., and Tummler, B. (2007). Population structure of Pseudomonas aeruginosa. PNAS. 104(19), 8101-8106.

Wilkinson, J. M., \& Cavanagh, H. M. (2005). Antibacterial activity of 13 honeys against. Escherichia coli and Pseudomonas aeruginosa. Journal of medicinal food, 8(1), 100-103. 
Wisplinghoff H, Bischoff T, Tallent SM, Seifert H, Wenzel RP, \& Edmond MB. (2004) Nosocomial bloodstream infections in US hospitals: analysis of 24,179 cases from a prospective nationwide surveillance study. Clin Infect Dis, 39(3), 309-17.

Woods, D.E., Cryz, S.J., Friedman, R.L., \& Iglewski, B.H., (1982). Contribution of toxin A and elastase to virulence of Pseudomonas aeruginosa in chronic lung infections of rats. Infection in Immunity, 36, 1223-1228.

Wright ML \& Romano MJ. (2006) Ventilator-associated pneumonia in children. Semin Pediatr Infect Dis, 17(2), 58-64.

Xiao, R., \& Kisaalita, W. S. (1997). Iron acquisition from transferrin and lactoferrin by Pseudomonas aeruginosa pyoverdine. Microbiology, 143(7), 2509-2515.

Yanaihara, A., Toma, Y., Saito, H., \& Yanaihara, T. (2000). Cell proliferation effect of lactoferrin in human endometrial stroma cells. Molecular human reproduction, 6(5), 469-473.

Yeterian, E., Martin, L. W., Guillon, L., Journet, L., Lamont, I. L., \& Schalk, I. J. (2010). Synthesis of the siderophore pyoverdine in Pseudomonas aeruginosa involves a periplasmic maturation. Amino Acids, 38(5), 1447-1459.

Yeterian, E., Martin, L. W., Lamont, I. L., \& Schalk, I. J. (2010). An efflux pump is required for siderophore recycling by Pseudomonas aeruginosa. Environmental microbiology reports, 2(3), 412-418.

Yoder, M. F., \& Kisaalita, W. S. (2008). Leaching behavior of a fluorescent pyoverdine immobilized in sol-gel glass. Open Biotechnology Journal, 2, 157-166.

Yoder, M. F., \& Kisaalita, W. S. (2011). Iron specificity of a biosensor based on fluorescent pyoverdin immobilized in sol-gel glass. Journal of biological engineering, 5(1), 1-12.

Zichichi, L., Asta, Gaetano, \& Noto, G., (2000). Pseudomonas aeruginosa folliculitis after shower/bath exposure. International Journal of dermatology, 39 (3), 270-273. 